

$$
\text { ชั }
$$





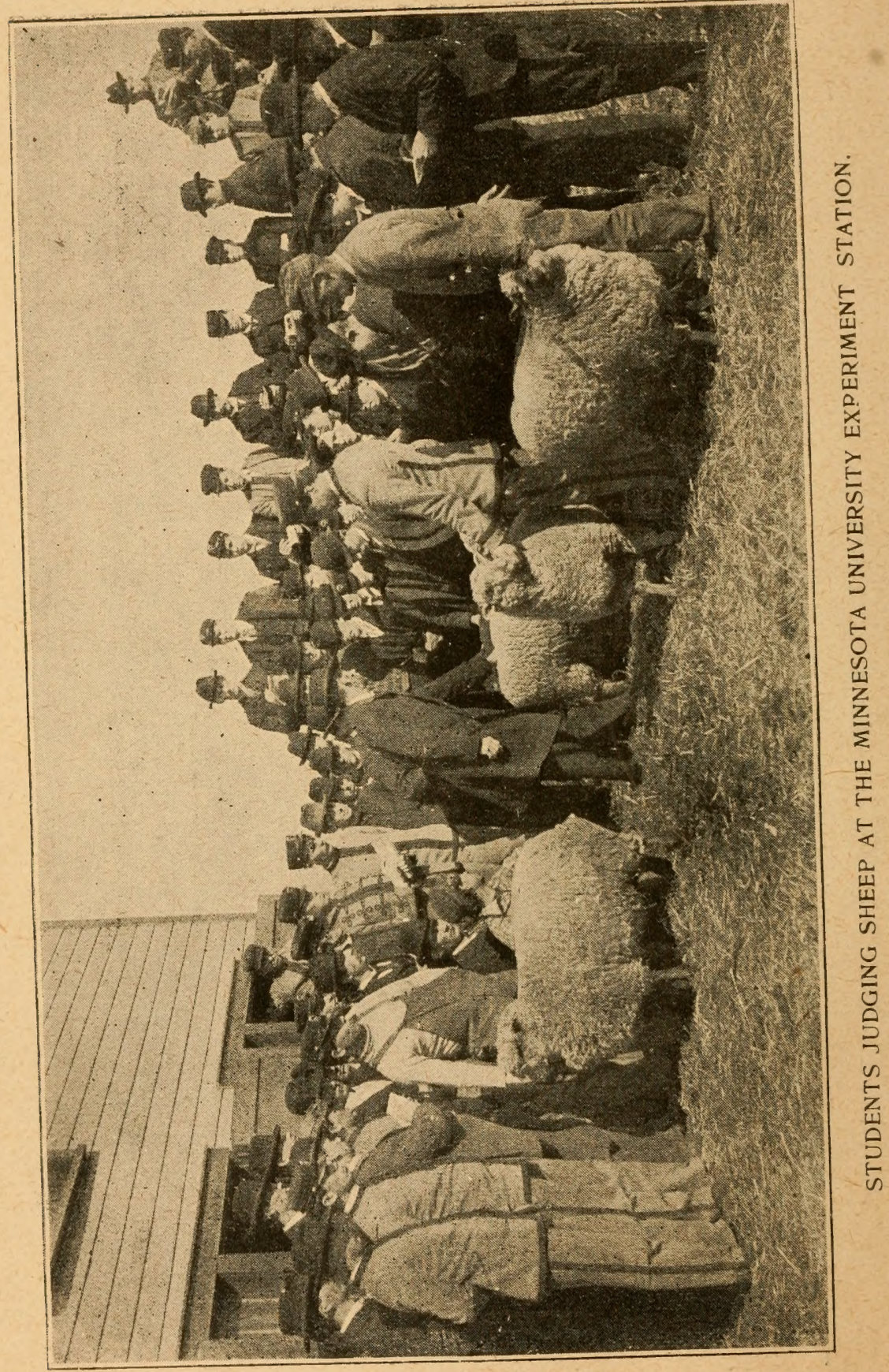




\section{SHEEP HUSBANDRY}

IN MINNESOTA.
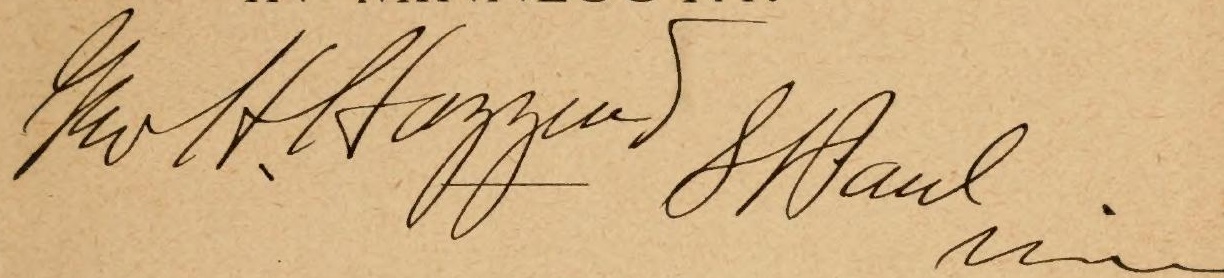

\section{BY THOMAS SHAW,}

Professor of Animal Husbandry at the University ARY OF CONGOR Minnesota.

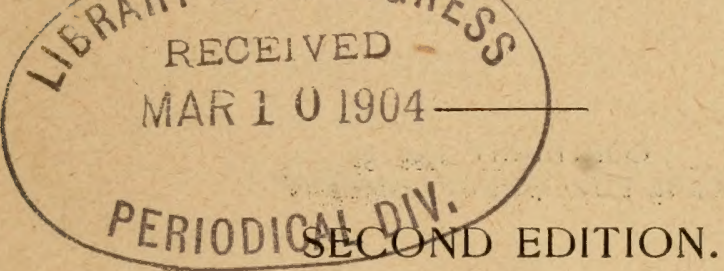

I0,000 Copies Authorized by the Legislature of Minnesota Thirty Second Session.

\section{AUTHOR OF}

"Public School Agriculture." "Weeds and How to Eradicate Them." "Forage Crops, Other Than Grasses." "The Study of Breeds." Soiling Crops and The Silo," Etc. 


$$
5_{5^{5}}{ }^{5^{5}}
$$

COPYRIGHT. 1900 , by WEBB PUBLISHING COMPANY.

$P$.

Minn. Territorial Pioneers' austin.

16. $\mathrm{Hr}^{\mathrm{N}} 04$ 
To the Farmers of Minnesota, and also to their Sons and Daughters, the coming hope of our magnificent state, this work is most respectfully dedicated by the author.

University of Minnesota, 1900 


\section{ACKNOWLEDGMENTS.}

The Author desires to acknowledge his indebtedness to Mr. Chas. P. Taylor and Mr. W. C. Palmer, of the University of Minnesota, for assistance given in furnishing the sketches used and also in various other ways while the book was being prepared. 


\section{THE AUTHOR'S PREFACE.}

This book is written in the hope that it may prove helpful to the farmers of our state. The author is continually receiving letters from those engaged in sheep husbandry asking for information bearing upon every phase of the industry. Many of the letters thus received ask for a book that will cover the subject from the standpoint of Northwestern conditions. Such a book has not previously been written, and the work is intended in some measure at least to supply the need. In writing it the author has endeavored to produce a book that will enable the farmer who has never kept. sheep previously to take up the work without the hazard of making mistakes such as are so frequently made by beginners. The measure of the success attained must be left to the judgment of a fair-minded public. The book is donated to the farmers of Minnesota in the hope that in some degree at least it will help to make our state what it may and ought to be, viz., the greatest sheep-producing state in all the Union.

Minnesota University Experiment Farm,

St. Anthony Park, Minn., 1900. 

LIST OF ILLUSTRATIONS.

Fig.

Page.

1. Students Judging Sheep at the Minnesota University

Experiment Station................. Frontispiece

2. Typical Rambouillet Ewe................26

3. Group of Typical South Down Rams..........28

4. Typical Dorset Ewe.................. 30

5. Typical Shropshire Ram................ 32

6. Group of Typical Suffolk Sheep............. 34

7. Typical Oxford Down Ewe.................... 36

8. Typical Cotswold Ram................. 40

9. Sheep Pasturing on Winter Rye..............54

10. Sheep Pasturing on Sorghum............. 56

11. Rape Grown for Sheep Pasture............. 58

12. Sheep Pasturing on Oats and Peas.............60

13. Sheep Pasturing on Soy Beans.............. 62

14. Plan of Sheep Shed for Breeding Flock......... 82

15. Ground Plan of Sheep Barn at Minnesota University

Experiment Farm...................... 84

16. Section Showing Frame of Sheep Barn......... 86

17. End Section of Feeding Rack.............. 88

18. Sheep Barn at Minnesota University Experiment Farm 90

19. Plan of Sheep Shed for a Large Flock.......... 92

20. Plan of Sheep Shed for a Good-sized Flock........94

21. Section of Movable Fence................102

22. Feeding Lambs Selected for Fattening at Minnesota

University Experiment Farm..............146

23. Lambs Fattened at Minnesota University Experiment

Farm for Market .....................

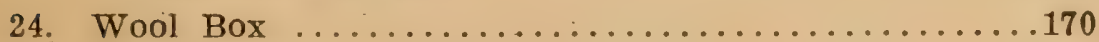

25. Small Home-made Dipping Tank............200

26. Hog-House and Dipping Tank Combined.........202

27. Side View of Draining Pens, Dipping Tank and Loading Platform 


\section{TABLE OF CONTENTS.}

\section{CHAPTER 1 .}

Page.

Benefits from Sheep Husbandry................. 9 CHAPTER II.

Minnesota Eminently Adapted to Sheep Husbandry..... 15 CHAPTER III.

Breeds Adapted to Minnesota Conditions............23 CHAPTER IV.

Foundation Flocks

CHAPTER V.

Pasture for Sheep.

CHAPTER VI.

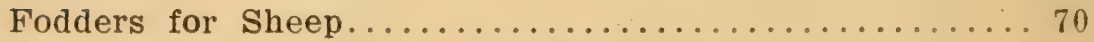

CHAPTER VII.

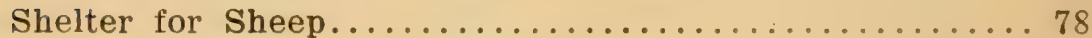

CHAPTER VIII.

Fencing for Sheep.......................... 95

CHAPTER IX.

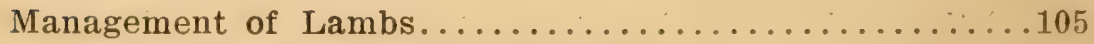

CHAPTER X.

Management of Ewes...............................

CHAPTER XI.

Management of Rams.

CHAPTER XII.

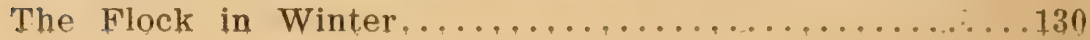


CHAPTER XIII.

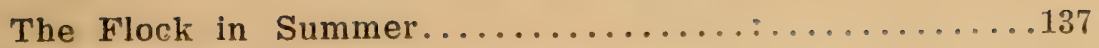

CHAPTER XIV.

Fattening Sheep and Lambs....................... CHAPTER XV.

Growing Winter Lambs...................... 157

CHAPTER XVI.

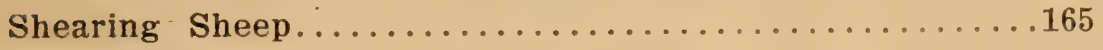

CHAPTER XVII.

The More Common Diseases of Sheep...............174

CHAPTER XVIII.

Dipping sheep............................... 195 



\section{CHAPTER I.}

\section{Benefits from Sheep Husbandry.}

The benefits from a wisely conducted system of sheep husbandry are many and they are also important. Prominent among them are the following: 1. Returns are secured twice a year, first, in the lambs and second, in the wool. 2. Pasture is utilized that would otherwise be wasted. 3. Weeds are destroyed in great numbers. 4. Fertility is maintained in the soil more perfectly than it can be so maintained by any other class of live stock kept upon the farm, and 5. There are incidental benefits, such as the food furnished for the farmer's table, the added neatness given to the farm and the salutary influences which tending sheep exerts upon the youthful members of a family.

Returns Twice a Year.-Grain husbandry, and particularly wheat husbandry, produces but one harvest in a year. Sheep husbandry produces two; that is to say, a harvest of meat and a harvest of wool. The wheat harvest is attended with considerable hazard. Not infrequently it measurably fails. Sometimes it is a great failure. The harvest from sheep never fails where the sheep are properly managed. It may fluctuate, but it does not fail. A few days' adverse weather when the grain is approaching maturity may cut down the hope of the wheat grower. Throngh no fault of his it may be smitten with rust or blight. Sheep husbandry is not 
thus so dependent on the weather, since sheep may and ought to be fed on a variety of foods, some of which may be expected to grow in reasonably good form whatever may be the character of the season.

The wool crop alone, which is as unfailing as the seasons, should pay for the food consumed in maintaining sheep under existing conditions in the Northwest, and the returns come in at an opportune season; that is to say, in the early summer, when money from other simurees is not usually plentiful on the farm. The lamb crop can be marketed at various times according to the mode of management, but in any event it brings in a second installment every year to reward the flockmaster. And, owing to the early season at which sheep breed and to the large increase relatively, large flocks may soon be secured without great outlay for the foundation animals.

Utilizing Sundry Pastures.-On every farm where sheep are not kept much pasture goes to waste every ycar. This is true in some degree of pasture in almost every field on the farm. Grain shelled while being harrested produces much pasture every autumn. Grass grows up in by places, such as lanes, around fences, along the borders of forests and within parks. Weeds grow up in the grain and mature innumerable seeds after the grain has been harvested. There is no other class of live stock that will gather such food with the same ease or certainty as sheep, nor is there any that will turn it to such good account. Almost everything in the form of regetation they will consume and turn into meat and wool if allowed access to the same while 
it is yet green and succulent. When thus maintained, sheep are in a sense scavengers, living in a considerable degree on vegetable products that would otherwise go to waste; and when thus allowed to gather food, the variety secured is so well suited to their needs, that when allowed to graze thus freely, they usually maintain themselves in a good condition of thrift. In this way a small flock of sheep could be maintained even on a dairy farm, without any real outlay in providing food for them during the entire period of grazing.

Destroying Weeds.-There is scarcely a variety of weeds found in the Northwest that sheep will not eat with avidity if they can have access to the same while still young and succulent. There are many kinds that they will eat more readily than grass, even in the early stages of growth, and for the reason chiefly that they are more tender and succulent, but as weeds become more and more woody, they will more and more refuse to eat them. These discriminations should be duly considered when the aid of sheep is sought in the war against weeds.

Sheep will also search diligently for nearly all kinds of weed seeds, and when they feed upon them the danger need rot be feared that the seeds will ever grow again, because of the thorough grinding given to them in conjunction with the complete digestion that follows. If allowed to graze in stubbles after the removal of a crop, the service which sheep will thus render is very great. When certain forage crops are sown in a close and continuous succession on weed infested lands, and 
when these are grazed down successively by sheep, there is perhaps no weed found in all the Northwest that will not soon succumb to such treatment unless it be couch grass.

Minnesota is not more infested with weeds than other Northwestern states, and yet it is probably true that more weeds grow every year on the arable farms of Minnesota than would sustain all the sheep in the state during the entire grazing season.

Maintaining Fertility.-No method of maintaining fertility has ever been devised that will compare with its maintenance by means of sheep husbandry. This fact probably more than any other gave rise to the proverb: "The sheep has a golden hoof." Cattle husbandry will not maintain fertility so easily nor so completely. This is owing in part to the fact that more of the droppings are lost owing to the way in which they are distributed. The same is also at least measurably true of swine. The droppings of sheep are scattered over the surface of the ground and soon become incorporated with the same, through the treading of the sheep. Since sheep are prone to live on elevations, the droppings are more abundantly distributed on these; that is to say, where they are most needed. And due weight should be given to the fact of such distribution. It means that the lands are fertilized during the entire season of grazing without any labor entailed by man. All fertility produced by sheep is also distributed by them in the best possible manner, except what is produced during the season of confinement, and this period is shorter 
with sheep than with any other kind of live stock kept upon the farm.

The fertility of farm lands can be fully maintained by the aid of sheep husbandry judiciously conducted and without the aid of commercial fertilizers. The fertilizer sent away in the flesh and wool sold, can be more than offset by the plant food deposited in the soil by legumes and drawn up from the subsoil by deep-rooted plants grown in the rotation to provide the food for the sheep. This explains why sheep are so frequently used in the renovation of soils, the fertility of which has been in a great measure removed by over cropping.

Incidental Benefits. - The food furnished for the farmer's table is one of the incidental benefits growing out of sheep husbandry. No food is more healthful. No meat grown upon the farm is more delicious and none is grown so cheaply. Especially is this true when only a small flock of sheep is maintained, as then they live chiefly on food in the summer season that would otherwise be lost.

A second of these benefits is found in the more neat and tidy appearance given to the farm because of the presence of sheep. They trim out the fence corners and by places on the farm. They put out of existence unsightly weeds; and they keep pastures even and nicely presentable because of their presence. If allowed to graze in the highways they will also keep the grass portion of the same- so closely shorn that pedestrians can walk over the same with added comfort, let the weather be as it may.

A third benefit is found in the softening and refining 
influence which tending a flock of sheep begets in the young people of the farm who may have them in charge. The gentleness and inoffensiveness of the sheep exert a salutary influence on the character of the young people who care for them while character is in the formative stage.

Benefits Not Sufficiently Considered.-The benefits which result from sheep husbandry wisely conducted have not been sufficiently considered by the farmers of Minnesota, or the number of sheep in our state would not be so small relatively at the present time. The statistics compiled by the United States department of agriculture give the number of sheep in Minnesota in 1899 as 419,218 , that is to say but 1 sheep for every 120 acres of land surface in the entire state. This number is regretfully small in a state possessed of the highest adaptation for growing sheep as will be shown in Chapter II. 


\section{CHAPTER II.}

\section{Minnesota Eminently Adapted to Sheep Husbandry.}

That Minnesota has pre-eminent adaptation for sheep husbandry is not generally known by the outside world. How could it be when so small a number of sheep relatively are kept within the state? Nor is this adaptation understood by the farmers as it ought to be. If it were so understood, sheep would soon be found on almost every farm within the state.

This adaptation manifests itself in various ways, as for instance, in the undulating surface of much of the soil, the varied food production of the same, the abundance of the water supplies, the plentiful shade, the productive soil, the plentiful supplies of the material for shelter, and in the bright and healthful character of the climate. The hindrances are few, but these also will be considered.

Undulating Surface.-Sheep love to graze on undulating pastures. Instinctively they seek the higher ground when taking rest, but the lower lands being more productire than the higher, they are thus far better adapted for producing grazing. The highest adaptation for grazing sheep is found, therefore, where a happy combination of hill and valley, of swell and depression exists. Such combinations abound in nearly every county in the state, including the major portions of the land usually denominated prairie. The exceptions are 
chiefly found in the Red River valley, and even in the counties in the said valley the water passes away so quickly that in but limited areas does its presence interfere with rearing sheep successfully. The soils of the state are also possessed of good natural drainage, so that water passes readily into the subsoil and thence into the numerous lakes and rivers. The naturally porous character of a very large proportion of the subsoil of Minnesota renders the soil eminently adapted to sheep husbandry.

Varied Food Production.-The rariety of food that can be grown in our state is very great. In this respect it is perhaps unrivalled by any state in the Union. The reasons are found in the varied soil and climatic conditions. Minnesota possesses nearly every class of soil from sands so light as to lift with the winds to the stiffest and most unyielding red clays. The climate is on the whole temperate, though warm enough in summer to force a luxuriant and varied growth. In nearly all parts of the state there is enough of rain in normal seasons, and so distributed as to produce an abundant growth unless in some instances in the autumn, when there is sometimes a deficiency in moisture. As a result, nearly all of the most useful grasses can be grown in the state with at least a fair measure of success.

The growth of all the leading cereals is very satisfactory. No state produces flax more abundantly. Corn and sorghum can be grown in fine form as food for sheep up to the Canadian boundary line. Even soy beans and cow peas may be made a success in Central and Southern Minnesota. Field roots, as mangels, 
turnips, carrots and sugar beets, are a magnificent success. Minnesota is a paradise for rape and cabbage. And the screenings extracted from the grain when cleaning it, furnishes an excellent food for sheep. They may thus be furnished with a great variety of food summer and winter, and, as every intelligent shepherd knows, variety in the food products is a prime essential to success in sheep husbandry.

Abundant Water Supply.-Minnesota, as the name implies, is proverbially the state of many waters. Its lakes number, it is claimed, seren thousand.

Its rivers are many. It is truly a land of brooks and streams and reservoirs of water. The water is the purest. It is so pure that the germs of malarial diseases du not seem to be able to live in it. Such water is excellent, not only for sheep, but also for men. And where water is not thus found on the surface there is scarcely any part of the state in which it cannot be found by sinking wells to a moderate depth.

Plentiful Shade.-Fully one-half of Minnesota was originally forest and park country. This means that in all the portion thus originally wooded shade is abundant. Since, even in the portions of the state thus wooded that have been cleared, a sufficiency of trees have been spared to provide ample shade for sheep. It means also that where such shade has not been spared it may soon be grown on the principle that where nature has succeeded in growing trees without the aid of man, she will grow them more readily with such aid. The Park region, which covers several counties, is peculiarly favored in the extent of the shade which it fur- 
nishes. And in the portions of the state originally prairie natural groves are springing up where they are protected. On other areas groves are being planted. And in no part of the state are the conditions such that shade from trees may not be furnished, and that within a few brief. years from the time of planting. The value of shade for sheep in summer cannot be easily over-estimated. Sheep do not take injury from low temperatures as such. In fact they scarcely heed them if protected from winds and falling storms. But they suffer greatly if not protected from excessive heat, and the more that they are laden with flesh, as the result of abundant feeding, the more do they suffer proportionately. A land, therefore, possessed of highest adaptation in growing sheep must also be possessed of abundant shade.

Froductive Soil.-The prairie soilis of the state are wonderfully productive as witnessed in the score of successive grain crops in the rotation. In this extraordinary productiveness is found an explanation of the way those soils have been abused in too many instances by the system of cropping practised. This abundant production is, however, exceedingly favorable to sheep husbandry conducted on the intensive plan. The soils of Minnesota could be made to sustain all the sheep in the United States; that is to say, approximately 50,000,000 , and without materially lessening production in other lines, on the assumption that all the arable land in the state was under cultivation. The sandy areas are, of course, not so productive. But even on these, relatively large numbers of sheep may be main- 
tained, as has been repeatedly demonstrated at the Minnesota University Experiment Farm. Approximately one hundred head of sheep and lambs have been pastured there on ten acres of land for successive seasons, beginning with 1896. In addition to the pasture, several tons of cured food have also been obtained every year from the same land. The land thus cropped was sandy in character, but when fairly well supplied with rain, the crops that followed each other the same season grew with much quickness. For the production of forage and fodder crops taken together the major portion of the lands of the state have high adaptation.

Materials for Shelter.-The materials for shelter under Minnesota conditions include lumber and poles for the erection of sheds, groves, natural or planted by man, to hold the winds at bay, and straw to cover the sheds when made of poles. Natural ravines in the prairies may also be turned to good account in providing shelter for sheep. No state in the Northwest east of the Rocky Mountains has so large a timber supply. In nearly all the counties of the state poles are accessible, which, in conjunction with straw, can be used in building shelter at but little cost.

The natural groves that abound in the state may be made exceedingly helpful in keeping at bay one of the worst enemies to sheep husbandry in the state; that is to say, the keen cold winds of winter. And where such groves are not found they can be provided within a few years by planting them and duly caring for them. The difference between locating sheep sheds on the prairie without such protection, and with it, can only 
be fully realized by those who have experienced it. The same is also true in locating sheds in a ravine in the prairie. These deep ravines, with their steep banks, are a feature of Minnesota prairies. Usually streams meander through them to feed the rivers, and more or less of timber grows upon their sides. They may be made to render the best of service in providing shelter for sheep.

Bright and Healthful Climate.-It would be difficult indeed to find a climate with higher adaptation to sheep husbandry than that of Minnesota. The air is usually dry and bracing. Violent storms are relatively few. The sunshine may well be the envy of other lands less favored. The number of bright and cloudless days is very large in winter as well as in summer. The weather conditions are almost ideal. The only drawbacks from this source are the sharp winter winds which sweep over the prairie and the cold rains which occasionally occur in spring. From both, sheep ought to be protected. The days are unduly warm for sheep for a short time in summer at midday, but the nights are nearly always cool. The uniformity of the winter weather is always quite favorable to sheep husbandry. While it is cold the sudden changes are few. The thermometer hovers around the freezing point for many days in succession, hence it is easy to keep the floor of the sheds and yards dry and comfortable. Nor is the appetite of the sheep a varying quantity as in warmer areas.

Present Hindrances. - The chief of the hindrances to sheep husbandry in the state at the present time are, 
the extent to which fences are absent, the great losses to flock-masters from the ravages of wolves and dogs, and the want of experience in sheep husbandry on the part of so large a number of the farmers.

On very many farms in the state there are practically no fences. This is the inevitable outcome of the exclusive attention that has been given to grain growing. Where sheep are kept on the farm more or less fencing is necessary. Without it that change of pastures can't be obtained which is so advantageous in sheep husbandry. But the fencing needed may be provided without great cost as is shown in Chapter VIII.

The losses from wolves, though considerable, must decrease with the clearing up of the country. The legislature is also doing much to mitigate the evil in the bounty which it offers. Not so, however, the dog nuisance. It is certain to increase with the increase in settlement in the state, and more especially with the growth of villages, towns and cities. A large proportion of those who kept sheep in former years have given up the industry because of losses suffered from dogs. The legislature has no right to prohibit the keeping of dogs in a free country like ours, but it has a right to so regulate the keeping of the same that they will not harm their neighbor's property and he have no means of redress. It is not creditable to our state that no provisions are on the statute books of the same to protect the sheep industry against dogs. They are not there because the farmers have not demanded with sufficient earnestness that they shall be placed there. As soon as the farmers unite in asking for such protection 
they will get it. And no farmer has a right to complain of the absence of such protection who has not put forth a reasonable effort to secure it.

The want of experience in keeping sheep on the part of many is perhaps the greatest hindrance to the growth of the industry in Minnesota at the present time. The number of farmers who have never kept sheep is very large. When they do engage in the work they are prone to make mistakes and so get discouraged. In the hope of preventing such results this book is being written. The teachings of the School of Agriculture and of the agricultural press will also exert a similar influence. The hope may be cherished, therefore, that in the not distant future this hindrance will diminish until it shall become the least of the hindrances that retard the progress of sheep husbandry in our state. 


\section{CHAPTER III.}

\section{Breeds Adapted to Minnesota Conditions.}

It would probably be correct to say that there is no pedigreed breed of sheep in the United States that could not be profitably grown in Minnesota. The fact remains nevertheless that some breeds have higher adaptation than others. The adaptation of the various breeds in the United States to the conditions of Minnesota will now be discussed.

The question is continually being asked as to which is the best breed. It is very natural that the question should be asked by those who wish to establish flocks. The answer to it always involves the careful consideration of the following questions among others:--viz., the object sought in keeping sheep; the conditions that relate to climate, shelter and production and the market for the finished product.

In all arable countries sheep are kept for the twofold purpose of producing wool and mutton. Sometimes, and with some breeds, wool is the more important consideration, and in other instances the same is true of mutton. At one time wool was considered relatively more important than mutton in this country. In this fact the explanation is found of the great numerical preponderance of the fine-wooled types in the United States. But this condition is now so completely removed, that except in the growing of range sheep, mut- 
ton is likely to continue the more important question. This fact should not be lost sight of in determining which breed or grade of sheep should be selected by the growers in our state. With Merinos the wool product has been relatively more important than the mutton product. This at least has been true of them in the past.

Adaptation to such conditions as relate to climate, shelter and soil should more than anything else determine the breed or grade of sheep that should be kept. Some breeds, as for instance the Merinos, are so hardy that they can withstand exposure to severe conditions. Others, as the coarse-wooled breeds, must have better care. Small breeds, like the Southdowns, can move about more easily and more actively than larger breeds, hence they are relatively better adapted to broken and rugged pastures and to lands not over abundant in production than the heavy bodied breeds. The latter, as for instance the Lincolns, require pastures more level in character and rich in production. The intermediate breeds, as the Shropshires, are best adapted to what may be termed average conditions.

The market for the finished product should always be duly considered. It should always have some influence in determining the breed of sheep that shall be kept, and in some instances it alone should decide the matter, as, for instance, when winter lambs are to be grown for the market, Dorsets and their grades are the only breed that will completely serve the end sought. Again, when pure-bred flocks are to be established, the market more than anything else, may settle the ques- 
tion. While it may not be wise at the present time to grow Rambouillets for the general market, it may be eminently so to grow them in the pure form to meet the needs of the range.

The Fine-Wooled Breeds.-The fine-wooled breeds of sheep in the United States may be classified as American Merinos, Delaine Merinos and Rambouillets. These are named in the order of relative size, the American Merino being the smallest. They are also nameil in the order of the fineness of the wool, the flecce of the American Merino being the finest, though the difference in this respect is not great. Length of fibre stands in the reverse order, that of the Rambouillet being the longest.

The American Merino is simply the Spanish Merino improved under American conditions. It is a somewhat small and deep-bodied sheep of only moderate width, encased in a fleece of very fine, close, short and dense wool, and carrying more or less of wrinkles or folds in the skin, especially about the neck and breast. The fleece, at all times dense and compact, is so glued together at the outer ends of the fibres by the hardening of the yolk as to render it almost impossible for rain to penetrate it. This, in conjunction with certain other properties, places the Merino at the head of the list in point of hardihood among the prominent breeds now found in America. Since, however, their muttonproducing properties are not so good as those of the Delaine and Rambouillet types, and since they are not now greatly sought for to improve range stocks, it is questionable if they can be made as profitable in the 


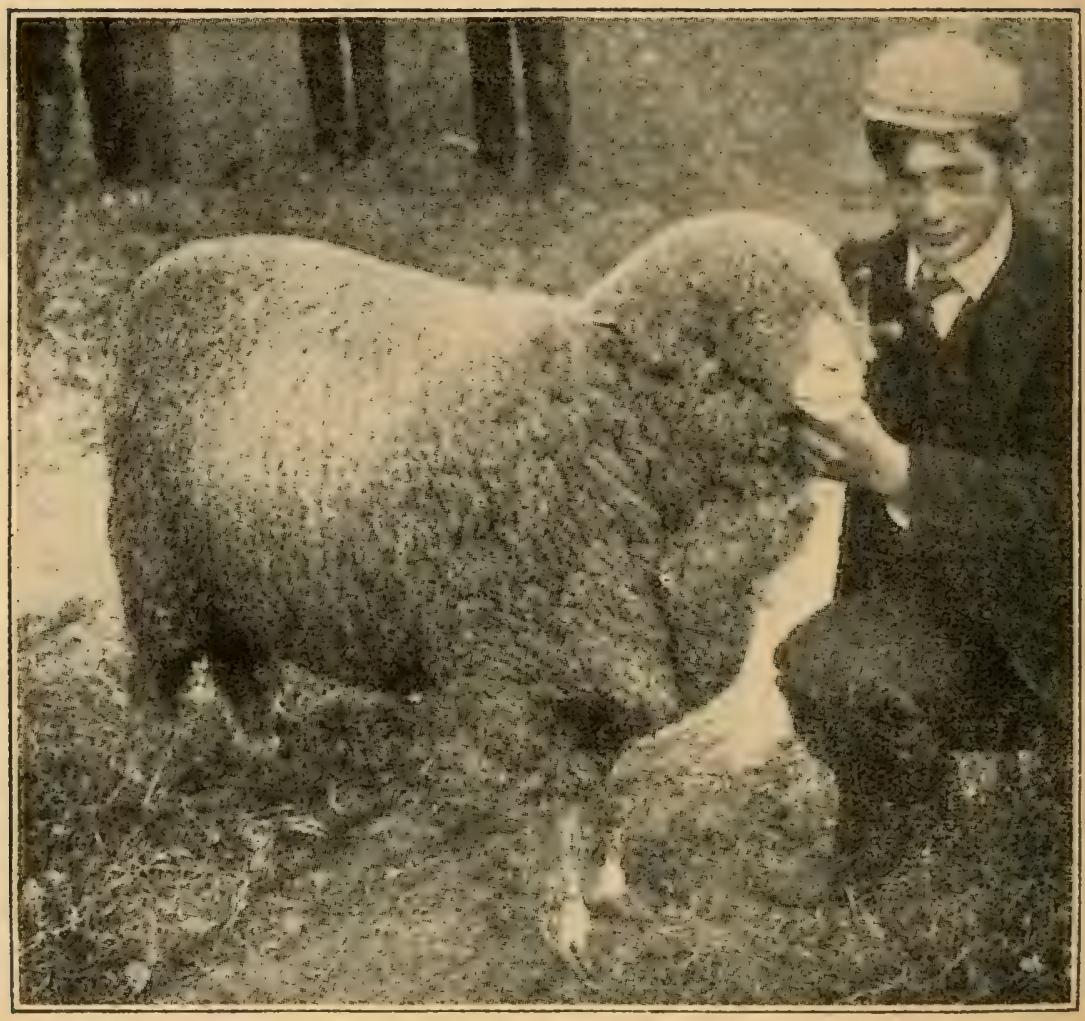

FIG. 2. TYPICAL RAMBOUILLET' EWE. Imported by Geo. Harding \& Sons, Waukesha, Wis. 
meantime, under our conditions, as the breeds just named.

The Delaine Merinos are the descendants of American Merinos, modified in form and in other respects, chiefly through selection in breeding. The Delaines, embracing several types and families, are compact and strong in build, nearly free from wrinkles and folds, and covered with an even and abundant fleece of fine, dense and beautifully white wool with a fair length of staple. Compared with American Merinos, Delaines are considerably larger and heavier, more compact and symmetrical in build, stronger in bone and possessed of better average spring of rib. They are more free from wrinkles, folds and dewlaps, and have a longer fleece, equally well distributed over the body, but not quite so fine nor so well glued together on the surface. They also mature somewhat more quickly, have higher adaptation for arable conditions, and are superior in crossing on range types for unutton production. For the last-ramed use they are much in demand at the present time, and as far as can be judged by present conditions, this demand is likely to be more or less permanent. Minnesota should therefore have a number of pure-bred flocks of Delaine Merinos.

The Rambouillet or French Merinos are a tall and strong class of sheep, a little upstanding and only fairly symmetrical in form. Compared with the American Merinos, the Rambouillets are much taller, larger, heavier, stronger limbed, and are somewhat more rangy. They have a mutton form, not quite so smooth or refined. The wool of the two types is very similar in 


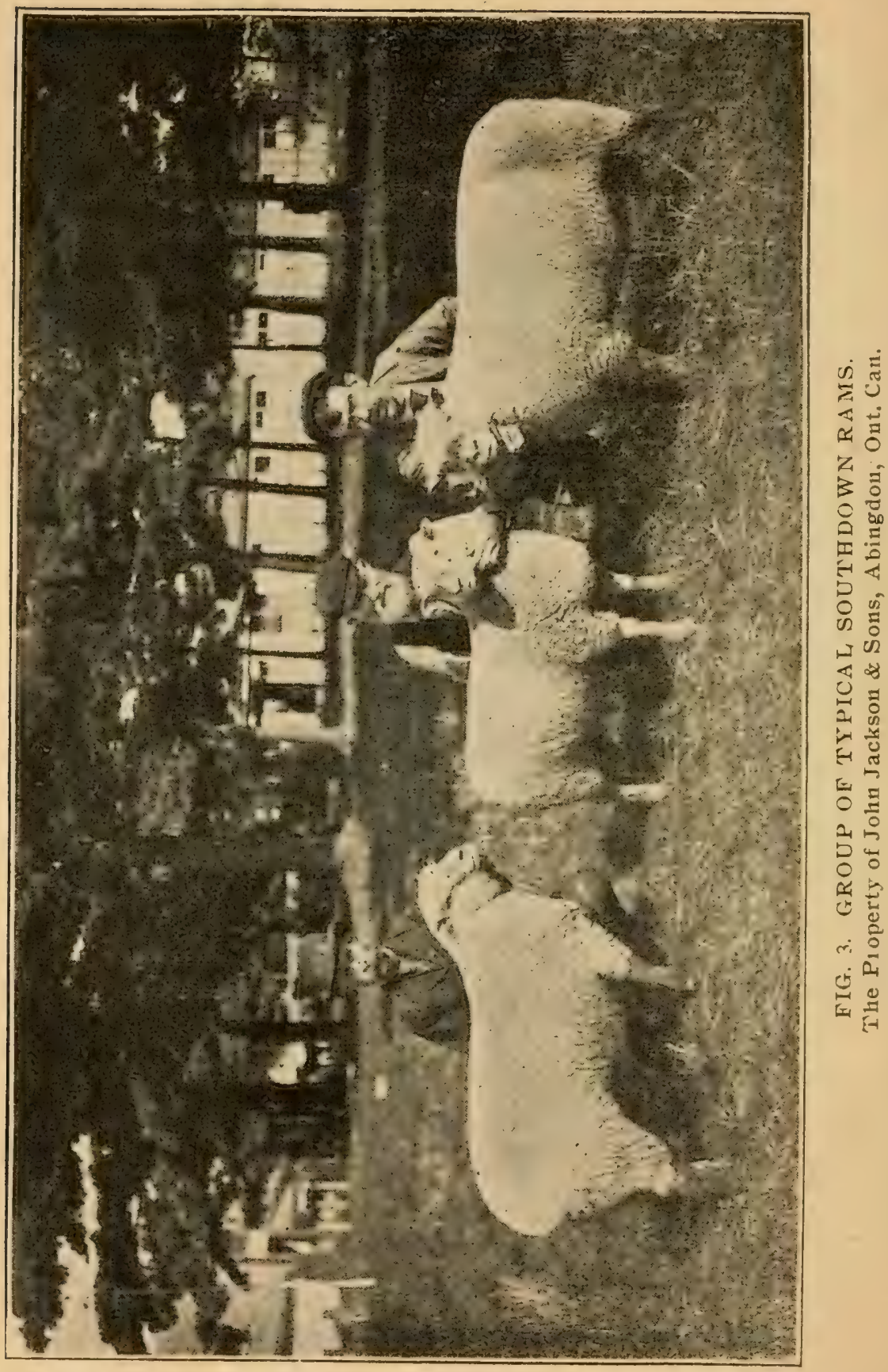


many respects, but the Rambouillet fleece is not so heavy in proportion to the size of the sheep, Rambouillets are much in demand at the present time for crossing on range stocks. If this demand should continue, the breeding of Rambouillets would be quite profitable in our state. But even though it should not continue, the investment should be a safe one viewed from the standpoint of the production of wool and mutton. combined.

The Middle Wooled Breeds. -The middle wooled breeds are the Southdown, Tunis, Dorset, Shropshire, Cheviot, Suffolk, Hampshire and Oxford. These are named in the order of fineness of wool, beginning with the finest. Of the above, the Distinctive Down breeds are the Southdown, the Suffolk, the Hampshire and the Oxford. They are so named from the "Down" lands on which they graze in England. The color of the face and legs in all these breeds is dark, varying from brown or mouse color in the Southdown to jet black in the Suffolk. The Shropshire, though not usually called a Down breed, is very similar to the Down breeds in form, color and essential characteristics. The darkfaced breeds are all noted for the production of a high class of mutton.

The Southdowns are small and neat in form and active in their movements. They furnish the true ideal type of the mutton sheep viewed from the standpoint of form and the quality of the meat. They are admirably proportioned and of perfect symmetry. The fleece is short, finer than that of any of the other British breeds introduced into America, and it is also more 


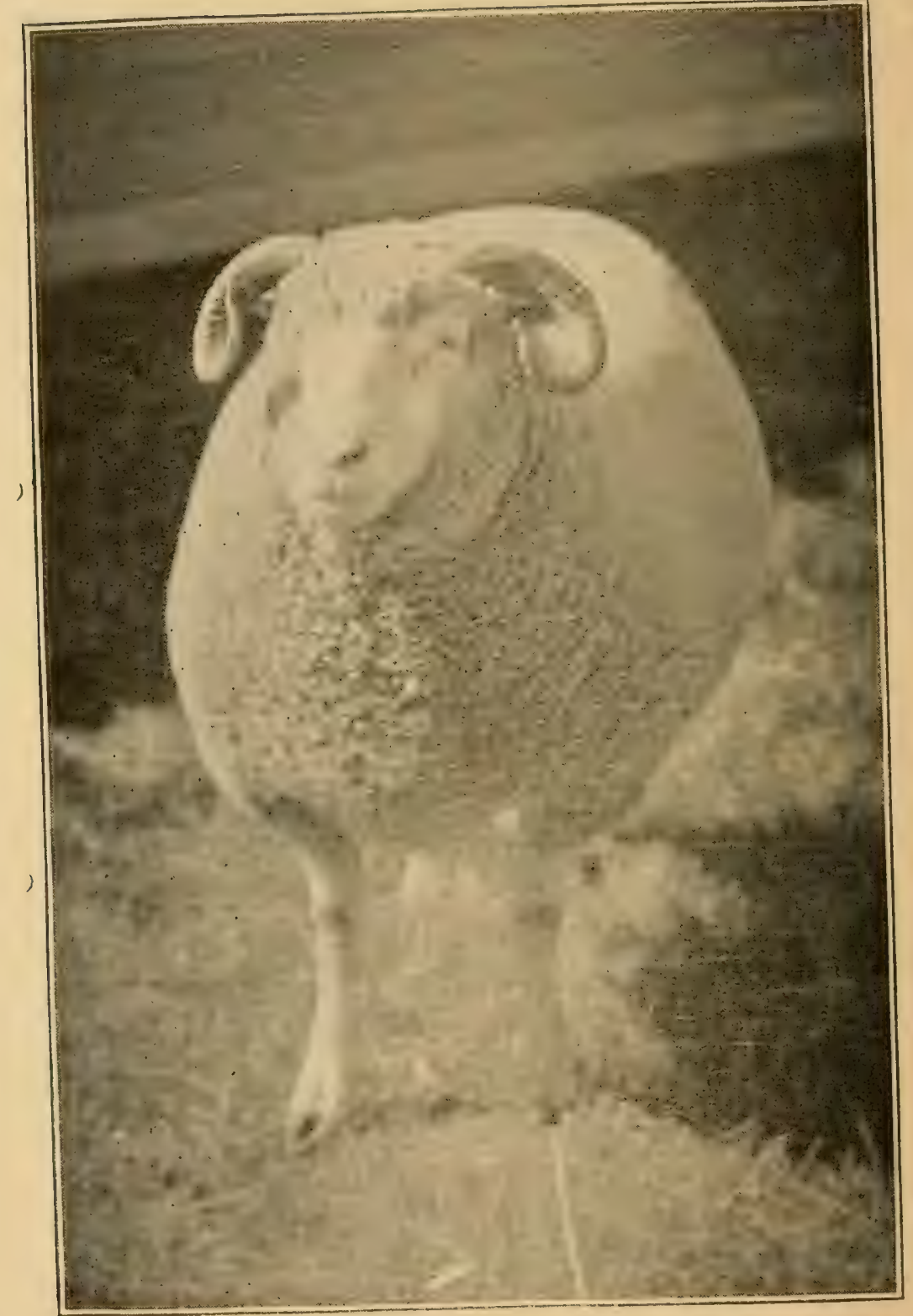

FIG. 4. TYPICAL DORSET EWE.

The property of Geo. Harding \& Sons, Waukesha, Wis. 
dense. The weight unwashed may be put at 5 to 7 pounds. Want of more size and of more weight in the fleece have made the Southdowns less popular than they would otherwise be. This breed is not numerous in our state, not so numerous relatively as it ought to be, as in hardihood, early maturing and easy keeping qualities it has a foremost place among Down breeds. It is pre-eminently adapted to bluff lands and to sandy areas of but limited productive capacity. It may also be used with decided advantage in crossing upon ewes too lank and rangy in form.

The Tunis breed, introduced from the north coast of Africa, are not yet numerous in the United States. They have been found well adapted to Southern conditions, but do not seem to have been tried as yet west of the Mississippi river. In general appearance the Tunis are not a large breed, but are fairly symmetrical, and are possessed of an active carriage. Compared with. Southdowns they are longer, though probably not much heavier, and are more rangy and somewhat longer in the limbs. The ears are longer and droop, and the tail is much broader. The head and legs are not quite so well covered, the wool is somewhat longer and coarser, and the fleece a little heavier. Like the Dorset, this breed will produce lambs at almost any season of the year.

The Dorsets are a somewhat long-bodied sheep, of fair symmetry and style, and they are active, easy and graceful in their movements. Compared with Southdowns, they are considerably larger and more rangy in form and limb, and both sexes have horns. They are 


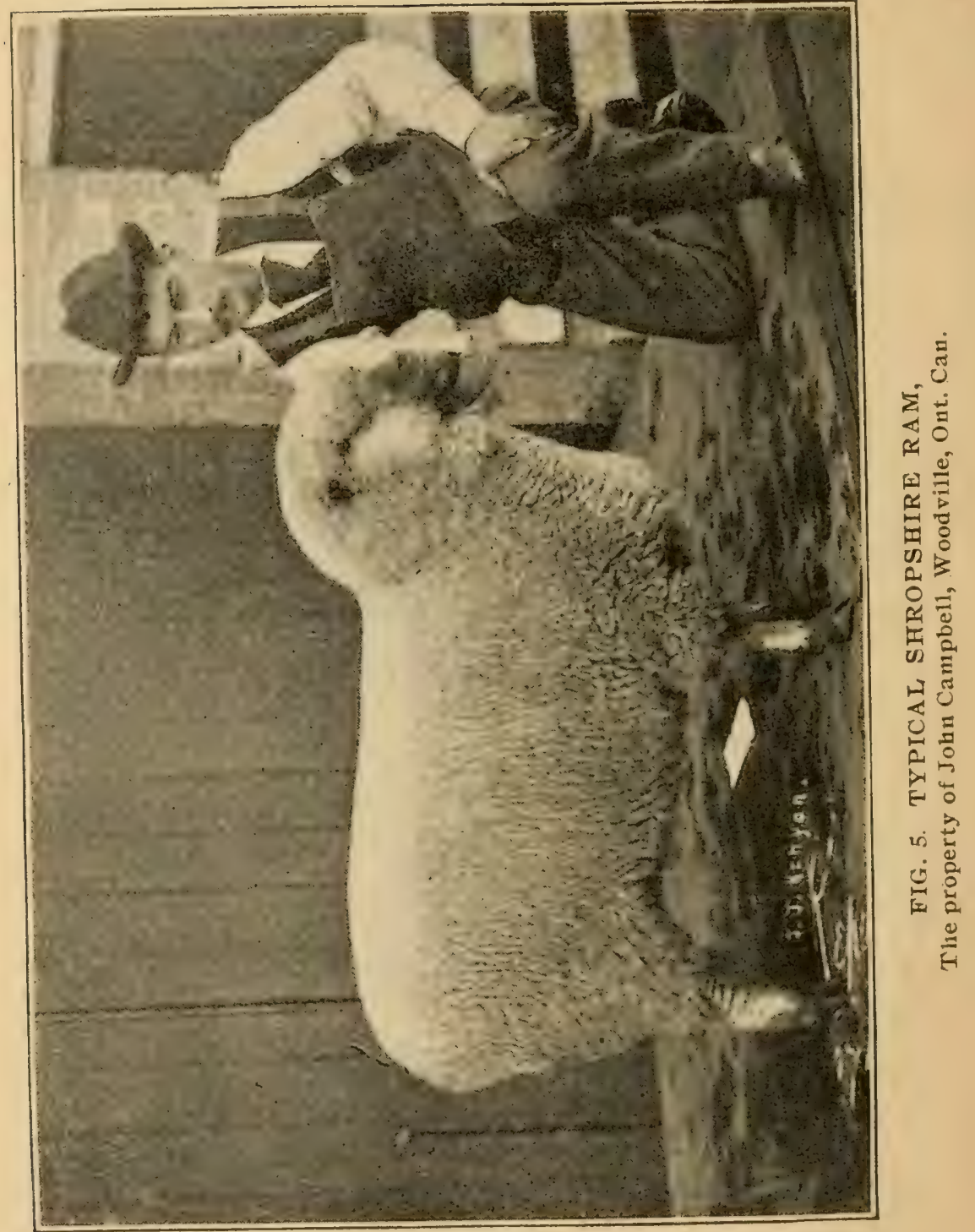


longer in the head, neck and body, not so plump relatively in the breast, shoulders and crops, nor quite so round in the spring of rib. The wool covers less of the head and legs, is longer, a little coarser, and considerably less dense. The head and legs are white, while those of the Southdown are some shade of brown. As Dorsets will breed at any season of the year, they are pre-eminently adapted to the production of winter lambs. As breeders, they probably stand first in prolificacy and in nursing qualities. They are also good grazers and feeders. But since the mutton form is not quite so perfect as in some of the Dorm breeds, the attempt should not be made to supplant these with Dorsets, except for the production of early lambs. For such a purpose there should be a prosperous future before them in Minnesota.

Shropshire in the pure and graded form are much more numerous in Minnesota than any other breed of sheep. This popularity is no doubt deserved, since Shropshires are possessed of what may be termed an equilibrium of properties which highly adapt them to the conditions of the average farm. They are of medium size and are possessed of much symmetry of form and uniformity of character throughout. When fully matured and in fair condition, rams should weigh not less than 225 pounds, and eves not less than 175 pounds. The average fleece from a good flock should clip 9 to 10 pounds unwashed in the ewes and more in the rams. The wool is of medium length and of more than medium density for the middle wooled breeds. Shropshires are good grazers on arable lands, feed well 


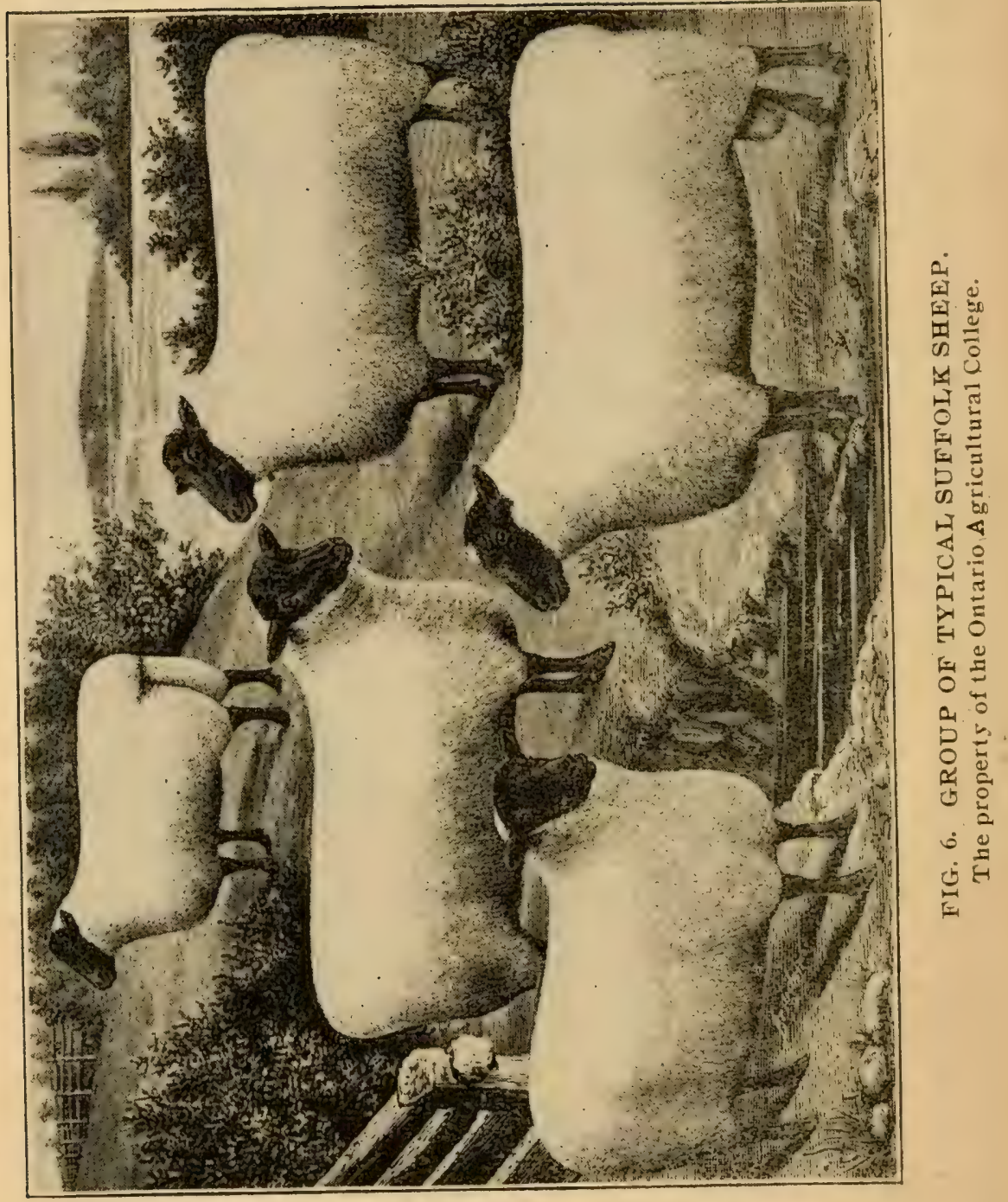


and produce a fine quality of mutton. Compared with Southdowns, they are larger and longer in body and carry a heavier fleece. The head has a more romplete covering of wool, and the wool on every part is longer but not so fine, and the color of the face and legs is considerably darker.

The Cheviots came originally from the Cheviot hills between England and Scotland. They have not yet been introduced to any appreciable extent west of the Mississippi river. This handsome breed is of medium size and has at least a fair degree of symmetry, and is unusually active and hardy for so large a breed. The head is bare and essentially white in color. The average weight of mature rams in good flesh is about 200 to 220 pounds and of ewes 150 to 160 pounds. The average fleece should weigh from $S$ to 10 pounds unwashed. There would seem to be a place for this handsome and hardy breed in Minnesota.

The Suffolk Downs are not numerous in the United States. Whether they will bocome as popular as the other Down breeds the future only can determine. They have a pleasing outline. The body inclines to long. The head is bare of wool, and both head and legs are jet black. The quality of the mutton is very good. The Suffolk Downs would seem to occupy an intermediate place between the Shropshire and Hampshire Downs.

The Hampstire Downs are a large and heavy breed of sheep, with robust form and strong limbs. They bear considerable resemblance to the Oxford Downs, but are not quite so heavy a breed, nor is the fleese so 


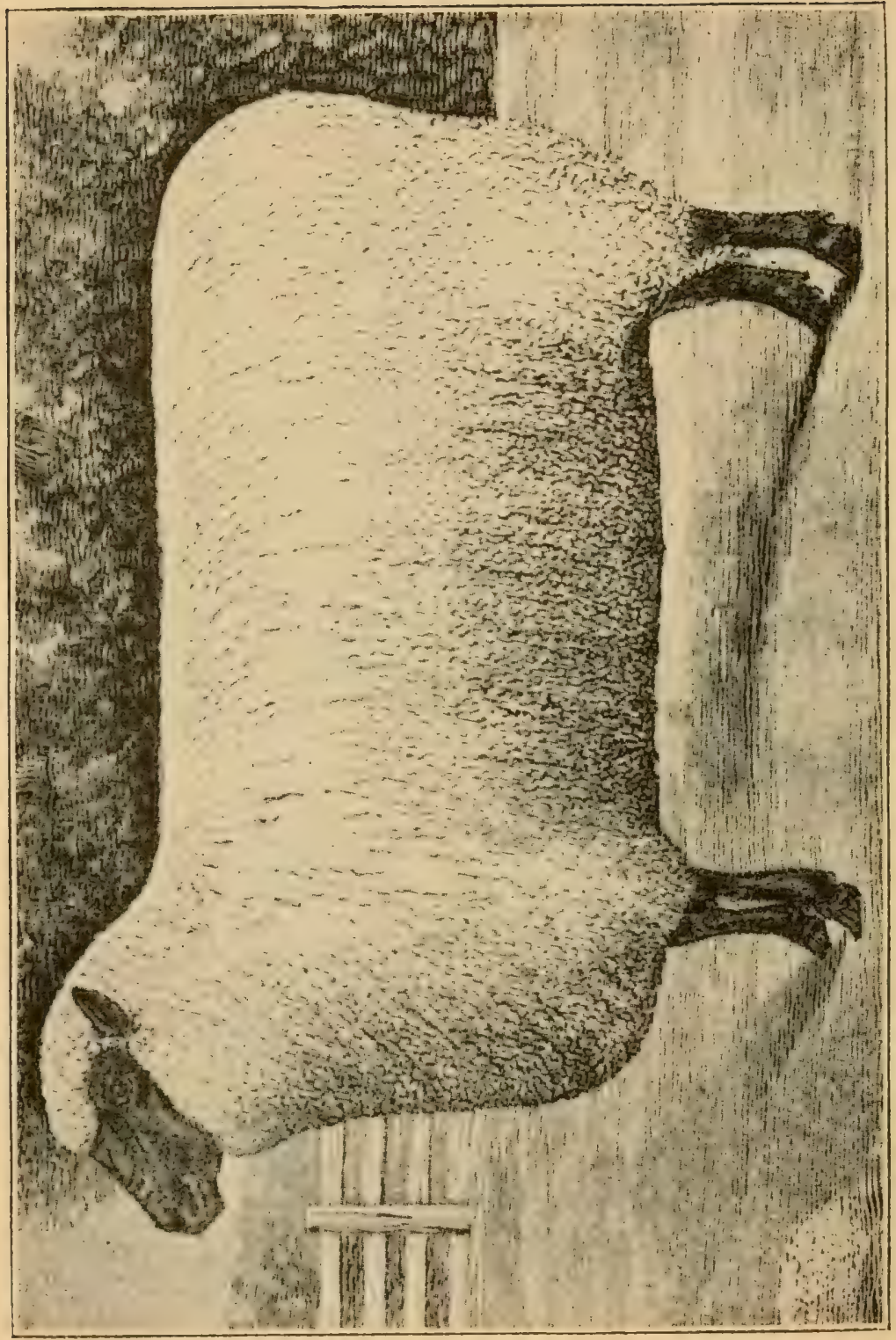

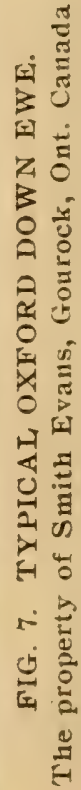


long or coarse. They are noted for prolificacy and abundant milk production, hence in Britain they stand high in favor for the production of lambs of good size and quality for the early market. There would seem to be no good reasons why they should not be grown for such a use in Minnesota, into which some good flocks have already been introduced.

The Oxford Downs are more numerous in the United States than any of the dark-faced breeds, save the Shropshires. Some good flocks have been established in Minnesota. Like the Hampshires, they are best adapted to arable conditions where the grazing is good and food production is generally abundant. Oxford Downs are large, substantial and stately looking sheep, neither rangy nor yet of the most compact or low-set type, and are covered with a heavy fleece of wool inclining to coarse and which stands at right angles to the body. Compared with Shropshires, they are considerably stronger in body and not so long for the width. They are longer in the head and ear and have less but longer wool on the head. The face and legs are not so dark and the fleece is heavier and coarser. When in good flesh the rams should average about 250 to 275 pounds in weight and the eves about 200 to 225 pounds. 'The average fleece in well-kept flocks should weigh from 10 to 12 pounds unwashed.

The Coarse-Wooled Breeds.-The coarse-wooled breeds in the United States for which pedigrees are kept are, the Leicester, the Lincoln, and the Cotswold. These have not attained the same popularity. as some of the fine and middle wooled breeds, but they are steadily 
growing into favor. There are relatively few flocks of any of the coarse-wooled breeds in Minnesota. They are all possessed of heavy and compact forms, are essentially white in the color of the face and legs, and are characterized by more or less of openness of fleece. It has been claimed, and probably with truth, that this openness of fleece has made them more liable to injury from cold rain storms. But there should be an important place for at least some of the coarse-wooled breeds in Minnesota. A cross of one or the other of these when judiciously made will usually speedily increase the average size of the animal and the average weight of the fleece.

The Leicester breed, though the oldest of the inproved breeds, is the least numerously represented in the United States. The reasons are not readily apparent, since there is not a coarse-wooled breed of much value in Britain on which the Leicester has not effected improvement. They are symmetrically, evenly and plumply developed, have a massive and yet refined frame, a restful but not sluggish carriage, and are, when in good form, truly beautiful animals. Their fleshing properties are of the best. The average weight of a mature Leicester ram in good flesh may be put at 225 to 250 pounds and of a ewe at 175 to 200 pounds. The author has not met with a pedigreed flock of Leicester sheep in Minnesota.

The Lincoln is the largest of the improved breeds of sheep, although in this respect it is but little ahead of the Cotswold. The average weight of matured rams in good flesh may be put at 250 to 275 pounds. The 
average weight of the fleece in good flocks is from 12 to 14. pounds unwashed. The Lincoln in full fleece has a square-like and massive form, the long wool coming well down toward the ground. When kept in the pure form they are well adapted to an intensive cultivation. A cross of the Lincoln upon the grade Merino has long been a favorite one with many ranchmen in the United States, and such a cross was never more popular than now. Compared with Leicesters, Lincolns are stronger in bone and more massive. The head is stronger, has a tuft of short wool on the forehead, is of a darker shade of white and has somewhat broader ears. The wool is longer, is more evenly distributed, and usually hangs in larger and more wavy spirals.

Cotswold sheep are much more numerous in the United States than either the Leicester or Lincoln breeds. In adaptation they are very similar to the Lincul:1s, and they are kept for somewhat similar purposes. They are stately looking animals, of rectangular outline when the fleece is well grown, massive in build, and possessed of a fairly proud carriage. Compared with the Teicesters, they are considerably larger and are a little more "upstanding." Their wool is longer and hangs in larger and more wavy spirals. They have a long and beautiful forelock and are of a less pure white in the face and legs. Compared with the Lincolns, they are somewhat similar in size and also in various features relating to form, but they carry a considerably coarser fleece and about equal in weight with that of the Lincolns, but it hangs in heavier spirals. 


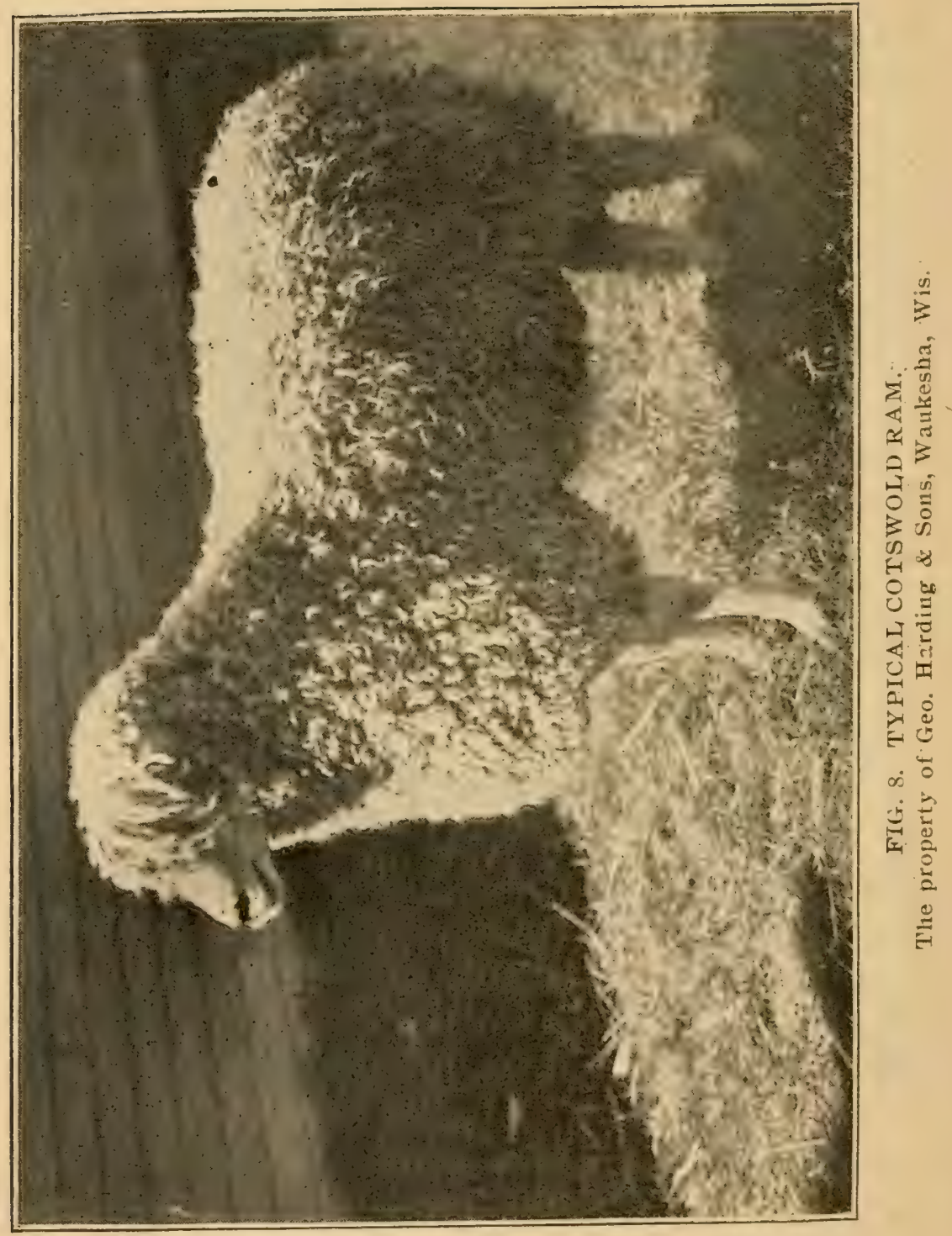




\section{CHAPTER IV.}

\section{Foundation Flocks.}

The flocks established will be pure or grade according to the object or objects for which they are kept. When sheep of the pure breeds are chosen, they will be kept chiefly with a view to sell the progeny for breeding purposes. The mutton and wool which they furnish will be secondary considerations. When grades are bred it will be for the mutton and wool obtained.

Great Opening for Purebreds.-There is a great opening at the present time for the establishment of purebred flocks in Minnesota. The proportion of farmers in the state who keep sheep of any kind is relatively small. There will unquestionably be an extension of sheep husbandry in all parts of the state, and in the very near future. Purebred flocks will be wanted to furnish rams for the flocks that will thus be established. There is also a constant demand for purebred rams of certain classes on the vast ranges of the west, and this demand is likely to grow more rather than less. 'The ranchmen as a rule do not grow their own rams. They purchase them east of the Mississippi and in Canada, going right across Minnesota in the search for them. There are no good reasons why Minnesota should not in the near future be able to supply this market. No state in the Union is better fitted by nature 
for growing them. Why should not our own farmers reap the profits that would be gathered in from such a harvest.

Who Should Grow Purebreds?-Every one is not fitted for such a work. The man who has never grown sheep of any kind should not engage in it unless he can secure the services of a properly qualified shepherd to supervise the work. The person who does not understand properly the requisites in form in sheep, and more especially the standard points of the breed which he desires to keep, should not engage in it. The individual who has not studied the more essential laws of breeding is not yet ready for the work. Nor should he launch out in the breeding of purebreds who is not fond of what may be termed the commercial side of farming, since the proper handling of a purebred flock involves a large amount of correspondence and no small degree of busincss shrewdness. 'i'he man of fair general business capacity who has made a success of a flock of grades would also be likely ti make a success of a fiock of purebreds; so would the farmer's son who has a natural fondness for sheep husbandry, and who is ambitious to excel in it. But young men of this class should proceed by the safe method of establishing small flocks, and thus growing into the business in a way that involves little or no financial hazard.

Establishing a Flock of Purebreds.-In deciding upon the breed to invest in, a due regard should be had to the present and prospective demand for the breed, but more especially to the latter. Having fixed upon 
the breed, select good fernales though a good price must be paid for them. It is folly to invest in a low grade of purebreds because they can be cheaply obtained, in the hope of improving then through careful breeding. Life is too short to spend it in that way. Every care should be taken to secure healthy animals and of good form, and withal possessed of good pedigrees. Avoid purchasing animals that have been exhibited at leading shows, as they are not so easily kept in good form as sheep that have not been forced so fast, nor are they likely to breed so well. First-class males only should be chosen and of choice breeding. A high degree of success cannot be reached unless correct judgment is shown in the choice of males. They must not only be high in individuality, but unless they are prepotent; that is to say, unless they have the power in a marked degree of enstamping their own characteristics on the progeny, they should not be retained for breeding. While prepotency cannot always be determined beforehand it is pretty certainly guaranteed by excellent breeding and evidences of much vigor and stamina. In breeding purebreds, as in breeding grades, inferior animals will appear occasionally in a flock, let the breeding be ever so skilful. These must be culled out as frequently as they appear and sent to the block, otherwise a sufficiently high standard in breeding cannot be maintained.

Establishing a Flock of Grades.-In establishing a flock of grades mixed breeding is not necessarily any objection to the females chosen as foundation animals. In fact, it may be a positive advantage in some in- 
stances, where the form of the animals is at least fairly correct, since the more mixed the breeding of the females the less will be their power to resist change sought by mating them with a prepotent male. In other words the more mixed the breeding of the female, the more likely is the progeny to possess the characteristics of the purebred male used in effecting improvement. There are no good reasons why much more than meat prices should be paid for such animals. They can be picked up anywhere in the comntry where suitable individuals may be found, or, they may be purchased at the stock yards by selecting from females sent down as stockers from the ranges. Such animals can usually be obtained most cheaply in the months of October, November and December. They may be selected in person or through a responsible commission agent as may be deemed advisable. In selecting foundation animals every care should be taken to grtard against the introduction of such diseases as scab, tape worm and stomach worm. Against the two latter however it may not be possible to guard, since it may not he possible to tell whether the animals chosen are entirely free from them. But when a flock is once established, and no traces of such troubles can be detected, it is greatly important that the flockmaster shall thenceforth raise the females used in breeding to avoid the risk of introducing disease by bringing in other females.

While the females may be of common or mixed breeding, it is imperative that the males shall be of good individuality and purely bred. The better they are in both respects the more certainly and the more speedily 
will they effect improvement in the progeny. Grade sires cannot certainly be depended upon to effect improvement, since their properties are not stable or fixed, and the more mixed their blood elements the less fixed will those properties be.

While it is important that the individuality of the rams and also their breeding must be good as stated above, it is not necessary that they shall stand high in what may be termed fancy points. To illustrate: A Shropshire ram, excellent in other points, may have a head too little covered with wool and somewhat off in color. These objections would justly bar him from being placed at the head of a valuable pure bred flock of Shropshires, lest the same undesirable characteristics should appear in the progeny. In such instances sales would be injured. But though these characteristics did appear in the progeny of grade females what harm would follow? They are being grown for the block. Wherein can the block value be affected by a scant covering of wool on the head or by the same being a little off in color? Pure bred males thus defective in fancy points may sometimes be purchased cheaply to head grade flocks, and when they can, such an advantage should be duly considered.

Select Males from One Breed.--In breeding grades the males should, as a rule, be always selected from one breed. There may be instances in which it will prove advantageous to introduce an outcross from another breed, and for cerain reasons it may be proper sometimes to continue to select sires from the breed chosen in making the outcross. And there may be yet other 
instances in which crossbreeding is legitimate, but what is termed zigzag crossing, that is to say, choosing successive sires from different breeds is to be deprecated. As a rule the males should be chosen successively from one breed.

In fixing upon the breed from which sires shall be chosen for grading up, adaptation to the conditions, the market demands and the taste of the individual, should be considered. The question of adaptation to conditions has already been discussed in chapter III. The market demands vary, but usually the cycles of variation are not so rapid as to seriously frustrate plans that have been well laid with a view to the production of mutton and wool of a certain class. The natural preferences of the individual should have considerable weight. If, for instance, either une of two breeds will answer fairly well from which to choose sires, they should certainly be chosen from that breed for which the individual has a preference. The work of up-grading will then be more congenial than if the other breed had been chosen. As the markets are at present, the sires should as a rule be chosen from one of the dark faced breeds except when winter lambs are sought, since grades of these breeds are in the meantime more popular than grades of the other classes of sheep. Possibly sometime this may change, but such a change is not likely to take place in the near future.

The advantage from choosing successive sires from the one breed when grading up may be readily demonstrated. Choose a purebred sire of good individuality 
from the Shropshire breed for instance, and mate hina with ewes of mixed breeding. When such mating is begun the difference in blood properties between the sire and dam may be represented by one hundred. If the purity in breeding and the prepotency of both sire and dam were equal the progeny would inherit of the properties of each about 50 per cent, that is to say, it would resemble one parent as much as the other. But in reality the offspring inherits more of the properties of the sire than of the dam, because the sire is more propotent than the dam. The more pure his breeding and the greater his vigor, the more prepotent is he likely to be, that is to say, the greater is his power to transmit his qualities to the offspring. On the other hand, the more mixed the breeding of the dam the less power does she possess to transmit her properties to the offspring. The properties transmitted by the sire therefore will ex. ceed those transmitted by the dam just in proportion as his prepotency exceeds that of the dam. This explains why, in up-grading, the progeny of the first cross bears so much of resemblance to the sire. Suppose 75 per cent of the properties of the lamb are inherited from the sire, the gap or dissimilarity in blood properties still to be bridged over is now represented by 25 per cent, whereas it was represented by 100 at the begin. ning. Choose the next sire from the Shropshire breed and mate with the female progeny the result from the first mating. The progeny will again bear a preponderance in resemblance to the sire, for reasons already given. But the improvement in the second instance is less relatively than in the first, for the reason that the 
room for effecting improvement was not so great. Continue to breed thus and in four or five generations the progeny will practically possess about 100 per cent of the properties of the Shropshire breed. In other langirage, for producing wool and meat, they will be practically equal to the Shropshires. This process, as has been indirectly intimated, is known as up-grading, and it is the plan of breeding that should usually be followed by farmers in the breeding of all kinds of grade stock.

But it may be found that after a time the average size of the breed has grown less. In other instances they may have grown too leggy or too rangy, and yet again the staple of the wool may have too much diminished. To remedy these and other defects, it may be necessary to make an outcross. In the case of grades that would mean the introduction of a male from some other breed. If for instance one were breeding Shropshire grades and the size became too much reduced, to counteract this defect a sire could be chosen from the Oxford or Cotswold breeds. A sire from either of these breeds would also lengthen the staple of the wool but probably at some sacrifice in its density. A sire from the Southdown breed would counteract undue lankness of form. The outcross having been made, the previous line of breeding may be resumed. But there may be good reasons when it would be advisable to continue to choose sires from the breed used in making the outcross. Such a course might be proper if the first chosen was found too large for the conditions of pasturage. It would probably be prudent in such an instance to outcross with 
Southdowns and to continue to choose sires from the Southdown breed. However, when the breeding, care and selection are what they ought to be, the necessity for out-crossing will be greatly reduced.

Cross-breeding may in some instances be legitimate. Usually it means the mating of animals of two distinct breeds, pure in their breeding or rich in the blood elements of some distinct breed. Usually it brings with it improvement in the first cross, but the results in succeeding crosses are likely to be variable and uncertain, and in many instances they are inferior to the results obtained from the first cross. Let it be noted here that these results in no way weaken the argument given above which virtually claims that in up-grading, improvement should be continuous until the level of the breed is reached from which the sires are chosen. Cross-breeding and up-grading are very different processes. The latter is far more certain in its results and is therefore the much safer of the two processes for the farmer to practice. In some instances hovevel crossbreeding may be beneficial. If, for instance, range ewes possessed in a considerable degree of Merino blood are purchased early in the season, and if they are then crossed by sires of some of the good mutton producing breeds to secure early lambs, and if when the lambs are sold the ewes also are sold early, the venture may prove a profitable one.

Zigzag crossing is to be deprecated. If sires are first chosen from one breed and then from another and another, no stable or certain properties can be secured. 
One cross may effect improvement, a second cross may result in deterioration. A farmer may breed thus through the whole of a lifetime and not in any degree lift up the average of results to a higher plane. He would be sailing on a sea without a compass. He is simply playing a long game of guessing.

Leading Essentials in form and Fleece.-These are given below as submitted by the author in "The study of Breeds" recently published by the Orange Judd Co., New York city :-

The mutton breeds all possess the same leading essentials as to form. These include width, depth and length of body and compactness of frame; the cylindrical shape which is the outcome of plump shoulders and hips, and well sprung ribs; and a fleece of even length and quality covering all parts of the body.

The minor points of difference include: Variations in size of carcass and brne; in the length of the leg and of the coupling of the body; in the color of the head and legs and the amount of covering on therr; in the form and carriage of the head; in the length, shape and carriage of the ears; and in the length and density of the fleece and the character of the staple.

The leading essentials of the rams of the mutton breeds as to form are as follows: Size.-Medium to large, for the breed, and the bone medium to strong, but not coarse. Outline.-The body should be smooth, compact and strong, cylindrical in shape and square at the ends. Head.-Medium to strong in size, short rather than long, but varying with the breed, and carried proudly. Nose and muzzle tapering but not too fine; 
nostrils wide and expanded. Forehead and poll, wide. Eye, large, full, bright and daring. Ear, medium in size and thickness for the breed, broad rather than long, erect rather than drooping and possessed of lively play. Neck.-Whort rather than long, not coarse, and carrying the head well erect. It should not be coarse at the junction with the head and should be free from throatiness. It should be round rather than flat, and should increase in width laterally and underneath as it recedes from the head. It shou'd fit into the withers evenly above, and into the shoulders evenly and strongly at the sides and underneath, the blending being imperceptible.

Body.-Long, wide, deep, round and equally well balanced before and behind. Back, level, wide, well fleshed and slightly rounded outward, with the spinal column hidden and even depressed from the loin to the tail-head. Loin, broad and full, underline straight. Breast, broad, deep, full, massive. Brisket, broad and well rounded. Shoulder, large, plump and smooth, wide above, rounded out from above, forward and below to the center, well filled before and behind, and well covered. Forearm, strong and well developed. Crops, well filled. Girth, good around the heart, and about equally good at the hind flank. Coupling, short rather than long. Ribs, well sprung from backbone, nicely arched and deep, not distant from one another and coming well forward and backward. Hindquarters, long, broad and deep, rounded out from above and behind toward the center of the hip, and broad at the buttock. Twist, well filled and placed low. Hind flank, well filled outwardly, low and thick. Thigh, broad and well 
filled within and without. Tail, set on smonthly and on a line with the back. Skin, a rich pink in color, and possessed of good handling qualities. Wool.-The whole body should be well covered with wool, characteristic of the breed. The wool should be of uniform length and texture and should possess the qualities essential in a first class fleece as given below. Lrgs.Short, straight and strong;, wide apart and yet weil under the body, and standing firmly on hoofs of gond shape and quality. Appearance.-The appearance st:ould be animated and the carriage easy, proud and gracef $n 1$.

The ewes of the mutton breeds possess the same leading essentials as to form as the rams, with the following; points of difference: They are not so large in irame, are finer in bone and are more round in the barrel or coupling. The head is smaller and finer and is carried less proudly. The neck is longer and finer, more especially where it joins the head. The twist is not quite so well filled and the wool is finer in fiber, at lesist in some instances.

The following include the more important of tl: : characteristics of a good fleece: Good length, strength and density of staple for the breed; eren distribution over the body, both as to length of staple and quality in the wool; a fine bright lustrous appearance; absence of cloudiness; freedom from kemp and cot; and tr.e absence of all such impurities as sand, burrs and chaff.

The distinctive peculiarities of each breed can only be learned by a careful study of the standard points for the same in conjunction with the study of the animals themselves. 


\section{CHAPTER V.}

\section{Pastures for Sheep.}

The iristures best adapted to sheep are those that are fine, juicy and nutritious, and that furnish succulent grazing during a large portion of the pasturing season. Some parts of Minnesota do not furnish such pastures so plentifully as states in which the rainfall is more aburidant and the distribution throughout the seasnu more complete. Much of the state is yet covered with natural grasses. These are excellent while they last, but the season of their succulence is short. To make sheep husbandry eminently successful, therefore, it is necessary to suprlement the grass pastures with other varieties sown from time to time.

Necessity for supplemental Pastures.-The nesessity for supplementing the grass pastures exists in sorne rlegree at least in all parts of the state, as indeer in all the arable sections of the northwest. But the necessity is greater in some sections of the state than in others. Tn southeastern Minnesota the growth of cultivated grasses is more luxuriant than in some other parts of the same. This also is true of northeastern and of many pirts of northern Minnesota. In other parts of the stats; there. fore, the necessity for supplementary pastures is rela. tively greater. Of the cultivated grasses there is none that will surpass blue grass in adaptatio: $1 n$ the neads of sheep, but usually its period of succulence in Minne- 


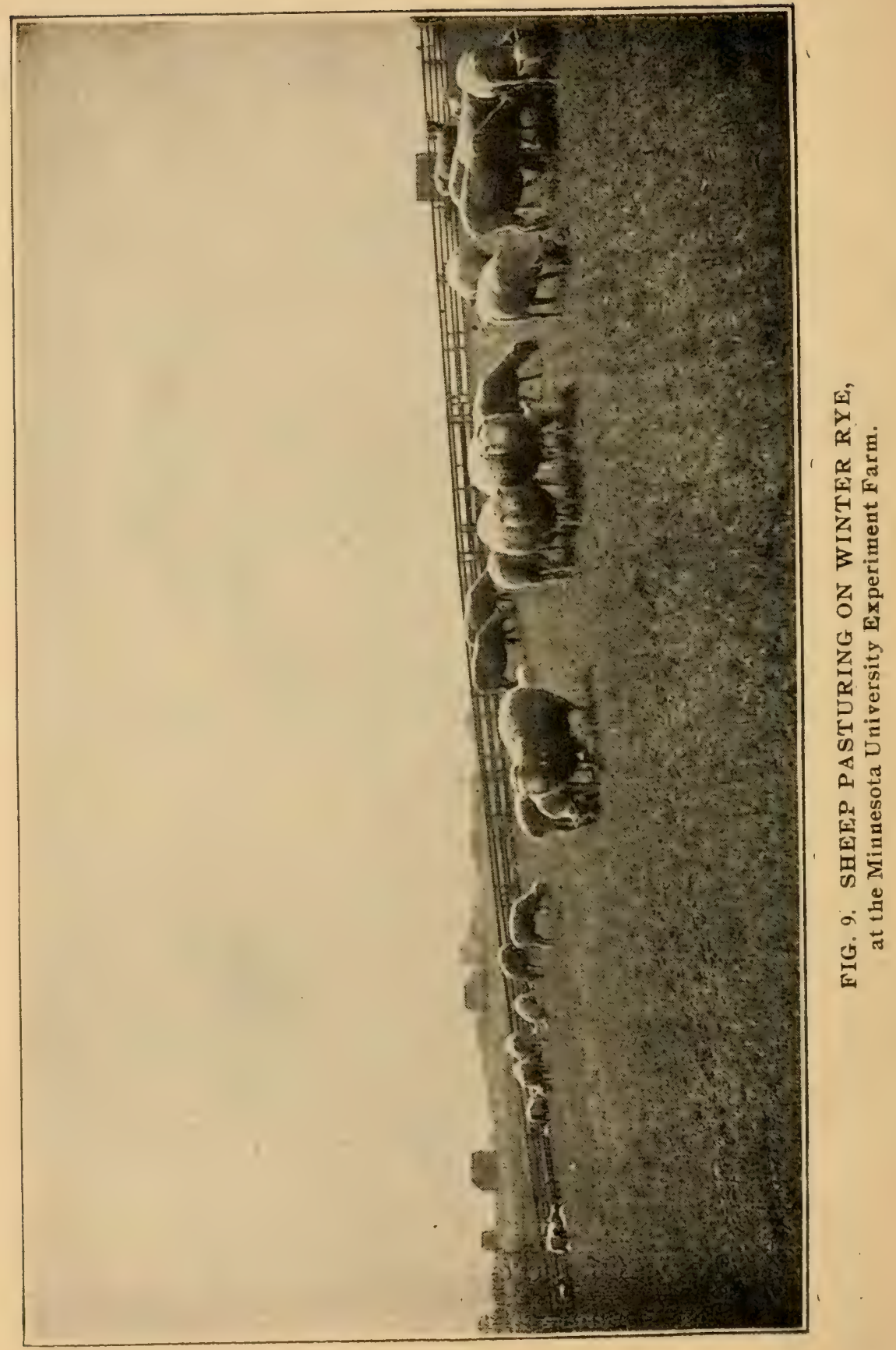


sota is confined to a few weeks in the spring and to a shorter period in the autumn. The new grass, Bromus inermis, known variously as Russian brome, Austrian brome and awnless brome has not been sufficiently tried yet under our conditions, to speak confidently of its merits. It has much promise however as a pasture grass because of the earliness, the latenss and the length of the period covered in its growth each season, and because of its higher relative adaptation rian timothy and blue grass for being grown on sandy land.

Benefits from Supplemental Pastures.-Prominent among the benefits from growing supplemental pastures are the following: First, the sheep may thus be provided with an abundance of succulent food during all the season of growth. Second, because of this the ewes milk much better during the period of lactation, the lambs grow more quickly, and the average size of the individuals composing the flock may easily be maintained if not indeed improved upon. Third, the number of sheep thus maintained on a given area may be greatly increased, and fourth, the change of pasture thus provided may be so managed as to much lessen the tendency to disease in the flocks.

Plants Best Suited for Supplemental Pastures.Prominent among the plants of highest adaptation in providing supplemental pastures under Minnesota conditions are, winter rye, corn, sorghum and rape. Those also valuable but not so high in adaptation include, mixed grains, millet, soy beans and cabbage. Of the former, winter rye is one of the most valuable. It may 


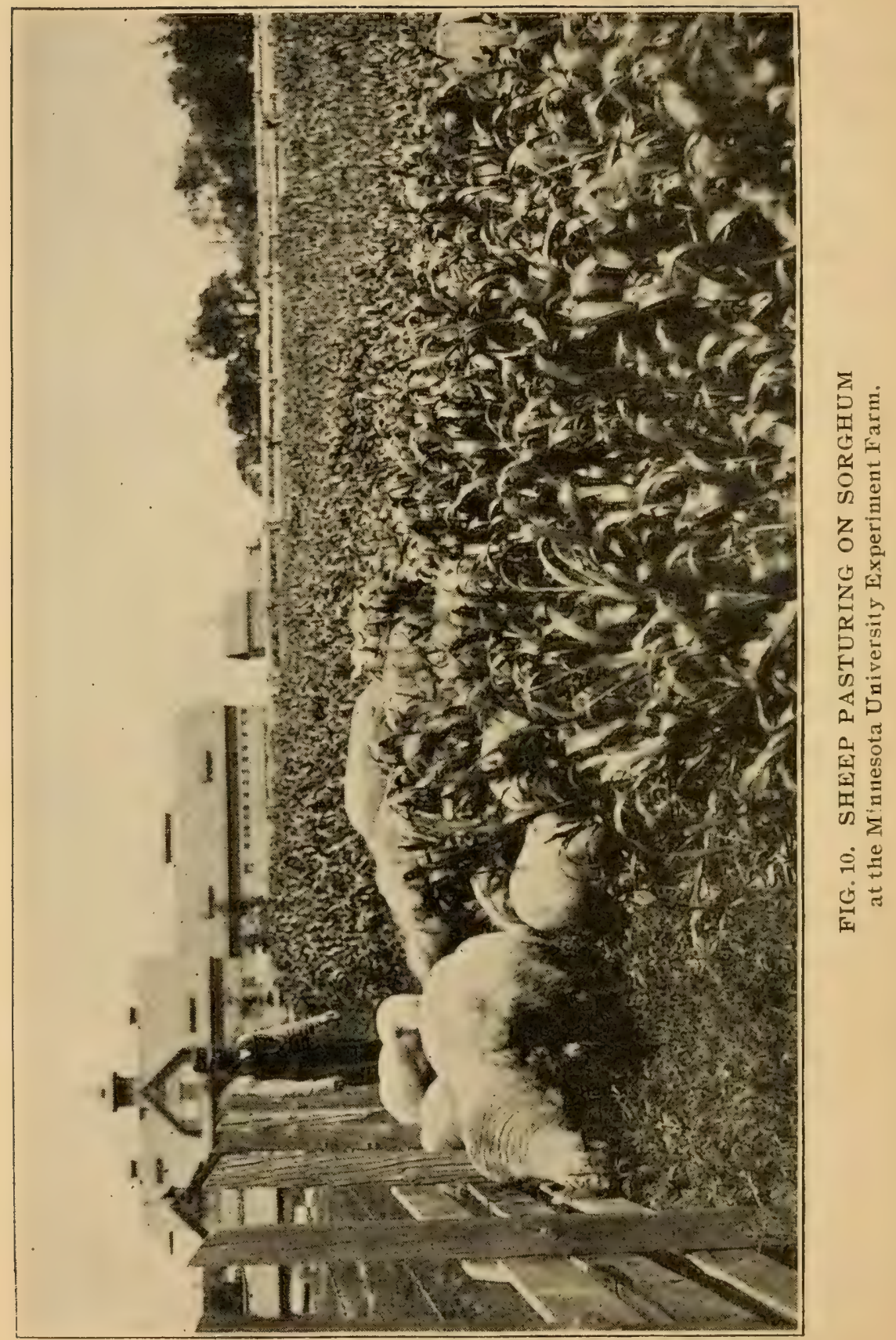


be made to furnish a large amount of pasture, fall and spring. Rye pasture when kept closely grazed is succulent, palatable and nutritious. It is ready earlier in the season than any other kind of pasture, and it can be grown to provide grazing at those times of the year which do not interfere with the growth of various other crops the same season. Winter rye may be made to furnish grazing for from 2 to 6 weeks in the autiumn and from 4 to 6 weeks in the spring.

Corn may be turned to excellent account in furnishing pasture for sheep during the summer months. When eaten down after the first joint has been formed, it will not grow again, hence it should not be grazed at too early a period in its growth. By sowing corn at different intervals it may be made to furnish pasture from some time in June in the southern half of the state until the arrival of frost. In the northern portions of the state the period for pasturing corn would be shorter.

Sorghum is even more valuable than corn as a pasture plant, for the reason that it grows again when cropped down. It is pre-eminently a hot weather plant, hence, it produces the most pasture relatively when the weather is warm. Neither corn nor sorghum is so palatable as rye or rape, but if not allowed to become too far advanced before being pastured, both are eaten greedily by sheep. Sorghum may be made to furnish pasture from about the middle of June until the arrival of frost. It furnishes a large amount of pasture relatively from a given area. As both corn and sorghum grow at their best in warm weather, both have highest adaptation for mid-summer grazing. 


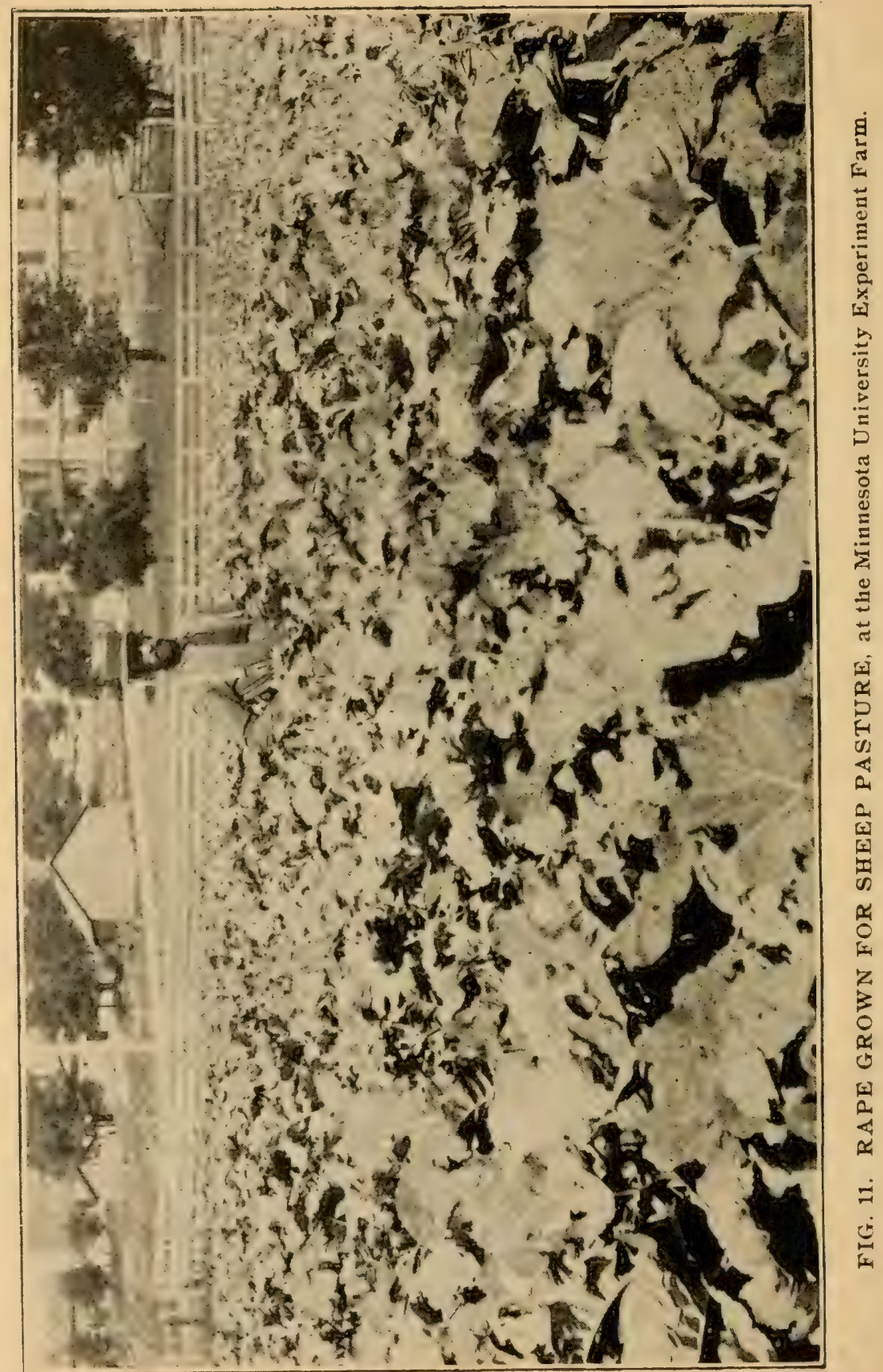


Rape, in the judgment of the author, is by far the best pasture plant for sheep that has yet been introduced into the northwest. It may be sown at any season from early spring until the middle of July, and even later than July when the weather is favorable. No plant grown as supplementary pasture is so highly relished by sheep. None is more highly nutritious, nor will any furnish more food per acre when grown on rich land. It makes a maximum growth in Minnesota in 7 to 10 weeks from the date of sowing, hence, by sowing rape at suitable intervals it will furnish pasture from early in June until the time when the ground freezes in the fall. Rape does not grow at its best during very hot weather, but even in mid-summer it will usually provide good grazing if sown sufficiently long beforehand to nearly reach its growth before the arrival of very hot weather.

Mixed grains include such combinations as barley and oats; barley and peas; oats and peas or barley; oats, peas and winter or spring rye. Of these, barley and oats are more frequently sown, and for the reason chiefly that the seed is usually on hand, but good results may be obtained by sowing only one of the mixtures named. The advantage from sowing a mixture over any single kind of grain arises from the longer period during which the mixed crop will furnish pasture and from the greater variety in the food thus provided.

Millet is not quite so well adapted to growing pasture as to growing soiling food, but it may also be made to serve a good purpose in providing excellent pasture for sheep in hot weather and it may also be thus grown as a catch crop. 


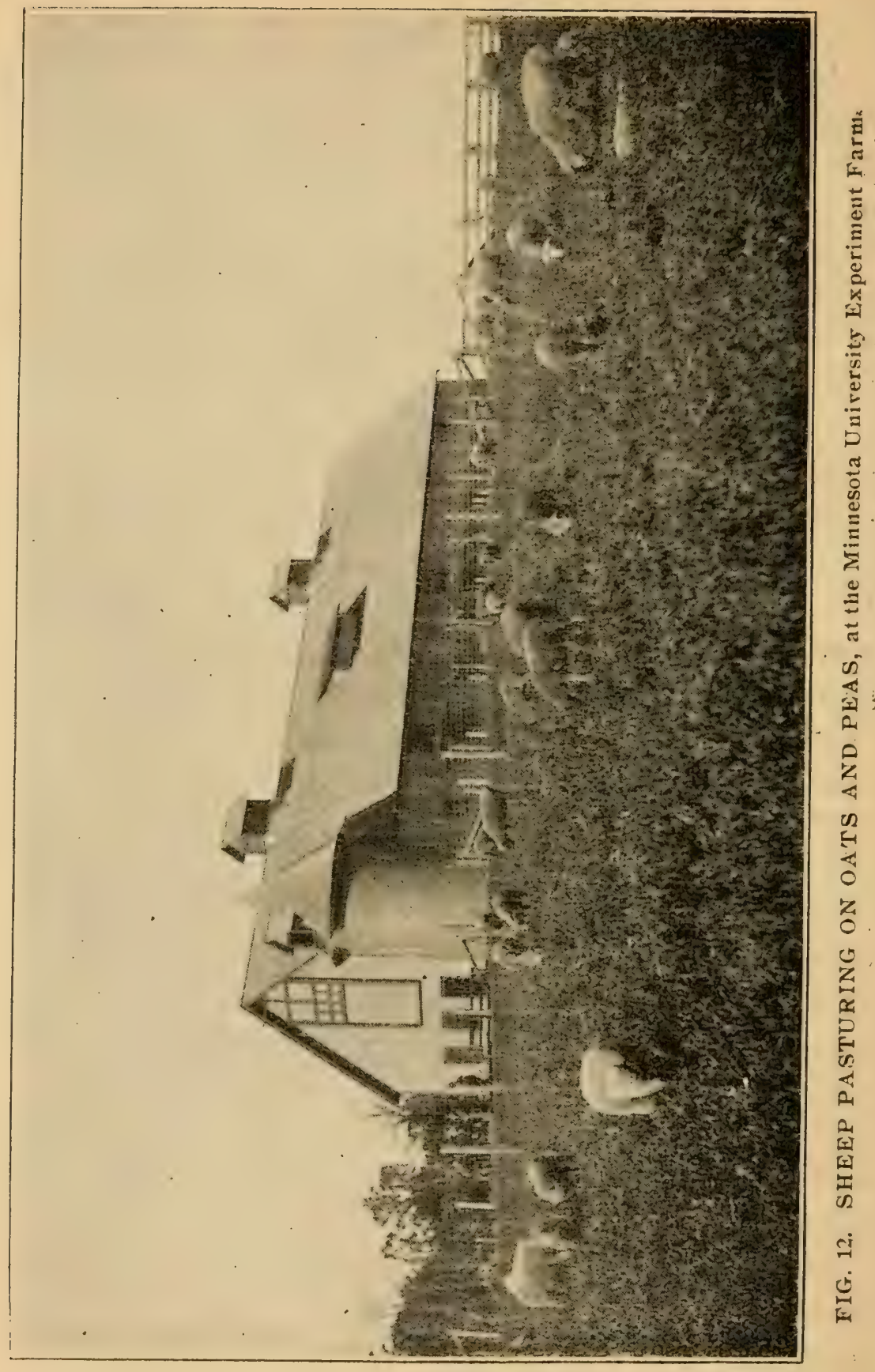


The Soy bean will probably be used to a considerable extent in providing pasture for sheep in Minnesota in the not distant future, or as soon as the seed can be obtained at reasonable rates. This crop is not only much relished by sheep but it is also an enricher of the soil, and it may be grown successfully in weather so dry as to hinder the growth of other pasture crops.

Cabbage furnish excellent pasture and a very large amount of it relatively. The only real objection to growing cabbage as pasture for sheep is the amount of labor involved in growing them. But no pasture grown is more suitable for them quite late in the season than cabbage.

Growing Supplemental Pastures.-In growing winter rye as pasture for sheep the aim should be to sow it not later than September 1st and on well prepared land. More pasture will be obtained if the seed can be sown and germinated early in August. Late sown rye does not provide any pasture in the autumn, nor is the growth sufficiently vigorous in the spring. Sow if possible with a grain drill and at the rate of from 2 to 3 bushels of the seed per acre. Heavy seeding is usually to be preferred.

Sow corn any time that the ground can be brought into a suitable condition after the usual corn planting season has arrived and until within 7 to 8 weeks of the usual time for the arrival of frost. Sow with the grain drill when practicable, all the tubes in use, and sow at the rate of 1 to 2 bushels per acre according to the variety of the corn. The crop should be harrowed before it comes up with a light harrow and also subsequently, 


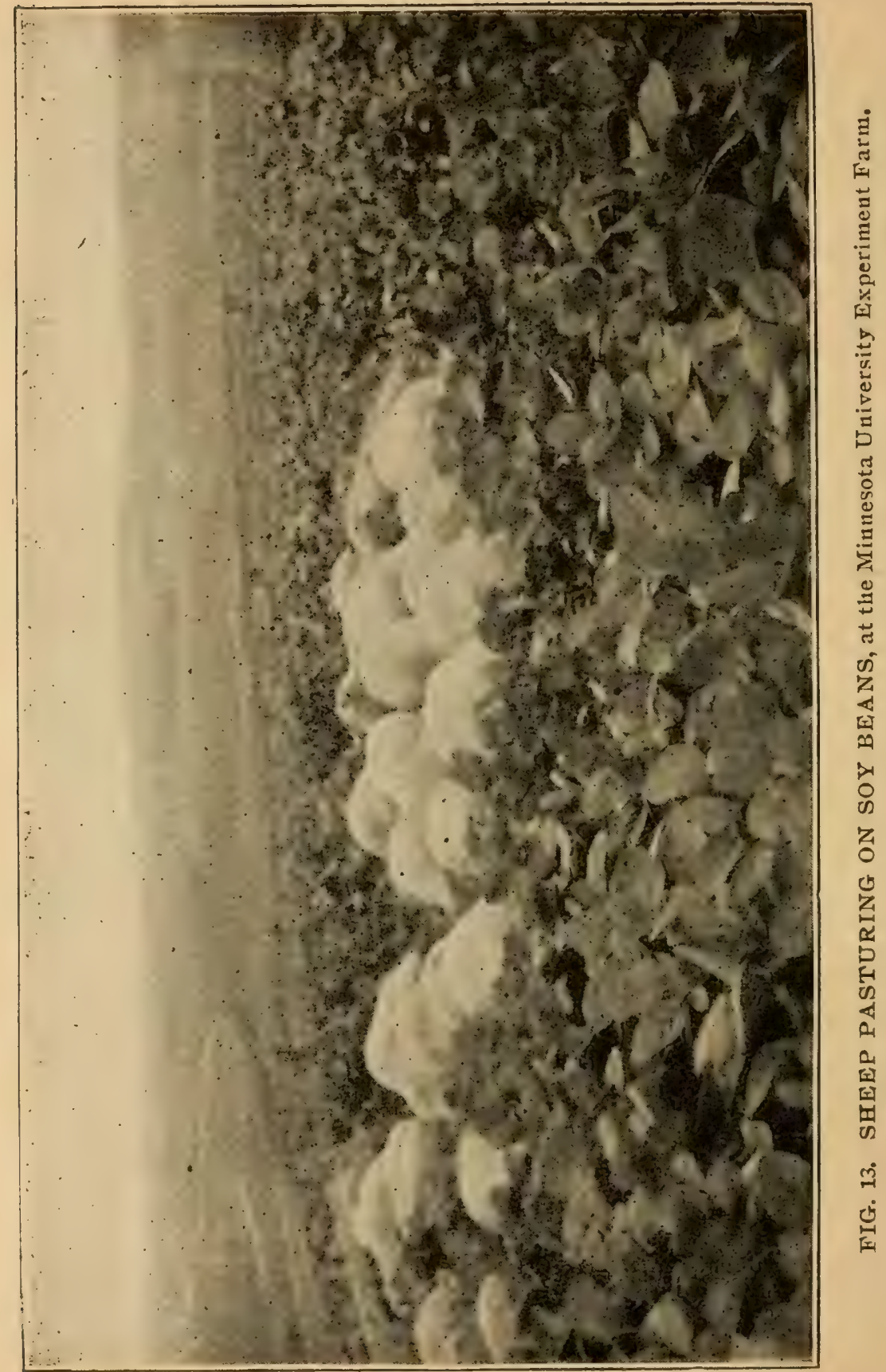


unless some other crop has been sown with the corn. The plan of sowing 2 to 3 pounds of rape seed just before the corn is harrowed has some advantages.

Sow Sorghum on land well pulverized and if possible made reasonably clean on the surface. Soil for a sorghum pasture may be thus prepared when it does not follow a crop grown previously the same season, and more especially when the ground has been plowed in the fall. There is then time enough to sprout many weeds on and near the surface before the sorghum is planted, by a free and judicious use of the harrow. Such preparation of the land is greatly important, because of the check which it puts on weeds and because of the moisture which it retains in the soil. Sow any time subsequently to the corn planting season, but not later than, say, the early days of July. Use one bushel of seed per acre. Plant it down about 2 inches in the soil, and just as the first blades of the sorghum begin to appear harrow the ground over with a light harrow, the teeth of which should slant far backwards when used.

Rape can be sown either broadcast or in drills. The advantages from sowing in drills are, first, that the land may be cleaned by the cultivation given, and second, that the plants may in consequence grow more strongly. But under Minnesota conditions it is more common to broadcast the seed and to cover it with the harrow. When broadcasted, about 5 pounds of seed should be sown per acre, and when sown in rows less than 2 pounds will suffice. Sow the Dwarf Essex variety. The rows may be made from 20 to 36 inches apart, according to conditions, such as relate to soil and the time 
of sowing. If rape seed could be planted by a drill as grain is planted, the results in the soft soils of the prairie would certainly be beneficial.

The practice of sowing from 1 to 2 pounds of rape seed per acre with small grain is becoming very common in Minnesota. The rape seed is usually mixed with the grain while it is being sown. More commonly the rape does no harm whatever to the grain crop, but in some instances, as when grain has lodged badly at an early period of growth, the rape has interfered with the harvesting and curing of the crop. When such a result is feared, the sowing of the rape should be deferred until the grain begins to appear. The rape seed should then be sown and covered with the harrow. After the grain crop has been removed rape sown along with grain will make a stıong growth in a normal season, but in a dry autumn the result may be disappointing.

Mixed grains may be sown at any time subsequent to the opening of spring, but usually the earlier they are sown the better will be the results in providing pasture. It is preferable to sow them with the grain drill, using not less than $2 \frac{1}{2}$ bushels of seed per acre. It may also prove a good plan to sow timothy and clover at the same time or immediately thereafter, in sections where clover will stand the winter. When sown just after the sowing of the grain, the grass seeds ought to be covered with the harrow. But the grass thus obtained should not be grazed so late in the season as to hinder it from forming a top that will afford sufficient winter protection,

Millet should be sown on well-prepared land, but not 
until warm weather has arrived; that is to say, not until the season for cornplanting or subsequently. The seed may be broadcasted and covered with the harrow, but is better planted with the grain drill. The foxtail varieties, as, for instance, Hungarian and German Millet, are the most suitable. From 3 to 4 pecks of seed are required per acre.

Soy beans should be planted in rows rather than sown broadcast. The rows should be made 24 to 36 inches distant, according to the conditions, and only early varieties, such as the Early Dwarf, should be planted. The planting should be deferred until after the usual season for planting corn. From, say 12 to 24 quarts of seed should be sown per acre. The ground should be harrowed before and after the appearance of the beans above ground, and it should also be cultivated subsequently. On good, rich and clean land the beans may be sown broadcast, using fully a bushel of seed per acre.

Cabbage should be sown on well-prepared land any time after the arrival of the month of May, and from that time onward for, say six weeks subsequently. They should be grom on strong land, and the late varieties are to be preferred. The seed may be sown with any kind of drill that will deposit it in rows from 30 to 36 inches distant from one another. From 1 to $1 \frac{1}{2}$ pounds of seed per acre will prove ample. The plants should be carefully cultivated on the same principle that cultivation is given to mangels or turnips. When from 2 to 4 inches high they should be thinned out with the hoe to the distance of 20 to 30 inches. 
Grazing Supplemental Pastures.-In grazing rye in the autumn very late and close pasturing will to some extent hinder abundant production the following spring. Early sown rye should, however, be grazed down closely for a time, and more especially when the early autumn weather is warm and dry, lest the crop should be injured by rust. In the spring the grazing of the rye should begin as soon as the ground is sufficiently dry. The aim should be to keep the rye eaten down closely, as when thus grazed it is relished better by the sheep. As soon as the rye reaches the earing or jointing stage, its power to provide good grazing is virtually gone.

Corn should be allowed to reach the height of, say 15 to 20 inches on the level before grazing it down. The sheep will break it down considerably when grazing upon it, but much of what is thus broken down will be eaten by the sheep in the partially cured form. If the crop is pastured at too early a stage the yield is reduced. If pastured too late the coarse growth in the stalk will be rejected by the sheep.

In grazing sorghum the sheep may be given access to it as soon as the plants will not pull out by the root when being grazed. This means that they may be put upon such pasture when it is but a few inches high. When the quantity to be grazed is limited the sorghum may be allowed to reach a more advanced stage of growth before feeding it off, as it will continue to grow again and again until frost comes. Sorghum furnishes more pasture than corn.

In grazing rape the author is now satisfied that more 
food will be obtained from a given area by allowing the rape to complete its growth or nearly so before beginning to graze it down than if it were grazed at an earlier period and allowed to grow up again. There may be occasions, however, when the latter course should be adopted, and when it is the rape should not be cropped too closely when first eaten down. It should also be remembered that when rape is eaten closely when young, its power to grow again is greatly impaired. Because of this it is not a good pasture plant to sow in mixtures that are to be grazed down at an early stage of growth. Except in hot weather rape will not take injury if not grazed off quite soon after it has ceased to make further growth. In such weather, however, it will not long retain its wonted succulence after that stage has been reached. And if indications of attack by the white aphis manifest themselves, grazing the crop down should not be deferred, otherwise it will become unfit for being pastured.

The grazing of mixed grains should begin as soon as they furnish plentiful supplies of food; that is to say, when they get a few inches high. The aim should be at all times to keep them from reaching the jointing stage, otherwise their power to grow, and also their palatability will be greatly lessened.

Millet should be grazed as soon as the plants will not pull out of the ground when being pastured. As when pasturing small grains, the aim should be to keep it from jointing and for similar reasons.

When pasturing soy beans they should probably be allowed to approach the mature stage before being 
grazed off, unless when the area to be grazed is very large. In such instances it should begin earlier lest a considerable proportion of the crop should be lost through over-maturity. More experience, however, is wanted in grazing this plant before the best methods of doing this can be known with absolute certainty.

Before the grazing down of cabbage should begin, they should be allowed to attain a maximum of growth. They have peculiar adaptation for late fall grazing, since they are not easily injured by frost.

Grass Pasture Necessary.-When grazing supplemental pastures, it is advantageous to have more or less of grass pasture on which the sheep may graze at certain times, as, for instance, when the supplemental pastures are wet and not sufficiently abundant. The ideal plan is to graze the sheep on the supplemental pastures during a portion of the day, and to have them remain on the grass pasture the rest of the time. But sheep may be kept entirely on supplemental pastures with the aid of cured food to feed to them as occasion may require, more especially when the weather is wet. Danger from Bloat.-In pasturing rape, as in pasturing green clover, there is some danger that trouble may arise from hoven or bloat. This danger is much greater when the sheep are first turned in upon the rape, when it is very succulent and also when it is wet from rain or dew. Because of this, care should be taken to avoid turning sheep onto rape when they are hungry. They should be accustomed to it gradually. After a few days, however, they may be allowed to remain upon it all the time. When the conditions will 
admit of it the results from grazing sheep on rape will be more satisfactory when they can also have access at will to an old grass pasture. In the experience of the author no instance of bloat has ever occurred from pasturing sheep on any of the other crops discussed in this chapter. 


\section{CHAPTER VI.}

\section{Fodders for Sheep.}

The term fodders is used in the sense of matured foods fed to sheep in the cured form, or in that form in which winter foods are stored away for winter feeding. These will include hay in its different varieties, millet, mixed grains, corn, sorghum, straw and field roots, although, strictly speaking, field roots are not a fodder.

Requisites in Fodders for Sheep.-The chief requisites in fodders for sheep include a relatively fine growth, a high protein content, palatability and variety. Sheep will not consume so large a proportion of fodders as cattle if they are coarse, even though palatable, hence the aim should be in growing such fodders to have them fine in quality. This can be accomplished by growing them thickly. The high protein content can only be reached by growing foods that are leguminous in character, as clover and peas. This question is one of great importance in sheep husbandry, and it would also seem to be one of considerable difficulty. In nearly all the Mississippi basin, it is relatively easier to grow carbonaceous foods, as corn. Much attention should, therefore, be given to this phase of sheep husbandry. Palatability may be aided by cutting the food at an early stage of maturity; and by curing it so as to preserve greenness in the fodder in a marked de- 
gree, and to prevent to the greatest extent possible the loss of leaves. Variety in the food is largely under the control of the grower. Much variety in the same would seem to have a marked influence on well doing in sheep.

Varieties of Hay.-The chief of these are clover, alfalfa, timothy, native hay and Russian Brome grass (Bromus inermis.)

No better fodder can be obtained for sheep than clover in nearly all its varieties. But the medium and alsike varieties are superior to the mammoth, as they are less coarse. To have clover at its best, it must be cut in the early blossoming stage, raked as soon as the raking can be satisfactorily done and cured in the cock.

Alfalfa requires even more care than clover when it is being harvested, as the leaves break off much more easily during the curing process. But little is known definitely as to the localities in which alfalfa may be grown in Minnesota, but it is probable that it will succeed on good soils deeply underlaid with a somewhat porous clay subsoil. Even clover cannot be grown successfully in all parts of the state, but the area in which it is being grown is continually extending.

Timothy, though much used in feeding sheep in this state, is not well adapted to such a use. It is too highly carbonaceous and is more woody than clover. If cut in the stage of early blossoming and properly cured, it possesses a far higher feeding value for sheep than if cut late and over-cured. When thus cured it is not much better than ordinary straw.

Native hay is of several varieties. It, too, should be cut before the succulence in it has been lost, but the 
proper time for cutting will depend very largely upon the variety and the kind of land on which it has been grown. What is termed npland hay, is considererl superior because of its greater fineness and palatability. The aim should also be in enring such hay to preserve its natural greenness of color.

Russian Brome Grass (Bromus inermis) it is thought will prove satisfactory as a fodter for sheep. But as yet it has not been much used for the purpose. It has an abundant leaf growth, which will increase its palatability, but, like timothy and millet, it is essentially a carbmaceons forkter. As the seed is dear, it will be well at the first to purchase enough seed to sow, say one acre, which will call for 12 to 15 pounds. It should be sown like other grass sceds, with or without a nurse croy. The next scason cnough seed may be secured to sow many acres.

Mitlet.-Millet makes a rery good fodder for sheep. It has high adaptation to northwestern conditions, and can also be grown as a catch crop. These are two strong points in its faror. It should be cut for hay when fully out in head, or just when the hearls on looking over the field are beginning to assume a yellow tint. If cut sooner the crop is lacking in weight, and also in nutriment. If cut late it is woorly and the seed shatters. It should he cured like clorer. If possible, millet should be sown on clean land and not carlier than the com planting season. It shonld be planted with the drill like grain, or broadcasted where such planting is not practicable, and from 3 to 4 pecks of seed shomld be sown per acre. 
Mixed Grains.-The question of mixed grains as fodder for sheep has not been worked out as yet under Minnesota conditions. It is a far-reaching question. The results from growing fodder's thus will probably exert a powerful influence on the future of the industry. The mixtures of highest promise at the present time are peas and oats and peas, onts and flax. The object in growing such mixtures is to sccure, if possible, a fodder that will prove highly palatable, that will yield well, and that will be in a sense a complete ration in itself for a breeding flock. Such a fodder is more likely to be obtained from growing peas, oats and flax and cutting the crop a little minder ripe than from any other mixture probably that can be grown under our conditions. In such a mixture there will be a hapry blending of the nitrogenous and carbonaccous elements and the flax shomld also tend to keep the digestion in good condition. There may he instances when such grains are being grown, in which increased fineness in the for'age will be obtained by grazing the crop down by sheep for a time in the early stages of its growth.

In growing such a crop, the method to follow would in outline be as follors:- - Sor the peas broadeast in the carly spring, using $1 \frac{1}{2}$ bushels of seed per acre. Harrow the ground so that the peas will not all grow in rows between the plough furrows. Then plough to the depth of, say 5 inches. Just before the peas come up, drill in oats and flax mixed. Use, say 1 bushel of oats per acre and from 4 to 8 quarts of flax. The flax will tend to support the crop. If flax is not sown it may be advantageous to sow a little spring rye along with 
the oats to assist in sustaining the crop. This phase of growing food for sheep is yet in the experimental stage, but it promises much.

Corn.-Corn will probably be much used as a fodder for sheep in all the future in this state. Its strong points are, the large yields obtained, the almost unfailing certainty with which it can be grown, and its high palatability. Its weakest point probably is its relatively low protein content. In growing corn as fodder for sheep, in the judgment of the author, the aim should be to grow fodder fine in character and abundantly supplied with leaves rather than to grow stronger stalks and more corn. To produce it thus, varieties will have to be chosen with much leaf growth, and they will have to be grown more thickly than corn is usually grown.

Such corn will commonly be grown in rows and cultivated to clean the land. The distance between the rows will usually vary from 30 to 36 inches according to the kind of the corn. It may be harvested according to the facilities for harvesting, cured in the shock, and stored later in stacks where it cannot be put under cover. On good, clean land corn fodder may be grown by sowing the seed as grain is sown and harvesting the crop with the grain binder. But, however grown, the harvesting should be done at an early stage of the ripening process.

Corn stover; that is to say, the stalks of husked corn may also be utilized in feeding sheep, but, owing to their coarse character, a greater relative consumption will be secured by running the stalks through a cutting 
box, a threshing machine or a shredder. Of the three processes, the sliredder renders the fodder the most palatable. Sometimes there is difficulty in keeping the shredded fodder in large quantities. When corn stover is to be fed to sheep much care should be taken to cut the corn at an early stage of ripening, and to keep it in a good state of preservation.

Sorghum.-Sorghum makes-a fodder for sheep that is very palatable when properly grown, and it produces a large relative yield per acre. It may be sown in rows or as grain is sown. When sown like grain it should be on land well cleaned on the surface as described when treating of growing sorghum for pasture. (See page 63.) Not less than 1 bushel of seed should be sown per acre. It should be grown so thickly that the stalks will be fine, should be allowed to grow until the seed is in the dough stage and should be cut with the binder, making it into small sheaves and putting it up into small shocks. For several reasons it is better to feed sorghum in the autumn and early winter than in the spring.

Varieties of Straw.-The straw of al the cereal small grains may be used as fodder for sheep under certain conditions, but they are by no means equally valuable for such a use. Rye straw is lowest in feeding value as a fodder for sheep, and pea straw is probably the highest. Rye straw is woody in a marked degree. It is not much relished by sheep. Wheat straw has higher value, especially when cut promptly as soon as ripe. Barley straw is still more relished, and oat straw is probably more valuable than barley straw. The 
value of all these fodders is relatively greater as they are finer, more free from rust, promptly harvested when ripe and well preserved after being harvested.

Pea straw is highly relished by sheep. Its feeding value when cut at early maturity and properly cured is not far behind that of clover hay. But it is easily injured by exposure to rain, either in the hurch or in the stack. Pea straw threshed with an ordinary thresher is also inferior to that hand-threshed. This fact furnishes a strong argument for growing peas thickly along with oats to be fed to sheep in the unthreshed form.

Flax straw has not been much used heretofore in feeding sheep, but the experience of those who have fed it moderately has been favorable. Sheep are fond of flax straw, and its influence on digestion would seem to be beneficial. It is the same in kind as that which arises from feeding the grain, but less in degree. Whether injury would result from the indiscriminate feeding of flax straw has not yet been definitely settled. In the meantime it should be fed with prudence, making it only a part of the fodder given.

Field Roots.-These include mangels, rutabagas, turnips, sugar beets and carrots. Mangels are probably the surest of these crops, and they are one of the most easily grown. Rutabagas grow better in the more northerly parts of the state. Sugar beets for sheep may be grown on some kinds of soil in every county, but it takes much more labor to grow and harvest them than mangels or turnips. The same things may be said about carrots. These crops ought to be sown 
only on rich land, and if at all practicable on land cleaned on and near the surface. Mangels should be planted in rows about 30 inches apart and thinned to, say 6 to 10 or 12 inches in the line of the row. The same may be said of rutabagas and turnips. Sugar beets may be closer between the rows, also nearer in the row, and carrots may be yet closer in both these respects.

Mangels, sugar beets and carrots should be sown reasonably early, as, for instance, early in May, rutabagas late in May or early in June, and turnips somewhat later. From 4 to 8 pounds of mangel and sugar beet seed should be sown per acre, and about 2 pounds of each of the other varieties. They should be thinned whon from 2 to 4 inches high, and should be given most careful cultivation. They should be harvested before being injured by frost and stored in a convenient place for winter feeding. Owing to the abundant yields from good soils and well cultivated, an acre or two of field roots will supply a breeding flock of 100 sheep from autumn until spring. 


\section{CHAPTER VIII.}

\section{Shelter for Sheep.}

Shelter for sheep need not of necessity be elaborate or costly. Sufficient outlay will, however, be justifiable, when it can be borne, to render the feeding of the sheep at least reasonably convenient. Sheds may be made of poles covered with marsh hay or straw, or baled straw or of lumber. Something will be submitted about the building of each, and also regarding the value of basement barns in sheep husbandry.

In building shelter for sheep, the aim should be to secure protection from falling storms and from wind, without undue warmth, plenty of light and ventilation, storage for fuhler and grain, and facilities for feeding. Storage is, course, also necessary for roots and ensilage when ircu are used. The arrangements for feeding breeding flocks, such as are kept upon the average farm, are nerer so satisfurt. where the fodder used cannot be stored overhead. 'Tr water supply should be within the shed where it is practicable to have it so.

Site for Sheep Sheds. -When choosing a site for a sheep shed, seek ground from which there is at lcast a little downward slope in every direction, but more especially on the side on which the yards are. Damp floors sin the sheds or damp yards are peculiarly harmful to sheep. If the place chosen has the protection of a grove on the windward side or of a bluff, it will be 
greatly advantageous. The yards for the breeding flock especially should be on the sunny side of the shed. In exposed situations some protection can be made for' the yards by building stacks of straw on one or both sides of the yard, and extending up to the shed so as to corner on it at the end or ends of the shed. The straw stacks and shed will then enclose three sides of a square or rectangle, the space within being the yard. High and strongly braced board fences may be made to take the place of the stacks. And the shed itself may be so built when the flock is large as to form two or even three sides for the space thus enclosed.

Sheds Made of Poles.-These can be built by placing the poles one over the other as rails are placed in building a "straight rail" fence. The poles will be made to lap at the ends. These sheds, usually open on the sunny side, may of course be closed on that side, access being gained to them through a door. If the sheep are not allowed to drop lambs until grass is plentiful, it is not really necessary to have such sheds closed. Poles are also used for rafters, and the roof should have but one slant. In selecting the poles, the aim should. be to secure them of durable wood and straight in kind. Tamarack poles are very suitable. The roof and at least three of the four sides should be buried in straw or marsh hay.

The objection to such sheds is that they allow snow to drift in when they are open; they are dark when closed; the food used in feeding has to be brought from without and in time water percolates through the roof. Such sheds are only recommended where the farmer 
is unable to build those more durable, hence, their use is commonly temporary. But when flocks are small and when lambs come late, they serve the purpose remarkably well.

Sheds Made of Straw.-These are built by laying up bales of straw as stones that have been sized are laid in a wall. The joints are broken in the alternate layers. When building the walls, frames for the doors and windows must be put in. In small sheds one door only may be necessary, and but one window. Plates of say two inch material and wide in proportion to the weight of the roof may be used in supporting the rafters. They can be kept from spreading where the roof is ridged by boards or planks spiked to them across the ends and also in the ceintre, or at intervals more frequent where necessary. The rafters may be made of straight poles or scantlings as desired, and the covering may be marsh hay, boards or shingles. Thatching would probably furnish the cheapest covering if the process were understood by our people.

Such sheds may be made to provide shelter very suitable for sheep. They are warm and are cheaply built, and yet have been erected by only a very small number of farmers. It may be that the outlay for roofing, satisfactory in character, has hindered their more general adoption.

Sheds Built of Lumber.- Sheds built of lumber may of course be erected in a great many different ways to suit the fancy and the requirements of the builder. An outline of four different styles of buildings will be submitted. The first of these has yards only on one 
side, and is well suited to the needs of an average breeding flock. The second has yards on two sides. The third has the special merit of furnishing rery ample protection to the yard. The fourth has the same merits, though less in degree, and is somewhat less costly. These are not intended to furnish actual models for flock-masters, but rather to suggest ideas that will prove helpful in the construction of any style of sheep shed.

The ground plan of a shed with yards on one side only is submitted in Figure 14. It was prepared by the author for the Minnesota Farmers' Institute Annual No. 6 in which it is described as follows: This barn is 72 feet long and 24 feet wide. It is divided into six equal parts without including the passage across the whole length of one side. This passage is designed to afford easy access for the attendant from one division to another, and it also affords a ready means of removing individual animals from one pen to another. The size of the respective divisions is shown in the plan. Of the main divisions only two are permanent, viz., those which separate the lambing pens from the pens next to them. The lambing pens should be boarded up to the ceiling to secure sufficient warmth, and may in addition if necessary be covered with tarred paper. The three central divisions may be separated by moveable double feeding racks. Two of these, each 10 feet long, are placed in line, end to end, between each division. By removing these racks the building may be virtually converted into an open shed, since the doors are 6 to 7 feet wide, or by removing one or more of the racks on 


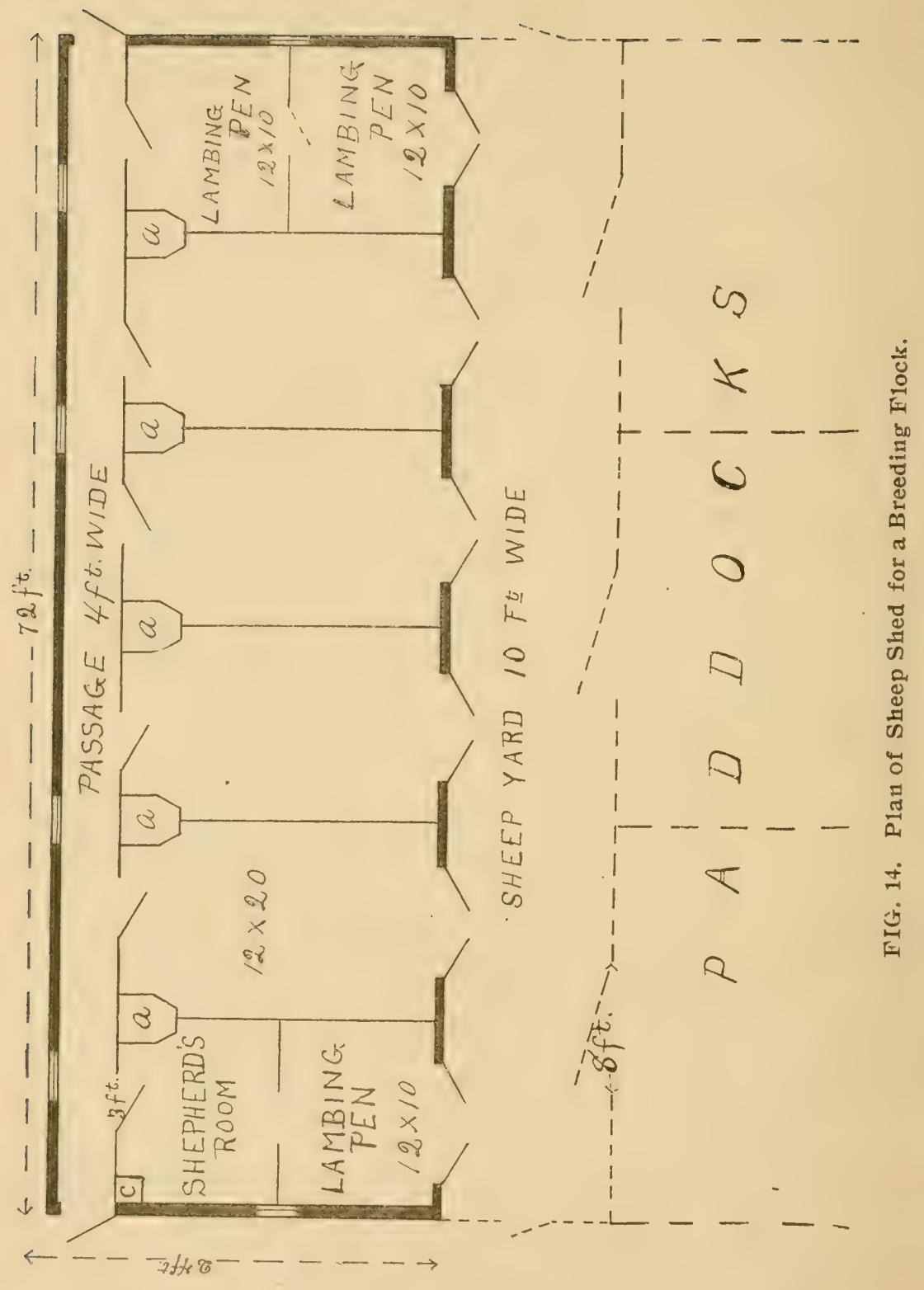


the yard side of the building, and enclosing the open space at the ends of those which remain, one part of the building may be used as an open shed. Any division, thus enclosed, would answer for keeping the stock ram in it, separate from the ewes, and also any rams that may be on hand. From the small boxes underneath the shutes, fodder can be readily obtained. These shutes are near the side of the building, and they extend up into the mow for some distance, hence they do not seriously interfere with the storing of the food orerhead.

The posts of the building may be of any desired length to suit the symmetry of the builling. There should be room in the loft to hold, at least, a season's supply of fodder, and if there is room for a season's supply of litter also, it is just that much more complete. Grain may also be conveniently stored in the loft over the shepherd's room. By using hoppers or hopper shaped bins above, ducts leading from these, and spouts below, which may be opened and closed at will, a supply of grain can always be conveniently obtained. The siding may be boards with battens over the cracks, or may consist of ordinary drop siding with or without a lining of tarred or building paper inside, according to circumstances. When the lambing pens are properly made, lining may not be necessary on the inside of the walls, but it is very helpful in keeping the building free from draughts.

It may not always be necessary to use so much space in the lambing pens, and when the lambs come late, these can be dispensed with altogether. The same is true of the shepherd's room. The yard may be readily 


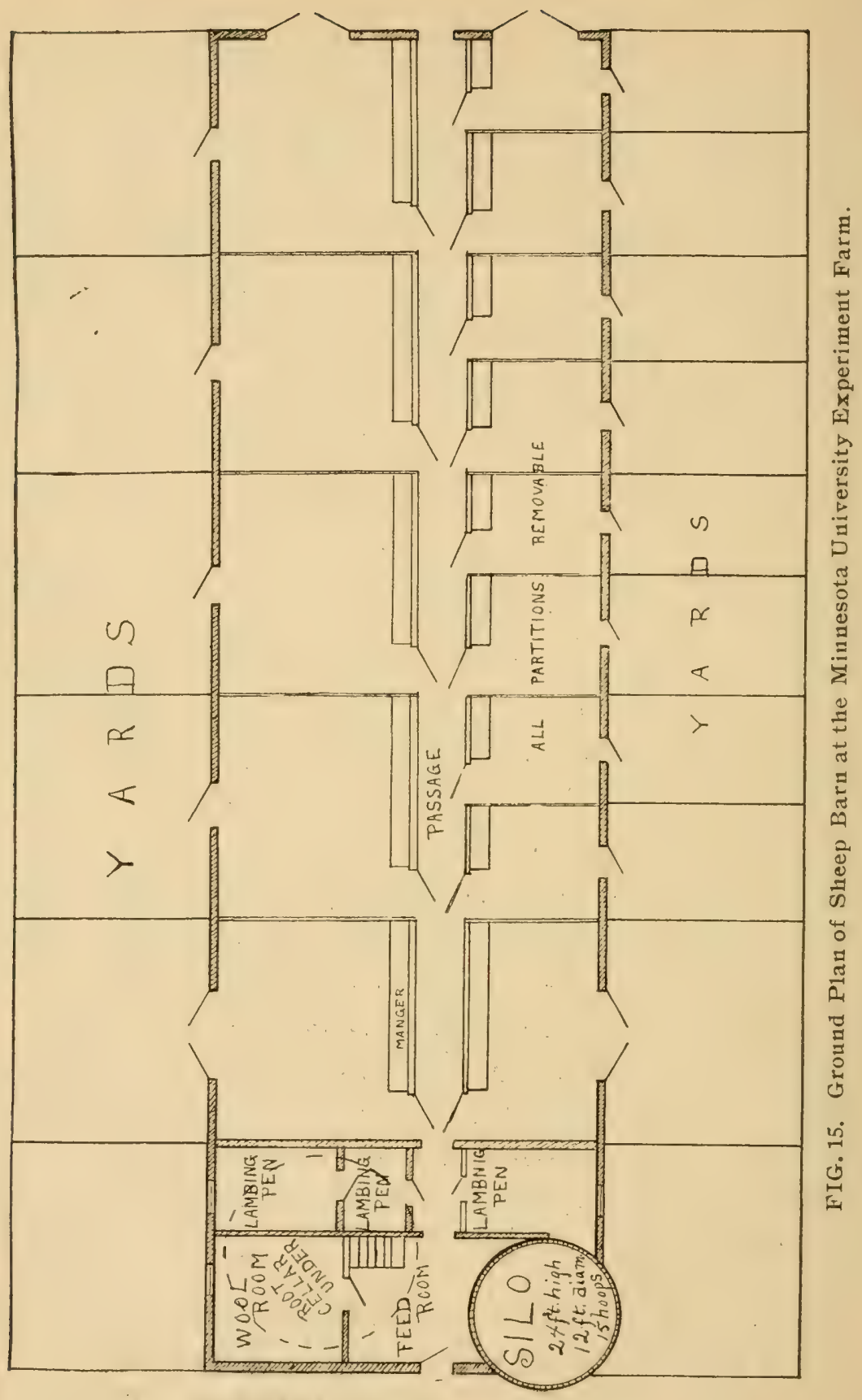


divided by running across it one or more movable partitions. Such a building should furnish accommodation in excellent form for a breeding flock of about 100 pur bred ewes, or for a considerably larger number of grades.

The ground plan of a shed with yards on two sides is shown in Figure 15. It represents the sheep barn at the Minnesota University Experiment Farm. There are certain features about the plan that can be profitably utilized by the flockmaster when erecting shelter for sheep on a much smaller scale.

The building was planned by the author with a vier to breeding and feeding sheep in an experimental way. It is 110 feet long and 36 feet wide. The posts are 14 feet high. They should be 16 feet, as designed by the author. Figure 16 represnts a section of the frame. On the one side of the front end entrance is a silo, and on the other a wool room, which may also serve as a shepherd's room in winter, if desired. The next two apartments are lambing pens, one on either side. Then follow the divisions for the sheep on either side of the passage. It will be observed that on the south side there are nine of these, and on the north side five. The former are for breeding stocks and the latter for sheep that are being fattened under experiment, although these divisions may also be used if necessary for breeding animals, as for instance ewe or rain lambs. Each apartment on the south side has a window, and on the north side each has two. The size is $30 \times 26$ inches, and the windows slide up and down. Each apartment is also furnished with a door cut in twain in the middle. These doors, 3 feet 6 inches across, open outward. 


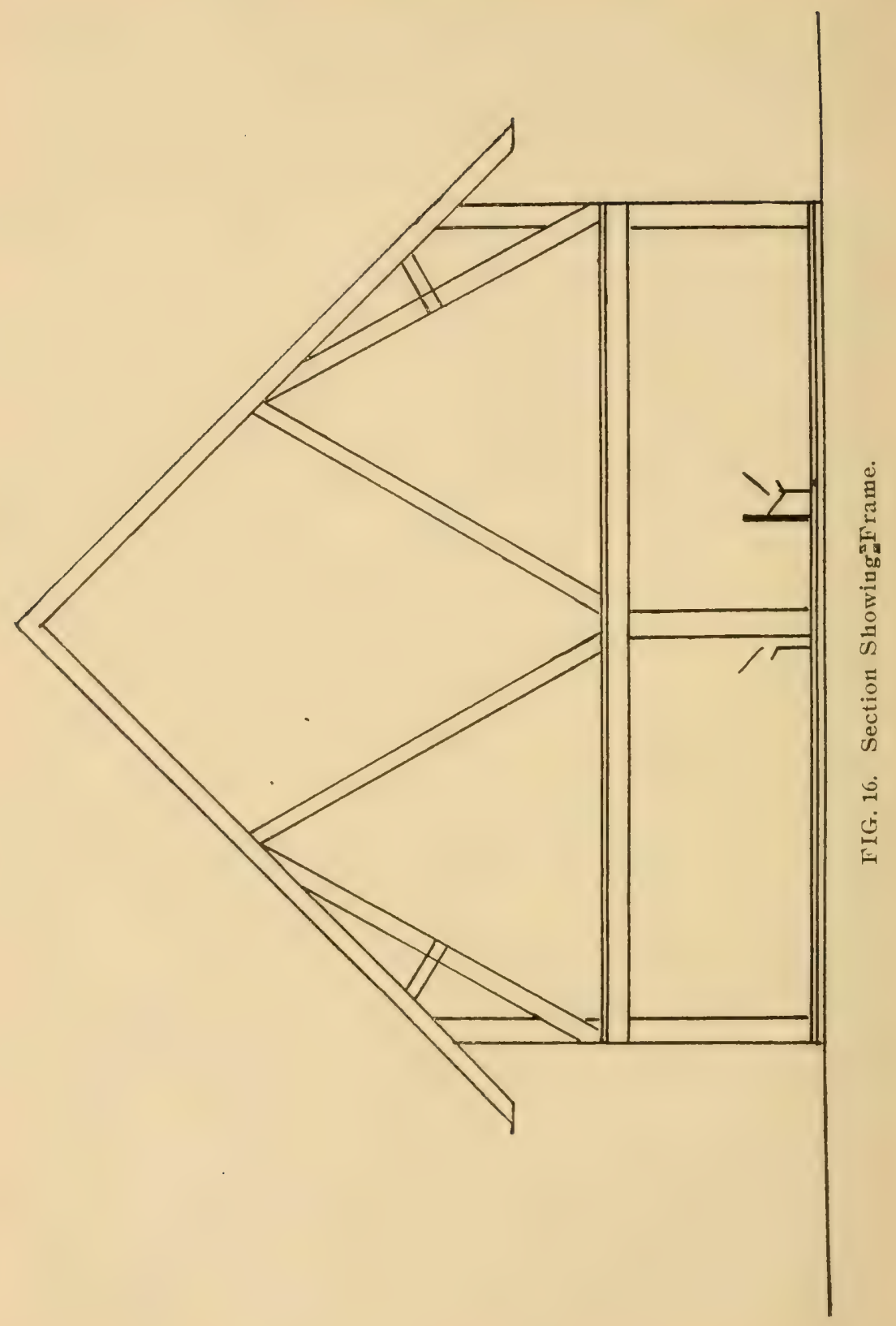


The divisions between these compartments are all movable. The feeding racks run along the passage on either side of the same. An end section of these racks is shown in Figure 17. A door opens from the passage into each division of the shed. The door is 2 feet 8 inches wide, and 2 feet 10 inches high, which is 2 inches less than the height of the lining on both sides of the passage. It will be observed that a double door, wide enough to admit a wagon opens from the outer wall of each compartment adjacent to the lambing pens. The wagon thus admitted can be driven along the one side or the other of the building until it reaches the rear end of the same, where doors of similar construction are made. The manure may thus be removed without the necessity of first pitching it out into the yards through the various side-doors. While the manure is thus being taken out, the partitions between the various divisions must of course be removed. This can be easily done, since they are movable, being held in place by grooves at both ends. The walls consist of drop siding nailed onto studs, with building paper underneath the siding. The floor is simply earth, except in the feed room, the shepherd's room and the passage.

Water is brought in by means of pipes connected with the water system that supplies the buildings. In the absence of such a system it could, of course, be introduced through means of a well, windmill and tank. It is drawn from hydrants into pails or buckets as needed. The floor of the loft is laid close, hence no dirt or chaff can fall through, and so it should be when practicable with all sheep lofts. There are three box shutes in the 


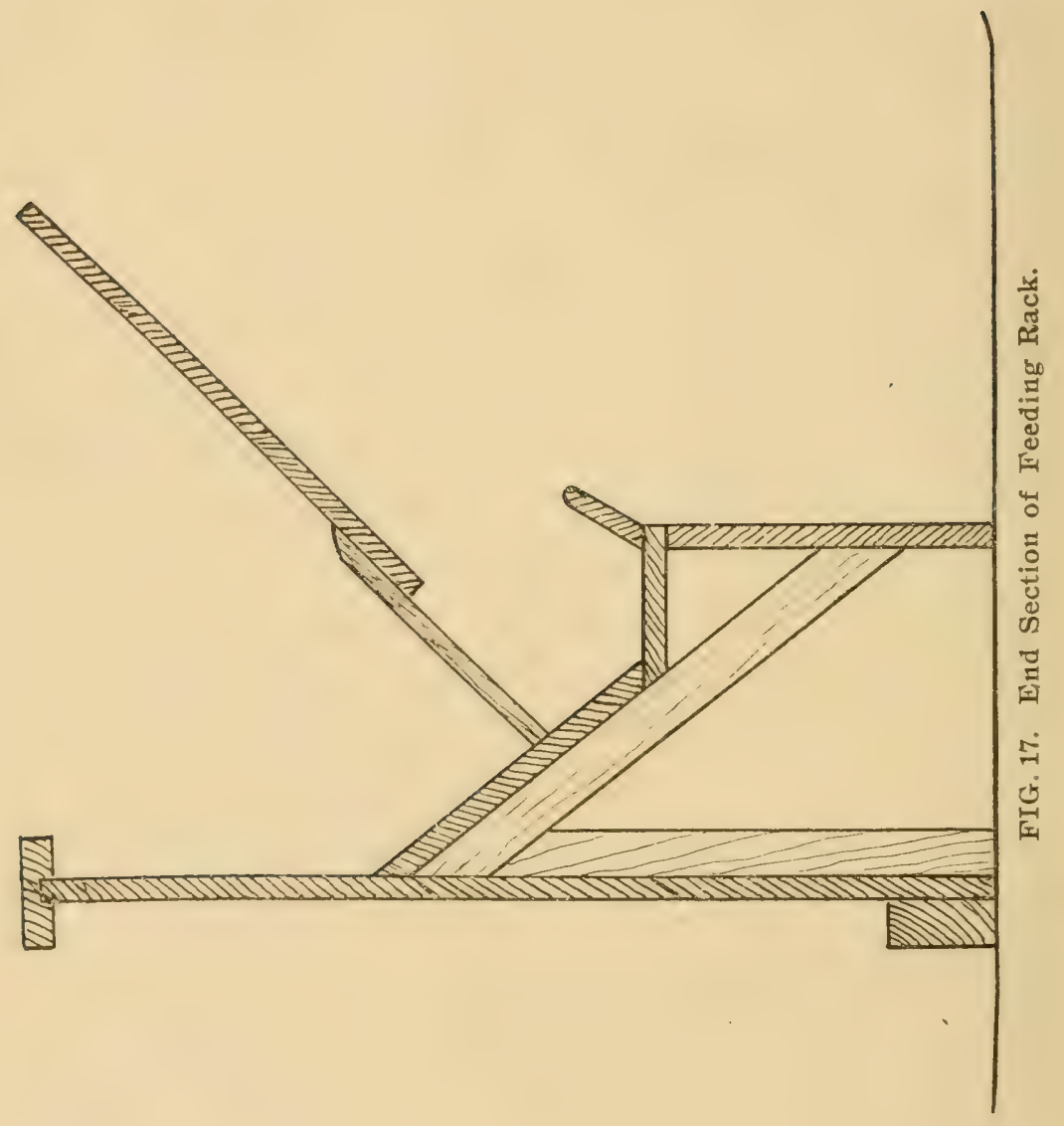


loft $32 \times 32$ inches and suitably spaced. Through these the fodder or bedding as wanted is discharged into the passage. As they extend upward they slant toward one side, so as not to interfere with the action of the horse fork when in use. When the different kinds of fodder are suitably stored in sections in the loft, they are at all times accessible.

The silo, as will be observed, is circular. It is 24 feet high and 12 feet across. The staves are $2 \times 3 \frac{1}{2}$ inches, and are tongued and grooved. This, however, is not necessary in building such silos. It is girded around with 15 hoops of $\frac{3}{8}$ inch band iron 3 inches broad. Twelve hoops suitably spaced would probably prove ample. The bottom hoop is just above the floor, and the distance between the hoops increases somewhat as they extend upward. Hinged doors open into a shute extending upward on the side next to the feed room, but these would better serve the purpose if they were not hinged, but rather fitted in from the inside, the edges being beveled. The size suitable for a box shute is $24 \times 32$ inches, and it should have a ladder within attached to one side. The doors may be 24 inches long and 18 inches broad. The floor consists of two thicknesses of bricks laid in cement. Those who may wish more definite information on the whole question of silos can obtain the same in the book, "Soiling Crops and the Silo," written by the author and published recently.

The root cellar is 16 feet in diameter. Its location and form will be readily apparent from the plan. The wall is bricks laid in mortar. In no part does the wall come nearer on the inside than 3 feet 8 inches from the 


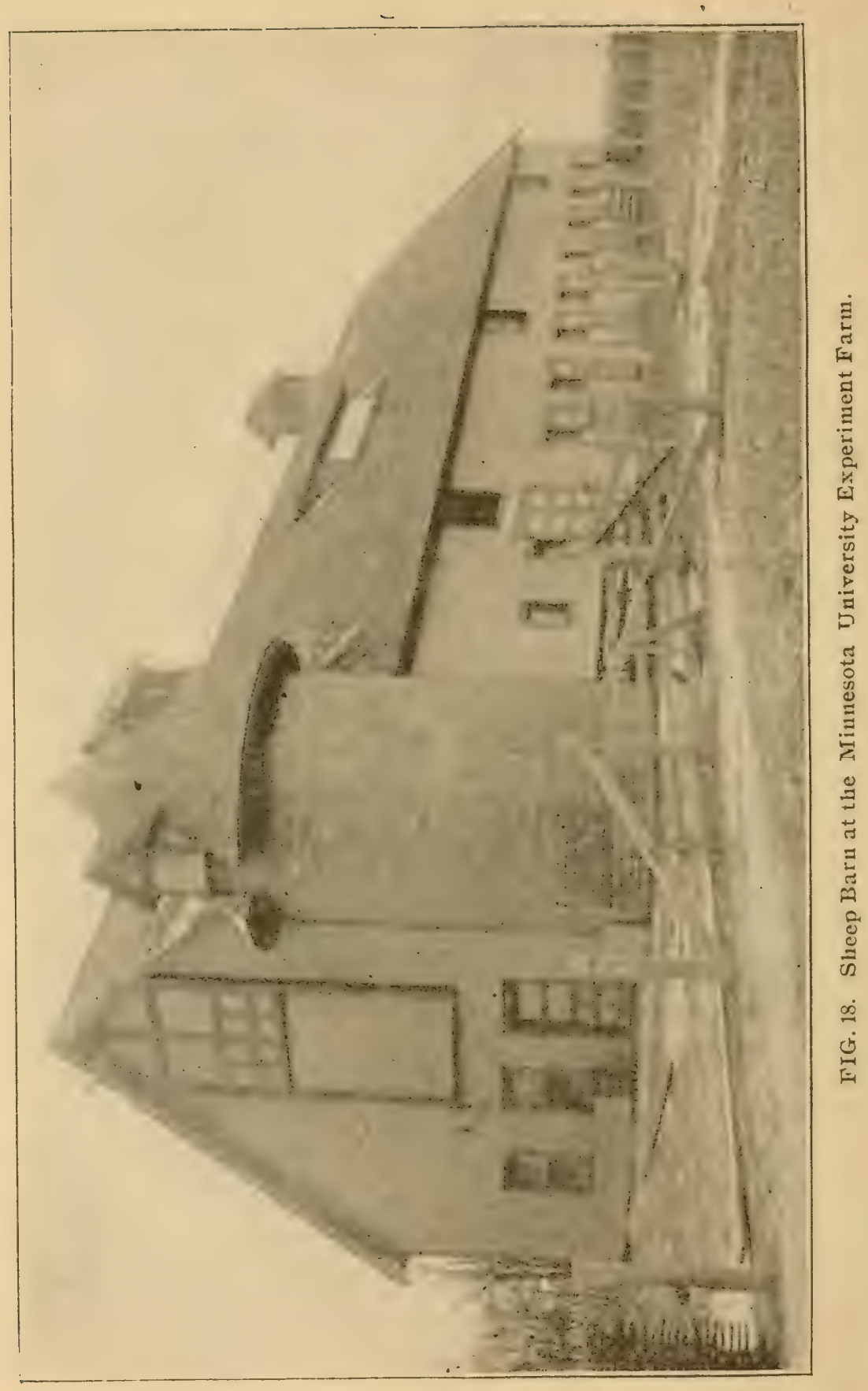


outer walls of the building, that frost may be more easily excluded. The window spaces which are also used as shutes have triple thickness of glass, in the form of a double window without and a single one within. The floor overhead is ceiled first with shiplap, second with two thicknesses of tarred paper, third with furring to make an air-space, and fourth with shiplap. The door which opens at the head of the stair has also two thicknesses of boards with tarred paper and air space.

The yards extend out 18 feet from the building on either side, and they are separated from one another by movable divisions, which extend from the shed to the tence of the adjoining paddock. The barn itself is shown in Figure 18.

The ground plan of a shed nearly enclosing three sides of a square or rectangle is shown in Figure 19. The buildings at the corners are for the storage of fodder and grain, and may be any dimensions necessary. The greater the height the greater, of course, will be the capacity for storage. The intervening shed and those at the wings are open. The buildings at the cuners as s'own in the engraving, are $24 \times 24$ feet and the posts are 18 feet high. The two long sheds are $16 \times 80$ feet, and the short one is $16 \times 40$ feet. The roof of the low sheds may be given only one slant, but is perhaps better with two, and the height of the same at the rear plate does not require to be more than 7 to 8 feet. The location of the lambing pen and root cellar are shown in the engraving. The feeding racks are placed along the front of the sheds, but they may be placed toward the rear or as desired. The hay shutes come down into enclosures 


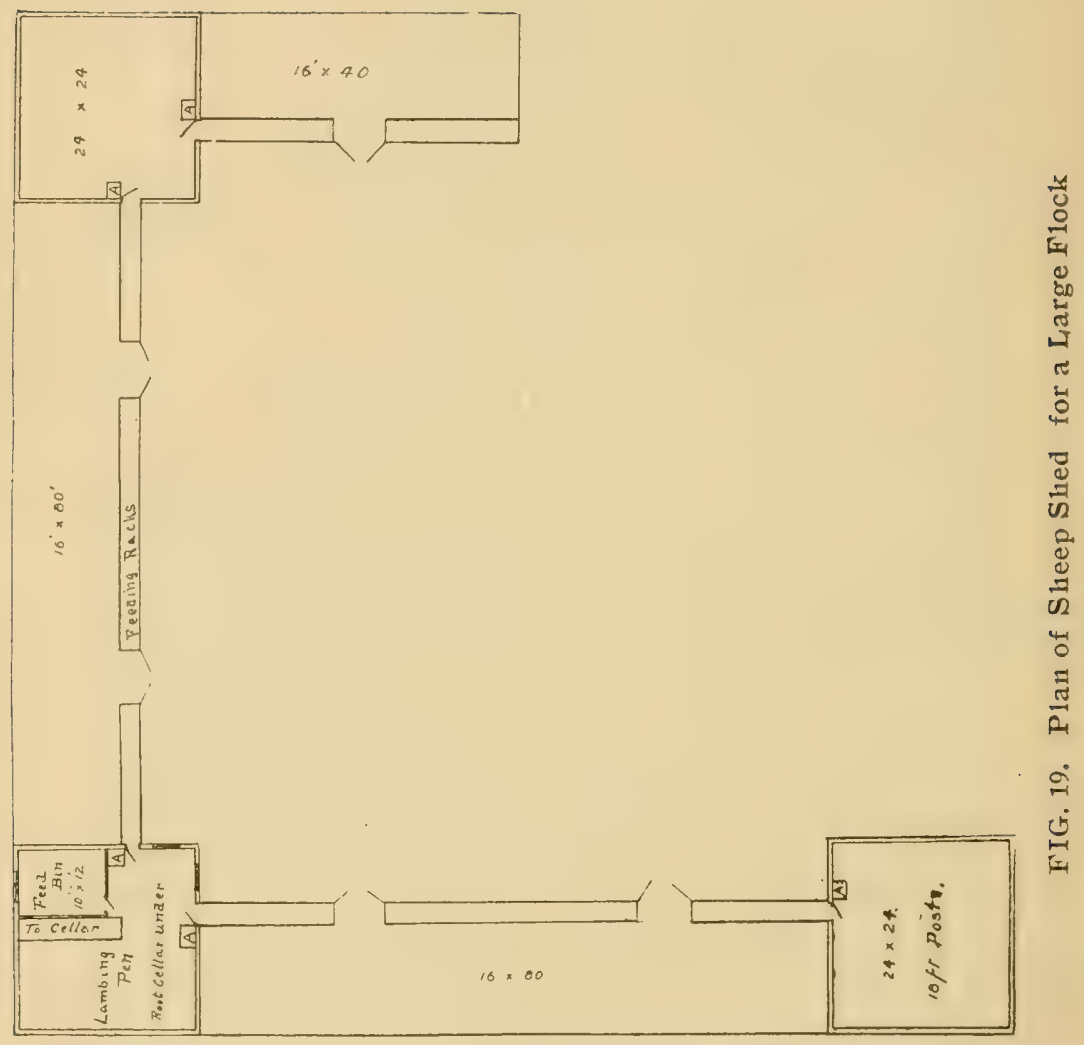


shown at $\mathrm{A}$. The feed bin, $10 \times 12$ feet, is shown in : $\mathrm{C}$ sketch and to the rear of it is the stairway leading 10 the root cellar. The loft over the lambing pen and focil room have a tight floor. The sheds may be diridta by movable divisions or fences. The yards may also be readily changed to suit changed conditions when they are enclosed by movable fences. All details of management, however, may be made to suit the necessities of the situation. This plan of building sheds would seen admirably adapted to the requirements where large flocks are kept. Figure 20, Section A, represents a side view of a shed for a good-sized farm flock, with storage for fodder overhead, also a ground plan of the same, section $B$, with sheds attached. The main building is 72 feet long and 16 feet wide, and each of the side sheds is $30 \times 16$ feet. The form of roof for the side sheds is brought out in Section A, and the same form of roof may be used in the low sheds in Figure 19. The height of the main barn, the internal arrangement of the same, and the divisions in the yards may be made as desireci. These sheds do not require to be higher than those described in Figure 19. The chief merits of this barn are its capacity in proportion to cost and the protection which it affords. 

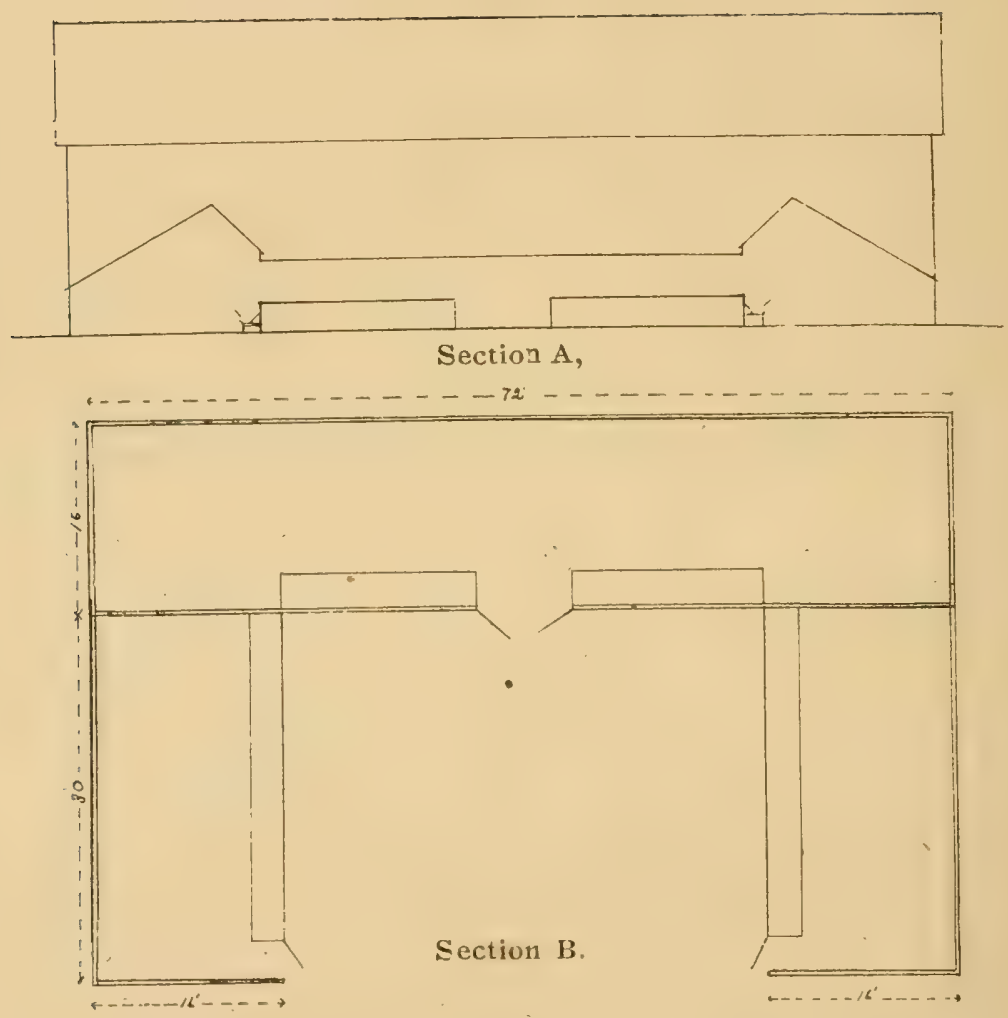

FIG. 20. Plan of Sheep Shed for a Good Sized Flock. 


\section{CHAPTER VIII.}

\section{Fencing for Sheep.}

More or less of fencing is indispensable to the suc. cessful management of sheep except under range conditions. At certain seasons of the year, sheep are capable of doing an immense amount of damage and of making no end of trouble mless properly restrained by fences.

Amount of Fencing Required.-The amount of fencing required will vary with the kind or class of sheep kept. A pure-bred flock calls for more divisions in both fields and sheds than a flock of grades, where the former is to be kept in reellent form. More divisions are also required when the sheep are kept much on green forage other than grasses, but in the aggregate such a system will probably call for less fencing than where the sheep are pastured alone on grass. It may be possible to keep sheep within a single enclosure all the grazing season, providing it is large enough ; but under Minnesota conditions such a system is not to be commended. They can, however, be kept within two enclosures for a limited term of years, providing pasture other than grasses is grown within one of these, and that more or less of movable fencing is used within the same.

If sheep are to be kept under suitable conditions on an arable farm, it ought to be fenced in. Such a system may appear costly at first thought, but the entire cost will soon be more than me: by the greater relative pro- 
ductiveness of the farm because of the presence of the sheep. Usually the fencing should be gradually extended as the needs of the increasing flock call for the same. The cost is then felt less by the farmer, since he can erect such fences by ordinary help of the farm and at seasons of the year when labor is not pressing.

Fences Made of Wood.-In the park and forest regions the old snalie fence made of poles or rails may be in order, but such a fence is only admissible when timber is abundant and cheap, because of the amount of the same required in such a fence. Where tamarack poles are plentiful a good fence may be made by planting posts 12 to 15 feet apart and wiring a stake to the post near the top and bottom of the stake. The space between the post and the stake should be sufficient to receive the ends of the poles which overlap them. This is frequently denominated the straight rail fence. There may also be localities where lumber is cheap in which board fences permanent in character may be built, but in fully two-thirds of the states, fences made of wood are entirely out of the question, because of the expense involved in the material required.

Fences Made of Wire.-Beyond all question wire is likely to be the material chiefly user in building fences to be used in sheep husbandry. The various forms of wire fencing are numerous. They include smooth wire, barbed wire, and woven or netted wire.

Smooth wire fencing when made by simply stringing the wires on the posts, is not suitable for sheep. They soon learn to push the head through between the wires and the habit of going through the opening thus made 
is soon learned. But if the wires are held in place by weaving wires up and down at suitable intervals the sheep cannot then get through. In the judgment of the author this style of fence answers the purpose as well as any other and it can be cheaply built, since the only outlay to the farmer is the cost of the posts, the wire, the staples and a small outlay for the machine used in weaving the stays. In constructing such a fence, any size of wire may be used that is strong enough, and the space between the wires may be varied as desired, and many or few stays may be woven as may be thought best. Two strands of twisted wire are sometimes used in preference to single strands. What is known as No. 12 is very suitable.

Barbed wire has been much used in providing fencing for sheep in the past. It furnishes a cheap fence, but one that is not very satisfactory. The wires tear off more or less of the wool, and unless they are closely spaced the sheep are prone to form the habit of pushing through them, especially if the grazing is short. In doing so they injure themselves more or less.

Wovên wire in several of the forms now in the market makes a very suitable fence for sheep. About the only serious objection to it probably is the cost. When used in combination with certain other forms of wire, the cost may be reduced, that is to say when making the fence the lower part may consist of woren wire and the upper part of barbed wire. The woven wire need not necessarily extend more than 24 to 30 inches upward. The number of barbed wires to stretch above this will 
depend upon conditions, but seldon more than two or three will be required.

The Woven Picket fence has fcatures that are corr: mendable. It is effective and durnblo when the pickets which are interworen by the wires are of soine strong and lasting wood, as oak, and relativo?y it is not very costly. But it usually sags more $\mathrm{Cr}$ less botween the posts, and in time diverges from the perpondicular, hence it becomes mattractive if not pos:tively unsir tly.

Posts for Fencing. - The best availab! materials for posts in our state are cedar, oak and tamarnck. These are lasting probably in the order name?. Enropean Jarch would probably grow in some sections of the state, but it does not appear to have been much tried. The posts in our state are cedar, oak and tamarack. The split posts from large trees last considerably longer than round posts composed largely of wood of recent growth. The growing of posts for fencing will call for attention in the not distant future, since the available supplies are rapidly being cut away.

The practice of charring posts before setting them and also of dipping them in boiling coal tar has been recommended, to hinder decay. That part only is thus treated between the base of the post and a short distance above the surface of the ground. But as yet it does not seem to hare been conclusively demonstrated that the benefit resulting will pay for the treatment thus given. Erecting Fences. - TWhen building straight rail, board or wire fences on th: arable farm, what is termed the bed of the fenc .... first receive attention. In constructing the sane, fro furrows should be thrown to- 
gether as high as the plough will raise them. The next twro furrows should be not so high, and if two others are plonghed they should be marle still lower. The ridge thus formed will be highest in the centre. This ridge should be smonthed off nicely, so that a mower knife may be run alongside of it to cut off the weeds if necessary. It should also be seeded to grass to prevent washing, and to keep weeds from growing. If an abrupt ridge is wanted, the land may be ploughed twice, turning it in both instances to the centre.

The posts will be set or driven according to the nature of the ground. When driven they must of course be first pointed. When set, a nost auger will make the holes speedily unless in hard oi gravelly ground. Much labor is usually saved by set.ing or driving the posts, when both soil and subsoil are moist. The standard depth for setting posts is about three feet, but in building wire fences the corner posts should be set more deeply and should be sufficiently braced to keep the wire from drawing the posts away from the perpendicular. In wire fences the distance between the posts varies much with the kind of wire used, but they are usually placed from one to two rods apart. When smooth or barbed wire is used, the distance between the posts mav be considerably more when a small upright is driven midway between the posts, or is made to rest on the ground. To this upright the wires are fastened with staples.

The number of wires wanted will depend on the character of the sheep, of the wire, and on tine number of the upright wires woven into those that run horizon- 
tally. Smooth wire calls for a larger number of wires than barbed wire. The nearer the upright strands are woven to one another, the less the number of the wires wanted. Sheep that are plentifully supplied with food and that have not previously learned the habit of pushing through between wires, have frequently been restrained by four barbed wires, but usually six or seven are required. Six barbed wires strung at the distance of $3,7,12,17,23$ and 30 inches, respectively, from the ground, should confine sheep when the fence stands on the centre of a raised bed. But if the fence is to be practically $\log$ and wolf proof, two more wires should be added and placed say 38 and 48 inches, respectively, from the ground. When wires are smooth and bound with upright stays or strands, the distance between the wires may be similar, but the top wire and perhaps the next one also should be barbed.

Strips of netted or woven wire 24 to 30 inches wide when strung along posts in the centre of a raised ridge should suffice to confine sheep, but io render the same dog proof, two barbed wires should be used as described. When wire fences are used for any purpose, due attention should be given to the loosening and tightening of the wires. But ferw objects on the farm are more unsightly than a neglected wire fence.

Movable Fences.-When forage crops other than grasses are grown for sheep, a certain amount of movable fencing will usually be found a great convenience, especially when the pastures are long and narrow in shape. While several kinds of movable fences have been used, all of which have more or less of merit, but 
two will be noticed here; one of these is made of boards, the other is wire.

The movable board fence is made up in panels, and for each panel there is a head piece. Any material will answer that is light and durable and that does not warp readily. White pine is very suitable. Each panel, as shown in A Figure 21, is composed of three boards $4 \times 1$ inches, and a fourth one at the bottom $6 \times 1$ inches. The panel when complete is 12 feet long and 3 feet 2 inches high. Three slats $4 \times 1$ inches are nailed perpendicularly across these horizontal boards. The end slats are nailed on the same side of the panel and six inches from the ends of the boards. The centre slat is nailed on the opposite side. The bottom space is 6 inches, the middle one $6 \frac{1}{4}$ inches, and the top one $7: 3$ inches. The second board from the top is cut off flush with the outside end of the cross bars.

The headpiece $\mathrm{C}$ in Figure 21 consists of three pieces nailed together so as to form a triangle. The bottom piece $6 \times 1 \frac{1}{4}$ inches is 3 feet 6 inches long on the ground side. The two upright pieces are $4 \times 1 \frac{1}{4}$ inches, and are 4 feet long. One is nailed on each side of the sole piece, and they cross each other at about 6 inches from the ends. The notches cut above and below as shown in the drawing are 3 inches deep and 2 inches wide. When in place the corresponding slats of the panels rest side by side in these notches. Wrought or wire nails are used, $3 \frac{1}{2}$ inches long and they should be well clinched. Longer nails are required for the headpiece.

When in place it is frequently necessary to stake down the fence to prevent heavy winds from blowing it 

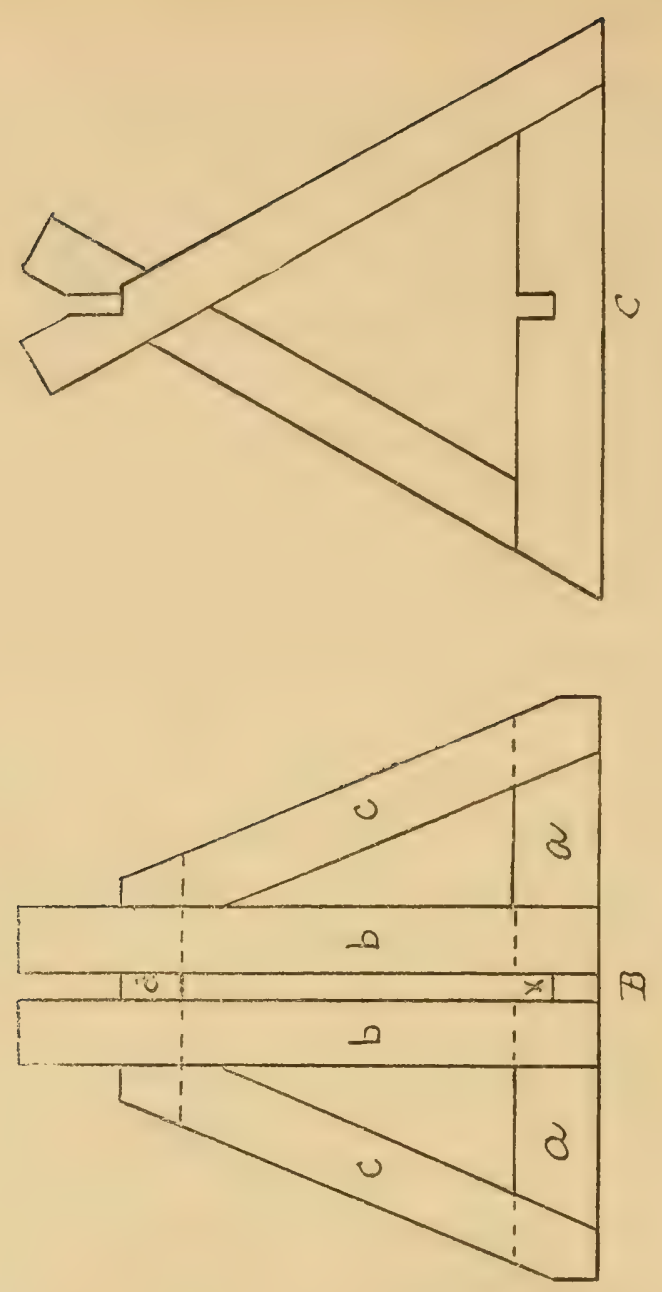

गें

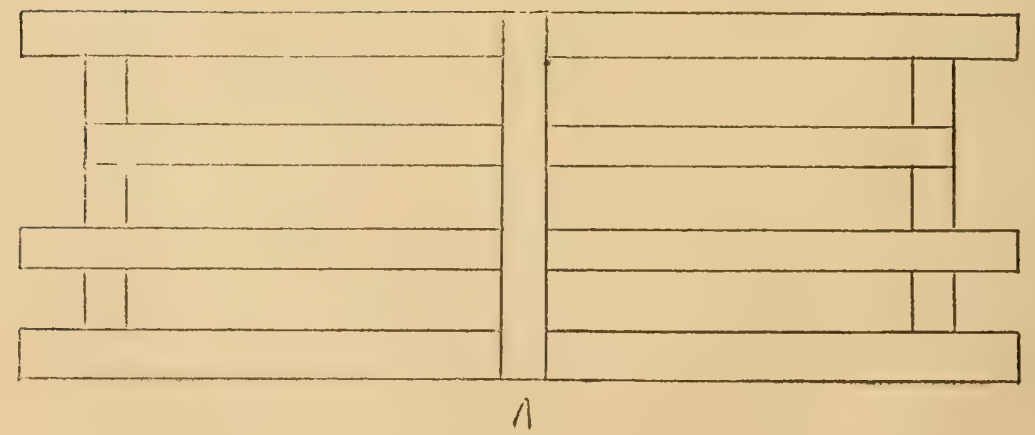


over. This is done by driving a small stake down into the ground a short distance in from the end of the sole piece, and then driving a nail, left unclinched, through the stake and the sole of the head piece. The stakes may be conveniently made of pieces of inch pine boards about 2 feet long. They are of course sharpened at one end and should be driven at intervals as may be found necessary on the windward side of the fence. When driven alternately on the two sides of the fence it is more secure against shifting winds. The stakes may be used again and again. If the panels are carefully handled and neatly piled up under shelter or in a dry place when not in use, they will last for many ycars.

Another and stronger make of headpiece is shown in B Figure 21. It was designed by Mr. W. C. Palmer, a recent graduate of the University of Minncsola. It consists of two cross pieces, AA and D. The buttom one is $6 \times 1$ inches and $3 \frac{1}{2}$ feet long, and is notclicd at $X$. The notch is $2 \frac{1}{2}$ inches deep and fully 2 i.:. incs wide. The cross piece $\mathrm{D}$ is $4 \mathrm{x} 1$ inches and $1 !$ fect long. Its lower edge is $2 \frac{1}{2}$ feet up from the bottom of the sole piece. Two uprights BB $4 \times 1$ inches and is feet long are nailed onto the cross pieces with a space of fully two inches between them, that in it the c:als of the boards in two panels of hurdles may orerlap fur a short distance. When in place two side braces CC, also $4 \times 1$ inches, $3 \frac{1}{2}$ feet long, and bevelled at the npipcl end, are then nailed as shown in the diagram. 'l!nc "1prights are all nailed on the same side of the cross picscs. The panels for this form of header are male the same as for that first described, except that the sccond boarl 
from the top is left the same length as the other boards. This form of header is considerably more durable, but it calls for more material than the other.

The movable wire fence should be not less than 30 inches high. It should consist of netting and is more conveniently moved if made in strips of suitable length: These are fastened to stakes that will stand driving well. When moving the fence, each piece is rolled up. The wire is rolled around the stakes. 


\section{CHAPTER IX.}

\section{Management of Lambs.}

If the flock is ever to become a model of excellence, every care must be taken with the lambs. Failure in managing the lambs properly will mean failure in the work. The measure of success therefore in growing the lambs is really the measure of success that will be attained in the management of the flock.

The Lambing Scason.-The best time to have the lambs come will depend, first, on the kind of sheep kept; second, on the object of the grower in rearing them; and third, on the facilities for taking care of them. Winter lambs, that is to say, milk lambs sold in the winter or early spring, must of course come in the autumn or in the early part of the winter. Pure-breds as a rule should come early, as, if the rams are to be sold the following autumn for breeding, they do not attain sufficient size to meet the requirements of purchasers unless dropped early. It has also been noticed that early lambs, like early calves, nltiniately attain a greater maximum of development when averages are taken. This is probably owing in part to their more advanced development when they enter upon the first winter. If the lambs are to be sold for meat in the early spring months or in the summer season, they should also come early to attain sufficient size for being thus marketed. If they are to be fattened in the fields on rape and kindred foods in 
the autumn and sent directly to the market, they should also come early. But if they are to be fattened the following winter, it would probably be wiser to have them come after the sheep lave been put permanently on pasture; otherwisc, they will probably be too heavy to suit the markets of today. When no lambing shed has been provided, the lam!ning scason should not be earlier than the arrival of plensant weather. Winter lambs should come, sny, from October onward; lambs for breeding fron Libnary owwarl; lambs for spring, summer and at:limu sale, say from March onward; and lambs for winter fecling, during the month of May.

Jhe mortality in young lambs will not be much greatcr wlic: bow's in winter than in spring, providing first, that a govel lombing shed is at hand, and second, that they sire giren duc care. The special care always requirad at the lambing season can also be given at a less sacrifice i: the winter and spring months than after the scrson of tillage begins. The least propitious time prolably for lambs to come is during the intrmediate perial whon the sheep are first turned out to the paslures. I'nt of the time they will be out and part of the time inside. The weather at such a time is usually mor cr less unpropitious. Young lambs dropped during the day are sometimes liable to get chilled, and there is tromble in bringing them to the sheds. The aim should br, therefore, to have them come before the turning out scason or after the same has arrived.

C'are of Lambs Newly Born.--In pure-bred flocks and cic:l $i: 1$ grades that are numbered, the owner should know just when each may be expected to have lambs. 
Two or three days previous to the birth of the progeny, the prospective mother should be put into an apartment of the lambing pen. The danger is thus to some extent averted of having the lambs chilled, as they are much liable to be when dropped in the night in a cold shed. If the crres are really healthy and vigorous there is not much danger that lambs will perish even in cold weather when born in a well made lambing apartment of the shed. But when a cwe has twins, she frequently gives attention to but one lamb, hence the other may perish. The plan therefore is a grood one on the part of the shepherd or farmer to risit the lambing pens once in the night. In this climate such visits may call for tho excrcise of much resolution, lut in a larege flow they will probably save many a lamb. The attondant shoul! prepare himself for such work by providing an alarm clock and making duc prorision agninst callungering lits own health.

When all goes well at the time of parturition, the less interference on the part of the attendant the better; bit if a lamb is born weak and mable to figlit its owal battle, the attendant should try and help it with a prident haste to some of the milk of the dam. If a yomng lamb is found chilled it should be submerged, execpt tha licnil, in warm water, and in a wam place. Judlecions sul continued rubbing should follow, first with a cloth ant later with the hand, until the lamb revives. It should then be helped to a little of the milk of the lan, n:ml many little things will be practisel by the crperienced shepherd which camnot be mentioned licn. Jlese a:"e such as relate to griving the cwes a wam drink scon after 
the birth of the lamb, assisting weak lambs to survive and thus to get their share of the milk in the case of twins, and in providing milk when necessary from another source than the dam.

When the dams fail to furnish a sufficient supply of milk, it may be supplemented with cow's milk. When so supplemented, the milk should be given to young lambs frequently, as warm as blood heat, and at first only a little at a time. It should not be diluted, and for lambs quite young it may prove advantageous to add a little sugar at first. $\Lambda$ s the lambs grow older, the plan of calling to the rescue the aid of a gentle cow with small teats is a good one. Two persons will succeed better than one, the first to manage the cow and the second to bring the weak lambs to help themselves. When thus allowed to get a feast twice a day, or eren once a day, weak lambs soon become strong. This practice is strongly recommended and is also practised by that sensible and safe authority on sheep, the Hon. M. F. Greely, of Gary, S. D.

If a ewe should lose her only lamb, she may sometimes be induced to take another of nearly similar age. She will own the lamb thus given to her more readily if the skin of the dead lamb or a portion of it is tied over the body of the living one. Some owes will also refuse to own their lambs, or, they may refuse to own one in the case of twins. In such instances if they can be placed in a stanchion and held so that the lambs can nurse frequently, they will sometimes become strong enough to help themselres without aid, and thus by mere persistence force the refractory dam into submission. 
Usually ewes will not disown their lambs if they have plenty of milk for them, and if the lambs do not get away from their notice soon after birth. They are more prone to disown them when they are so reduced in flesh that they can furnish them but little milk.

Lambs, when strong, may be removed from the lambing pen in two or three days after birth and placed along with others previously removed. In large flocks it is an advantage to be able to grade the ewes in the feeding pens with their lambs, as both ewes and lambs may then be fed more in accordance with their precisis needs.

Feeding Toung Lambs. - Young lambs should, if possible, be given food apart from the ewes, but this may not be necessary after the evves have been turned out ?o pasture. This may be accomplished by having what is termed a "lamb creep" in conjunction with the enclosure in which the dams are fed. The lamb creep is simply a division of the feeding place of the dams, but inaccessible to them, and in which food is placed for the lambs. The lambs get access to it through one or more openings between boards or strips nailed up and down, and through which the ewes may not pass. Such creeps may be morable and so made that they may be let down in the corner of a pen.

In the little racks or mangers within these creeps some fine well cured fodder should be placed. If possible they should be given finely sliced roots. They will learn to eat both when only a few days old. The younger ones learn all the sooner from being with those a little older. And they will learn to eat meal, as 
ground or crushed oats, bran and oilcake, even sooner than they learn to eat hay. As they get older it is not necessary to grind the grain, and various mixtures of grain may be used providing that a fair amount of protein is fed in the same. The lambs should get about all they will eat of such foods until they are turned onto pasture, and when they are to be sold early it may be well to feed them thus within a creep in a pasture, as more gain is obtained from feeding grain directly to lambs than by feeding it to them indirectly as when it is fed to the ewes. When the lambs are to be reared for breeding, or when they are to be fattened in the autumn or winter subsequently, it is seldom necessary to feed them grain when the pastures are abundant. Field roots finely sliced will soon be taken with eagerness by young lambs when they can have access to them, and roots are most excellent for promoting growth.

Docking and Castrating.-Lambs should be docke.1 when only a few days old. But when they are to be sent to the block in the spring or early summer, it is not necessary to dock or castrate them. Docking is frequently done by one person holding the lamb on its feet and a second person taking the end of the tail in one hand and removing the same with one cut of a sharp knife.

This method may answer well enough for lambs that are to be sold for meat, but more care should be taken when docking lambs that are to be kept for brecding. The following method is a neat way of doing the work: One person places the lamb with its buttock on a smoot! block of wood. The back of the lamb is toward him and 
the four fect are held in one hand. Ile then draws the skin of the tail towaril the junction of the same with the body. A second person with a sharp chisel and a mallet severs the tail with one blow between one and two inches from the borly and preferably at a joint. The loose skin then draws dow partially over the wound and heals over smoothly. There are shears which are also used in docking. Care should be taken when the bleeding does not soou stop to sear the wound with a hot iron, otherwise even young lambs may bleed to death.

Lambs should be castrated when quite young, under rather than orer three wceks. There is always a slight element of danger in castrating old lambs, and even though there should not be any loss from death, the loss from the check given to growth is always considerable. When lambs are castrated early, they grow better, make better meat, and consequently sell for more money and are more easily managed on the farm.

When castrated young there is no more satisfactory method of doing the work than the following, notwithstanding that to some there may be a repugnant element in it: One person gathers the legs of the lamb in one hankl, and presses the back of the same against his breast. A second person siezes the skin enclosing the purse and gently draws on it, and with a sharp knife cuts off a part of the same so that the testicles become visible. He then jlaces the thumb and fore-finger of his left hand close to the body of the lamb and forces the tosticles forward. He next seizes them, one at a time, with his tecth, and gently draws them out casings and all. While doing so, the thumb and forefinger are 
pressed moderately tightly together, and are kept close to the body of the lamb. Forceps or pincers may be used instead of the teeth. When the testicles are drawn out, draw slightly on the scrotum and the operation is done. It is well to choose a moderately cool day and to perform the operation in the morning rather than the evening.

In castrating lambs that are older, the person who holds them can do so with more comfort if on his knees, drawing the back of the lamb at the same time close against his body. A considerable portion of the scrotrm is then removed with one free stroke of the knife. The testicle is then pressed out until the casing around it can be cut open. Above the testicle the cord appear.; as though composed of two portions, one of which is largely made up of blood vessels. The other portion is first severed and the rest of the cord freed. The testiclo can then be drawn out a little further and the other portion of the cord is then cut. With large lambs and oid rams this portion of the cord should be scraped off rather than cut to prevent bleeding. The other testicle is of course similarly removed. The tendency to stiffness will be lessened by having the animals take exercise voluntarily, or if necessary, enforced. Much swelling is evidence of the closing of the wound, and when observed the wound should be opened by pushing a clean finger gently into the opening and woll up into the same.

Weaning Lambs.-Lambs should be weaned at the age of 4 to 5 months. When taken from the dams they should if possible be given good, fresh tender and juicy pasture. It may consist of such plants as blue grass, 
second growth clover, winter rye and barley or rape. The last named pasture is the most valuable. As it ir important that lambs should have such food as soon as they are weaned, provision should be made for this in planning for the food that shall be grown for the season.

The lambs should also have grain added as soon as they are weaned, but this is not so necessary when abundant rape pastures are on hand. This food may consist of oats and bran, barley and bran or the three combined. Oats alone will serve a good purpose. When lambs have been used to grain in the spring, they will at once take to the same when it is placed before them after they are weaned. But when they have not yet learned to eat grain they may take but little at first. It may be given to them in sheds or in troughs in the fields as conrenient. The troughs may be made simply by nailing two boards about 6 to 8 inches broad together in the form of a $\mathrm{V}$, and by supporting the same on short leg's. A narrow strip resting on edge on the ground and nailed to the legs will prevent the trough from being overturned. Unless when the lambs are to be pushed for some specific purpose, one pound of grain per day per lamb will be ample to feed. A less amount will frequently suffice.

The ram and eve lambs should be separated at the weaning season, and it may be necessary also to further sub-divide them, as for instance by separating breeding lambs from those that are to be prepared for the block. 


\section{CHAPTER X.}

\section{Management of Ewes.}

The treatment suitable for lambs up to the weaning period has been given in Chapter IX. Then it is that the selections for brecding ought to be made. At that time the lambs will be sufficiently dereloped to render it possible to make selections without the hazard of mistake.

Selecting Breeding Ewes.-In making selcetions for breeding the best specimens shonld invariably be chosen. The owner should nerer allow himself to be tempted to sell the best of his erve lambs to be sent to the block before or after the weaning period, cven though they are only grades, otherwise he will never reach that high level of attainment that ought to be the aim of every breeder. The reading indications as to form have already been given in Chapter IV. To what has been said there the caution will be added, to guard against making size only the chief ground on which selection is based. Although good size is greatly important. Femininity and symmetry of form are among the more important considerations in selecting ewe lambs for breeding.

Management Untit the Mating Senson.-Is a rule the ewe lambs selected for breeding should be separated from the lambs that are to be fattened as soon as weaned, as the former do not require so stimulating a diet as the latter, but there may be conditions when all 
may run together as when feeding on rape or other nourishing pastures. Until they are bred the aim should be to feed food that will produce growth rather than fatness. The first winter the ewe lambs may run with the breeding flock up to the lambing season when the flock is small, but when it is large they will do better with a separate apartment. When so separated the fodder should consist of that variety so helpful to well doing in sheep, and which has been dwelt upon in Chapter VI. It may be necessary to give a light grain ration, as, for instance, oats and bran, but the fodders being suitable, from $\frac{1}{2}$ pound per day to 1 pound should be ample. The amount of grain to be fed should, however, be guaged by the condition of the sheep. The grain ration should cease when the young ewes are turned out to pasture. They should be given food sufficiently succulent to prevent constipation. Roots may be fed freely to young ewes and with excellent results, as they are very helpful in promoting growth and also in regulating digestion.

Age at Which to Breed.-Usually young ewes should not be bred until they are about 19 months old. To breal them as lambs will tend so to hinder growth that where such a practice is adopted it will not be possible to maintain normal size in the flock. Nor will they sustain their lambs as well as ewes that are older. Loss of stamina will also follow to some extent and the wool yield will be lessened. But when young ewes with their progeny are to be sold as meat the following season, it may be admissible to bired them as lambs.

Maling Eues. - The mating season will, of course, 
depend upon the object in rearing the lambs. As the period of gestation covers 21 weeks, the mating will usually begin not sooner than September and will end with the close of the year.

When the lambs are taken away from the dams, the latter are usually somewhat thin in flesh. For a few days after the removal of the lambs they should be kept on a diet low and dry. Two or three times within the next week or ten days the udders that give indications of distension should be examined and partially milked out to prevent permanent injury to the udders. The ewes should then be put upon a generous diet to enable them to recuperate before being mated. If the pastures are good it will not be necessary to add grain to the food which the pastures provide, as the ewes have from two to three months in which to regain lost flesh. For building up eves at such a season no pasture is superior to rape, nor is any probably equal to it.

If when the mating scason arrives the ewes can be bred within a reasonably short period, the labor at the lambing season will be lessened, and the lambs will be more uniform in age and consequently in size. The disadvantages from having the lambing season extend over a long period are many. It makes the feeding of the flock more difficult and also interferes with the weaning of the lambs. The mating of the ewes may be hastened by putting them on a stimulating diet. This can be done by feeding them grain for a few weeks previous to the mating season, by putting them on nutritious pastures, or what is sometimes better, combining both methods. Barley and wheat unground are among 
the more suitable grains to feed, but oats will answer. One pound or a little more than that will be fed per day. The most suitable pasture is rape. If the rape is well grown additional grain food may not be necessary. The impulse thus given to the system by building it up quickly is shared in by the procreative porvers, consequently the time of breeding is thus hastened.

Going Into Winter Quarters. - When the management is proper, the ewres will be in fair condition when they go into the sheds. They should be given access to the pastures until snow covers the ground, even though the latter should be bare. The exercise is good for them. But it is frequently necessary to add supplemental food to the pastures before the latter are covered.

A sudden change from a diet more or less succulent to a dry diet is to be guarded against. As pasture is usually more or less succulent in the late autumn when the change is made to dry food, the aim should be to give the ewes a small supplement of such food, as bran or field roots. In the absence of such food the bowels are much prone to become more or less constipater. This disarrangement of the digestion is probably the origin of more of the troubles that afflict sheep in the winter than all other causes combined. The aim of the feeder, therefore, should be to provide a sufficient quantity of such foods as tend to regulate digestion, to carry the flock through the winter. These foods include bran, oilcake, ground flax, field roots and ensilage. Of these bran and field roots are probably the most valuable.

Grading the Flock. - When the dams go into winter 
quarters it will not be necessary to grade them; that is, to subliride them when the flock is small and when all are vigorous. But when the flock is large; that is to say, composed of more than a hundred, the results obtained from a brecling flock will be more satisfactory if it can be graded according to the age and rigor of the erres. Yariations may then be made in the food given as may be lesired, except, howerer, with flocks that are of more than orlinary raluc, this would seldom be necessary.

Food Previous to Lambing.-The aim should be to kecp the cres in a grood condition of thrift previous to the lambing period rithout orerloading them with fat. The lict should contain a large proportion of nitrogenous elements, otherwise the young lambs will not be well dereloped. It is also indispensable that there be factors $i_{i}$ it that will prevent constipation. Good, finc corn fodder will serre a good purpose once, a day; and the same is probably truc of sorghum, but experience in fecling food so sweet to brecding ewes for a lengthened period is too limited to speak confidently in regard to it. The other fodlers should consist of such fools as native hay, millet, a mixture of clorer and timothr, and best of all clover and alfalfa. Quite frequently straw may be fed morning or evening, and what is meaten strewn around for belding before the sheep are again fed. Corn straw only, along with the straw of small grains, is too lacking in protein, henec, if the ewes must be confined to such fodder, the lack of protein should be made up in the grain fed. With good 
clover or alfalfa, a breeding flock will want but little else, so well balanced are those foods.

Corn or sorghum when given in the uncut form may be fed upon the ground while the latter remains frozon. It may be advantageous to feed it in an enclosure just outside the small yards in connection with the shcds, that there may be room to scatter it widely. 'Tlis other' fodders should be fed in racks. In any event the rards attached to the sheds should be amply littcrel with straw, and more especially in damp weather, to proride a comfortable resting place for the sheep. The fecling racks should be cleaned out every day, and what is better, after each feed. Usually the grain portion should be very moderate before the lambing scason, schlom exceeding one pound per head per day. 1 mixturc of oats and bran, with a trace of oilcake or flax meal in it, cannot well be improved upon. When roots are fel, oats alone will suffice. Barler, duly admixal with bran, is good. Corn should be fed sparingly, it is so carbonaceous, but more of it may be fel in cold weather. Field roots are also excellent, but should not he fol at the rate of more than, say 2 to 4 pounds a diay to brecting erves on a balanced ration, lest the lambs shall to over-developed in muscle and lacking in bonc. But when erres are almost wholly confincl to a folder complement of corn, timothy liay or native hay, then fielal roots may be fed with much freclom cxecnt in cxtremely cold weather. Roots should he giren, sliced or pulped. Screenings of rarious kinds of grain are also more or less excellent according to the variety, but the exceedingly variable character of screcnings should not 
be lost sight of in determining the amount that shall be fed.

Exercise for Ewes.-When there is a large pasture not too distant from the sheep sheds, the ewes will take ample exercise in it if allowed free access to the same while the ground is bare. In seasons of prolonged deep snow it is different. It may then be advantageous to strew some food over the snow some distance from the sheds, and if possible where drifts do not gather. A snow plough run to the place when necessary will very quickly make a good track. A load of food, protected by hurdles, may be placed hard by for convenient feeding. The question of sufficient exercise for breeding ewes is one of great importance. When it is wanting there is likely to be much trouble at the lambing season, though the food and management in other respects should be correct.

The Lambing Season.-In cold weather the lambing shed is the proper place for the ewes at such a time. In one little division of this shed the ewe and her newkorn progeny should be kept for a few days, or until the lambs are well started and the ndder of the ewe is safe. The grain food given to the ewe, light at first, should be gradually increased. When all is right she may then be drafted to that division of the flock with the youngest lambs in it.

Food Subsequent to Lambing.-Whatever the kind or kinds of the food fed subsequent to the lambing season, it should be of a character such as will produce abundant milk-giving. As before the lambing season various fodders may be fed subsequent to the same. 
The most suitable are clorer hay and alfalfa, but good corn fodder is valuable. The grain should be increased. If the lambs are to be sold early, the ewes may be given practically about all they will eat clean. The kind or kinds of food fed may be the same as those given before the lambing season, but increased in quantity. More corn. relatively may also be fed to aid in preventing too great loss of flesh in the ewes.

When field roots can be spared the ewes may be given about all they will consume of these. Roots are exce?lent for promoting milk-giving. A less amount of grain is required when roots are fed thus freely. In the absence of roots, bran or flax in one or the other of its forms should be fed more or less freely.

Corn ensilage may be fed with advantage to breeding ewes before and after lambing. It is not usual to feed more than 4 pounds per head per day, and less than that is given in very cold weather. The succulence in the ensilage aids digestion, but ensilage is not so good a food as field roots, though as a rule it probably costs less to obtain it. It is not common to feed both ensilage and roots at the same time, nor is it necessary to the well-doing of the sheep, but it may be done if so desired.

When ewes are out on fresh grass pasture, they do not commonly require any other food after the pasture has become plentiful, but to this there may be exceptions, as, for instance, when the ewes and lambs are to be prepared early for the market.

The Weaning Period.-The lambs shonld, if possible, be taken quite away from the ewes at once; that is to say, the lambs when separated should not be allowed 
to return to the dams again. The latter should also be put upon dry food and kept for a few days where they will not be disturbed by the bleating of the lambs. As soon as the crres are dried the culling process should follow. Then it is that the ewes which are to be disposed of should be marked in some way, and when praeticable separated from the flock and put upon a special diet. Any whose udders may be defective or who are too old, also shy breeders and poor nurses, should bo removed. In determining which shall be retained, the preference may be given to ewes that produce twins or single lambs aceording to the design of the breeder. That this may be possible each ewe should have an ear tar and number, and a record of the progeny kept. This may not be practicable in very large flocks, but it is usually practicable with the ordinary farm flock.

Ordinarily it is not customary to keep ewes beyond the age of firc rears; that is to say, the ewes are required to produce but three crops of lambs. When fattened at that age the process is not so difficult or costly as at a later age, and they scll for better prices. They are also disposed of before they reach that condition through old age, when they require special feeding. But in the case of cxecptionally good dams, and especially when purely bred, and therefore of superior ralue, they may he kept longer. Some breeds may also be licp:t to a greatcr age than others. Notably is this truc of Mcrinos.

llie culls thus separated should orcinarily be disposed of while yet on pasture. They do not fatten so 
easily or profitably as lambs, and if sold before going into winter quarters they are out of the way. No other food will fatten them so easily or so quickly as a pasture of rape well advanced in its growth. 


\section{CHAPTER XI.}

\section{Management of Rams.}

Rams used in breeding, when properly bred and reared, exert a greater influence on the progeny than all the ewes combined which they are bred to. The former influence will exceed the latter in the individual progeny as much as the breeding and prepotency of each ram exceeds the breeding and prepotency of each ewe. It is greatlv important, therefore, that rams should be well reared.

Care Subsequent to Weaning.-The care and management of ram lambs to be kept for breeding are the same as are suitable for other lambs up to the weaning season. Only in purebred flocks will uncastrated ram lambs be found at the weaning season. This at least should be true of farm flocks. But even in purebred flocks all the males of but little promise should be castrated when not more than two or three months old. Even at the weaning season, should any uncastrated males be found in the flock of inferior development and promise, they should be set aside for the block.

The breeder of purebreds cannot afford to sell rams of decidedly inferior individual merit even at a low price, otherwise his reputation will suffer, nor can the breeders even of common flocks afford to buy such rams, though they should be cheaply purchased. Purchasing such males has greatly hindered the improvement tha: 
might otherwise have been attained. Rams of uncouth build, though large, should be rejected more readily than those a little under size, but well formed. The latter may develop later, especially if they are twins.

When the ram lambs have been weaned they should, if possible, be given rich pastures. These should be supplemented by a grain portion that will promote muscular development and good bone. In other words, the grain should be rich in protein. There is no better mixture for them probably than one of oats and wheat bran with enough oil meal in it to secure that degree of flesh that will induce a ready market when sold to breeders the same season. Here also good rape pastures will be greatly helpful. But in pasturing purebreds on rape, great care should be exercised to so manage the lambs that they will not suffer from bloating. To avoid such hazard some flock-masters feed the rape as soiling food to the sheep as well as to the lambs. Ram lambs should be quite removed from the females of the flock that they may feed more quietly.

Management During Winter.-The rams not sold should be kept separated from the ewes. They should, of course, be comfortably housed, and allowed the unrestrained freedom of an adjacent or contiguous yard or paddock, except when storms are falling. If practicable to keep the young rams separate from the older ones, they will probably fare better on the whole. But it may be necessary sometimes to keep them together. When it is, they should have ample room for feeding lest the weaker rams should not get their proper share. When first brought together it should be in a very small 
inclosure lest the strong ones should injure the weak by fighting them. They shonld be kept there until they become used to the newcomers.

Food in Winter.--The food should still be of a character to promote growth. While various grain mixtures may be fed with good results, no mixture will be found superior for prolonged feeding than oats, bran and a small addition of oilcake. Field roots will prove greatly helpful in stimulating growth, but the fact should not be overlooked that there is an element of danger in feeding mangels to rams They have in instances not a few interfered with urination to the extent of proving fatal, but this danger does not appear to be present when they are fed to ewes.

Various fodders may, of conrse, be fed, but none are more suitable for young rams than good, well-cured clover of the medium and alsike varieties and alfalfa. Hay, composed of peas and oats properly grown, is also excellent, not only for rams, but for all classes of sheep. The aim should be to keep the young rams growing continuously without overloading them with fat. And with the rams it is quite as important as with the ewes to give them a food that will prevent a constipated condition of the bowels.

Management in Summer.-In the summer the rams should be out on pasture until the season of the mating of the ewes. It is also equally important to provide shade for them as for the erres. Where there are but one or two stock rams there can be no serious objection to their ruming with the flock or with a section of it during the early summer months. It will also be as 
well or better to allow the rams to go without grain during these months unless from some cause they should be in lean condition. Feeding grain freely and without interruption to rams is like driving a machine at too high a rate of speed.

Management at the Mating Season.-Some weeks previous to the mating season rams should be confined to a grass paddock where at the same time they will have access to a shed. Grain feeding should then begin, and if it can be supplemented with succulent and nutritious soiling foods, as, for instance, rape or secondgrowth clover in the absence of good grazing. The rams will prosper all the better for it. It is important that the rams shall be in a good condition of thrift and bodily vigor when used in service. Such a condition has a bearing upon the vigor of the progeny, and it is believed also upon the number of the same. The more exacting the service required of the rams the better should they be nourished. The standard grain food, oats and bran, may be fed to the rams, but it will be improved if some barley or wheat or both is added. Wheat especially, when fed in moderation, would seem to be helpful in stimulating the generative function. The quantity to be fed daily will depend on the condition of the ram and the extent of the service. The necessity for feeding more than 2 pounds per day will seldom occur and usually less, than that will suffice.

When rams are thus confined to the paddock the flock should be driven to the yards morning or evening during the mating season. The rams when turned in to the flock will then single out the ewes in heat. The 
ear number of each ewe thus served should then be noted and recorded. It may seem like taking much trouble to manage thus, but in a valuable flock, and especially in a purebred flock, labor thus bestorwed will be abundantly rewarded.

When the flock is small, and especially where it is a grade flock, it may answer fairly well to allow the ram to run with the flock. If quite tame, as he ought to be, he may be given grain daily in the field. Only a few minutes are required for its consumption, even though the attendant should have to wait. And in other instances it will be proper to feed grain to both rams and ewes.

When it is desired to have the ewes marked by the ram at the time of service, red ochre or some coloring substance should be applied to his brisket daily. The ochre is powdered and is then moistened with water and applied to the brisket of the ram with a cloth.

Young or Older Rams.-Better results may be looked for from matured rams than from those immature or so old as to be past the period of their best vigor. They should be at their best at, say from 2 to 5 or 6 years, but will vary somewhat with the breed. It is admissible sometimes to use ram lambs on a flock that does not exceed, say a score, especially if the lambs come early in the season and are well developed, but the extent to which ram lambs are used in service is to be regretted. The age to which rams may be profitably used - will vary with the individual and with the breed. Usually they should not be used beyond the age of, say 
6 or 7 years, but rams of the Merino types have frequently proved quite useful to a greater age.

Amount of Service.-The amount of service that a ram can profitably render will depend upon vigor, age and breed. It is not enough that a ram shall beget progeny. It is far more important that he shall beget a sufficiently vigorous progeny. This he will not do when overworked. A ram at his best should be able to serve from 50 to 100 ewes in one season. He can be profitably mated with a considerably larger number when confined to a paddock and fed and managed as described above than when allowed to run with the flock.

When there is but one stock ram, he can only be used in the same flock but two vears. If he has proved a good sire it would be unfortunate to send him to the block. Some one should purchase him for service in another flock. There is no hazard in using such a ram. His value has been proved, while in using a young ram there is always an element of uncertainty as to what the exact results will be. 


\section{CHAPTER XII.}

\section{The Flock in Winter.}

In sheep husbandry troubles will accumulate from defective management much more rapidly in winter than in summer. It is therefore, more highly important that close attention shall then be given to all the little details that have a bearing upon success.

Going Into Winter Quarters.-The change from the fields to the yards should be gradually made when practicable. As soon as the weather becomes stormy in the autumn, sheep should be protected from the storms. Exposure to one severe and prolonged storm of rain or sleet may produce catarrhal troubles that will affect the sheep during all the winter months, even though none of the animals should succumb to such exposure. They should be yarded at night as soon as the pastures become crisp from night frosts. Before being turned out to graze in the morning, they should be given a light feed of some kind of fodder. Such yarding is not so necessary when sheep are pasturing at that season on an old grass pasture with much dead grass in it. Grazing upon succulent food crisped by frost when the stomach is empty is not good for any kind of stock, and in the case of sheep it may lead to digestive trouble:; that prove fatal.

Succulent Food.-When sheep are changed from summer to winter quarters as described above, the 
change is made so gradually from a succulent diet to one that is not succulent, or at least one that is much less succulent, that no setback is given to the sheep. But provision should be made in some way to provide more or less succulent food. And this will be all the more necessary if the preceding summer has been a dry one, as then the fodder will be more than ordinarily dry. It can be most cheaply provided in the form of corn ensilage. While that is a good food, in the judgment of the author roots are better, though not so cheaply raised. In furnishing ensilage the caution should be observed to not build a silo with too large a diameter in it, as when it is thus built the food is removed too slowly to keep the exposed ensilage in a good condition. A round silo with a diameter of 10 feet and a height of 24 feet will be amply large to provide ensilage for 200 sheep.

In the absence of ensilage and roots, wheat bran or bran and oilcake should unquestionably be fed in more or less quantity to the sheep. As previously intimated, more than half the ills that befall sheep in the winter season have their origin in a constipated condition of the bowels. This more than anything else perhaps is to be guarded against in the management of sheep in winter under our conditions.

Variety in the Food. - Variety in the food is not so important as succulence, but it is by no means unimportant. A change from a more palatable to a less palatable food seems grateful to sheep occasionally. This is witnessed in the extent to which they will eat oat or wheat straw even when good clover hay is being fed to 
them. Such a variety should be duly planned for, provided and stored away. And care should be taken to hold in reserve the most appetizing and nutritious foods until the lambing season. Too much of sameness in the food characterizes a great deal of the feeding that is done in the state. The extent to which flocks are confined to fodder consisting only of corn or of native hay is not favorable to the most marked well-doing in the sheep.

Dipping the Flock.-In nearly all instances there will be more or less of ticks on the flock in the autumn. If not destroyed these will multiply so as to give the sheep much unrest. This will, of course, seriously hinder well-doing, hence dipping should not be neslected in the autumn. Nor is it well to defer the same until the weather gets cold. The mode or modes of dipping is discussed in Chapter XVIII.

Grading the Flock.--If the flock can be graded or divided it will thrive better than when this cannot be done. The grading should be based on age, thrift and sex. The great advantage from such grading arises from the opportunity it furnishes to give to the sheep of each class the kind of food suited to their needs. Of course such grading involves more labor in feeding the flock. It also calls for more divisions in the sheds than would otherwise be required, but these need not involve much outlay, since the divisions can be so made as to be moveable and easily changed and readjusted. Such grading will he equally helpful to a feeding as to a breeding flock, but the latter is more inportant because of their greater value. 
Fodder and Grain.--The proper adjustment of the fodder and grain is important. So long as sheep can be kept in a suitable condition as to flesh on a diet of fodder without grain, they will be more cheaply fed, but when fed fodder only, if they begin to lose flesh grain feeding should be at once resorted to. The effort should be made to retain the condition as to flesh which the sheep bring with them from the pastures. If a breeding flock is allowed to run down in flesh before the lambing season, they will not nourish their lambs nearly so well, nor will it be possible to get them up again in good flesh until after the lambs are weaned, even though the feeding should be liberal and the food suitable. It is possible to have breeding ewes in too high flesh, but in nearly all instances the mistake is in the opposite direction.

Housing 'Too Warmly.-The mistake of housing sheep too warmly should be most carefully avoided. The evils that follow are many, as for instance, loosening of the wool from overheating, mortality in newly born lambs and general ill-doing. Sheep do not appear to take any harm from low temperatures if protected from wind. But they soon suffer seriously from crowding in stables without ample ventilation. If the yards are kept well bedded the sheep, if allowed to choose, will generally stay outside, except in stormy weather, not only in the day, but also at night. If shut in close and ill-ventilated quarters at night and then allowed to go out at once into a chilled atmosphere, the flock will not prosper. Of course, it is practicable to keep sheep inside for weeks in succession under certain conditions, 
as for instance, when they are shorn in the fall and are then fattened. But when thus fed the sheds are properly ventilated.

Freedom From Draughts.-The flock-master should carefully guard against exposing sheep to draughts. When they lie in a dranght they are liable to become affected with catarrh and to contract colds which produce coughing more or less violent. These coughs frequently become chronic. Something has already been said on this question in Chapter VII. when treating of the construction of sheds. When the walls are free from openings and when doors are only made on one side of the building, the danger from exposure to draughts is slight. But if the door's and windows are on both sides of the shed, much. watchfulness is required. When thus open on both sides at the same time, currents of air are pretty certain to move across the shed. Unless, therefore, in still weather the aim should be to have these open only on one side at the same time. When young lambs are exposed to draughts, the danger is greater than from exposing mature sheep to the same.

Use Bedding Freely. - The floors of sheep sheds being usually of earth, will soon become foul in damp weather unless kept well littered. The same is more emphatically true of the yards. Lying on a damp bed or amid offensive exhalations is peculiarly hurtful to sheep. Such exposure should be sedulously avoided. At the lambing season increased vigilance is necessary, as then in rainy weather the ewes and lambs are more likely to be crowded. Filthy quarters are peculiarly hurtful to lambs and will soon prove fatal to them. At 
some seasons litter should be strewn over the floors of the sheds daily. To allow sheep to be insufficiently supplied with bedding would be indefensible in this land of burning strawstacks. The more litter that is supplied the more also will the sheep furnish of valuable manure.

Water and Salt. - The old idea that sheep do not require water when they have access to the snow was a very mistaken one. True, sheep will eat snow when no water is supplied. But such a necessity is simply cruel. When on dry food, sheep not only require water every day, but they will do better when water is constantly accessible, and the more stimulating the diet the greate ${ }^{\circ}$ will be the amount of water consumed. If it can be supplied indoors the trouble from freezing will be lessened.

A free supply of salt seems essential to the well-doing of sheep. It is better to keep it constantly before them than to give it to them at intervals, and it is also more convenient to supply it thus in boxes or shallow troughs.

Exercise.-This question does not need to be considered in climates so mild that sheep go from the sheds to the fields to graze during much of the year. But when the winters are long as in Minnesota, it is an important question. In open winters it is not so difficult, for then the sheep will take exercise voluntarily. They will roam about in a grass pasture sufficiently during the day, even though they do not get much food. But when the snow is deep it is different. It may then be advisable to feed them more or less in some spot not too near the sheds, as described in Chapter X. Another way is 
to plough a track, circular in form, if convenient, and to strew fodder along some part of it every day.

Trimming and Tagging.-Ordinarily not much trimming or tagging is necessary in the winter, but the occasion for both is always more or less present in it flock that is to be kept in a nicely presentable condition. Loose locks of wool are unsightly and should be removed. The same is true of any adherent filth, fresh or in the dried form, around the buttocks. And in purebred flocks trimming is quite in order when the time for it can be secured, especially is this true of the males. 


\section{CHAPTER XIII.}

\section{The Flock in Summer.}

Certain phases of this question have been touche! upon in previous chapters, viz: in those that relate to the management of lambs, ewes and rams respectively. But some features of summer management, general in character, remain to be discussed.

Turning Out on Pasture.- Sheep should be changed gradually rather than suddenly from a fodder and grain diet to ore of pasture. When they have access to grass pasture all the while, even in winter when the ground is bare, the change will be gradually made in the spring, as then the green food gradually increases with the advance of the season. This process is, however, hard on the pasture. If a blue grass pasture can be reserved from early in June onward to provide early spring pasture, the following year it will furnish very suitable grazing for the early spring. True, the long growth of the previous year will be sere and dead in this climate, bceause of the intensity of the cold. But it forms a mulch that protects the roots of the grass so well that growth is rapid early in the season. When grazing at such a time, the sheep eat the dead grass along with the new, hence undue laxity of the bowels is prevented.

When the sheep cannot be grazed by either of these methods in the spring, the pastures should be allowed to get a start before turning the sheep onto them. The 
period of grazing should be short at first and gradually lengthened until the change is completed. When first turned out there should be no diminution of the grain fed. The fodder should be gradually withheld as indicated by the decreased consumption of the same. When practicable the best of the fodder should be saved for such a time to tempt the appetite, as the sheep are less inclined to eat fodder freely after grazing on young grass. The reduction of the grain food should also be gradual until finally none is given except in special instances.

Change in Pastures. - When it is practicable to furnish an occasional change of pasture, the sheep will do better than when they are kept upon the one pasture. This, however, may not be true where the pastures are so large that they furnish abundant food for the sheep and cattle that graze together upon them. Sheep are fondest of grass short and of recent growth. When they can be alternated on pastures such grass or other grazing is more easily supplied. More food will also be secured when the grazing is not continuously close in character.

Pasturing Brush Land.-Sheep may be made to serve an excellent purpose in pasturing brush land with a view to use them as aids in killing the brush. But they should not be kept continuously upon it. Such food will not sustain sheep in good form when it is the sole dependence. The ideal way to graze such lands is to pasture the sheep upon the brush from morning until noon, and on other pastures in the afternoon. The brush land will then in time be subdued and without 
hindering the well-doing of the sheep, but more time will be required to accomplish the work. Such food is also much more readily consumed in the spring when the leaves are young and tender.

Pasturing Swampy Land.-The relation between pasturing sheep on low, swampy or undrained land and parasitical diseases has long since been noticed. It has also been noticed that hazard from such a source is greater in lambs than in old sheep, and in the early part of the season than in the late fall. The aim should be, therefore, when practicable, to keep the sheep away from such lands altogether, and when this cannot be done to keep them away until midsummer is past. Then after the long and coarse grass has been eaten by cattle, sheep may be allowed to glean.

Corralling at Night. - The practice of yarding or coralling the sheep at night may in many instances be necessary, but it hinders rather than helps well-doing iis the sheep. When sheep are thus yarded or corralled, there is oftentimes crowding. They usually have to travel some distances to the enclosures and from the same. They are also required to spend the late evening and the early morning in the corralls, and these are the portions of the day above all others during which sheep love to graze in the hot summer season. There is also serious loss in fertility unless the enclosures are kept well littered. Such protection may, however, be necessary, as otherwise dogs and wolves may prey upon the Hock. The extent to which sheep suffer in Minnesota, especially from the first-named source, is peculiarly unfortunate. 
When sheep can lie in the pastures they graze in contfort in the evening twilight.

They lie down on the nearest rise of ground to which they happen to be near. With the early dawn they are up and grazing again. And when the sun waxes warm they seek the shade and there remain until it is cool again. One can see at a glance that sheep thus at liberty should prosper better than those confined at night.

Providing Shade.-The question of shade for sheep in summer is greatly important. It has a far-reaching influence on their well-doing. So important is it, that the flock-master should not fail to provide it where nature has not done so.

When nature has furnished groves ar forests and the sheep may have access to the sarne, the question of shade would be easily disposed of were it not for the mischief sometimes produced by the fly which deposits the egg that produces what is known as "grub in the head." Because of this, valuable flocks of sheep should have access to the shade of a shed during the heat of the day, from, say the middle of July until the middle of September. The windows of the shed should be darkened by hanging over them some kind of screens, as for instance, coarse sacking. Ample ventilation is also indispensable where sheep are thus sheltered. When windows are numerous and on opposite sides of the shed such ventilation may thus be secured. The flies will not come into those dark resting places. The freedom thus secured from flies generally furthers well-doing. in the sheep.

But the shade of trees is also very necessary when it 
can be obtained, for sheep will take refuge in the same in the heat of the day from the turning out season until the arrival of the cool days of autumn. Where nature has not provided, shade trees should be planted to provide the same where sheep husbandry is to be a permanent work. They may be planted in clumps of some size, on elevated ground, but to this plan the objection holds that it makes trouble while the field is being cultivated. The objection thus made is obviated by planting the trees in the corners where four fields come together. The trees may thus be made to occupy the angle in each corner. But when planted thus it should be where fences are to be permanently maintained and on high ground. The best tree for the purpose under Minnesota conditions would probably be the American elm. It does not grow rapidly, but the tramping of the sheep over the roots do not injure it as it does many other trees.

Until such shade can be provided when it is absent, temporary shade may be furnished without great cost by building a low shed in one or more of the pastures. In building such a shed, plant posts in the ground, spike scantlings over these, and nail thin boards over the scantlings, giving the boards some slope. Two or three board- may be nailed across the upper part of each end and the work is done. It is not necessary to have the roof more than a few feet from the ground. Under certain conditions some cheap but durable cloth could be used instead of boards.

Tagging the Sheep.-When sheep are first turned out to pasture the fresh grass induces a more or less lax 
condition of the bowels. This may necessitate more or less of clipping away of the soiled wool below the tailhead, but when the sheep have been shorn previous to the grazing season, trouble cannot, of course, arise from such a source. Tagging may also be necessary at sủndry times during the season, as for instance, when sheep are first turned into a pasture of rape or other food equally succulent.

Water and Salt.-Water is not so necessary in sum. mer as in winter except when the pastures have lost their succulence. There may be times when sheep graze on such pastures that they will not take any water, especially is this true when they are grazed on succulent rape. But usually they should have access to wate:, abundant and pure. Such water should be supplied from wells, pure lakes or running streams. It is ha:ardous to allow sheep to drink from stagnant pools, lest parasites should thus be taken into the system. In hot weather when sheep are on dry pastures, they drink very freely.

While sheep consume salt in considerable quantities at all times when they have access to it, they have an increased craving for it when feeding on succulent food. It is specially beneficial to them at such times. It is thought it tends to counteract the tendency in some degree to undue laxness of the bowels. But sheep should have free access to salt during the whole of the period of grazing.

Protection From Burrs.-Burrs of various kinds will get a footing in the pastures or in the grain fields grazed by sheep after harvest. These should be de- 
stroyed with much care as they are especially injurious tu the wool. They are not usually difficult to eradicate, since they are either anmuls, as the cockle burr or biennials as the burdock. All kinds of burrs will soon be cradicated by careful ploughing where none are allowed to seed. In bye-places hand spudding may be necessary. Cutting them below the crown will in all instances destroy the plants. 


\section{CHAPTER XIV.}

\section{Fattening Sheep and Lambs.}

The fattening of sheep and lambs may yet grow into a towering industry in the state. Until recent years it has chiefly been confined to the stockyards. Gradually, however, the industry is being extended to the farms. The more it is thus extended the better will it be for the state, and also the farmers. Fattening sheep upon Minnesota farms would mean the consumption of many kinds of bulky farm products that are in the meantime wasted or sold at a sacrifice. It would also mean the consumption of grain that now finds its way to the market. The fertility in the foods thus sold is forever lost to the farms. It would also mean ultimately that screenings would be found too valuable to send to the elevator, hence they would be fed on the farm. And it would give employment to the farmer in winter profitable in character where wisely conducted.

Sources of Supply. - The sources of supply are twofold, viz: the farm and the range. Those who feed may grow their own supplies, or they may, of course, add to what they grow by purchase from their neighbors. The aim should be, however, to finish on the farm the animals grown upon it. The objection to it, viz.: that lots less than a carload cannot be marketed without too much cost may he met by two or more neighoors, who have small lots, combining in the ship- 
ment of the same. On rery many farms, however, there would be no difficulty in having at least a carload to ship every year. Better lambs can be grown upon the farm than upon the range, and the facilities for growing them are superiur. This does nct mean, however, that sheep and lambs reared on western ranges are not well adapted to fattening.

The stockers from the ranges can usually be purchased to the best advantage by farmers who buy at the stockyard centers, but where the work is done in a large way, it may be advantageous to purchase on the range. The buying may be done in person or through a responsible and trustworthy commission agent.

Two Classes of Feeders.-Feeding on the farms will probably be done more and more by two classes of feeders, viz: by those who feed only stock of their own rearing, and by those who feed only what they buy. Such a division of the work would tend greatly to hinder the spread of disease. The breeder of valuable purebreds should hesitate before he brings into his yards sheep and lambs for feeding from an outside source, since, in so doing, he may introduce the germs of parasitical diseases that mar give him no end of trouble in his future work of breeding. When they are so introduced, the aim should be to confine and finish them in yards separate from the others.

The Class of Sheep to Fatten.-The aim should be to fatten home-grown stocks when they are young; that is to say, under one year old. Mutton can be more cheaply grown up to the age of one year than beyond that age. This arrives from the law of animal development which 


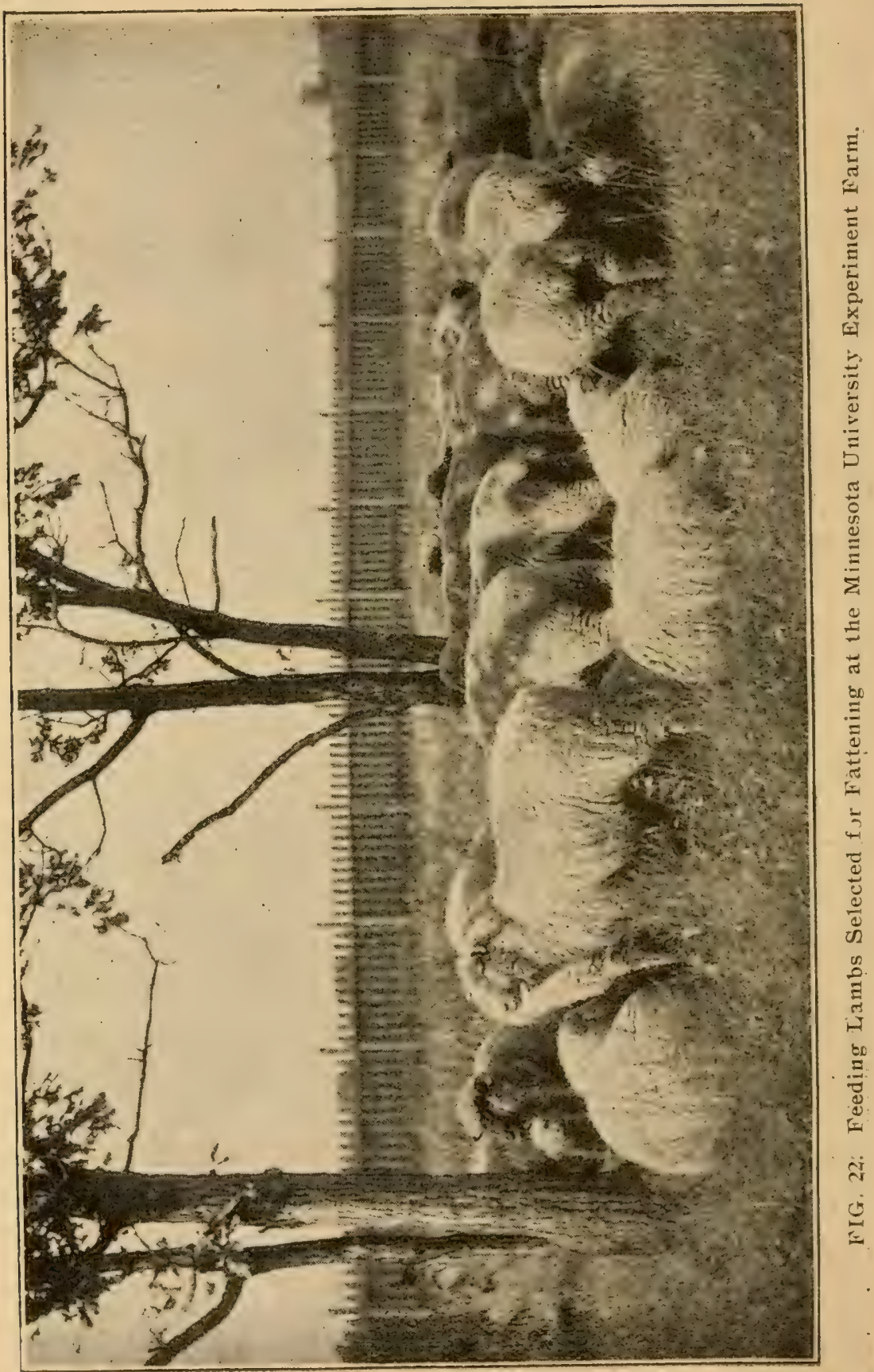


informs us that as the birth period is receded from the cost of making a pound of gain increases. It will seldom be so profitable, therefore, to grow and fatten wethers on the farm as to sell the progeny under the age mentioned. But there will always be a certain proportion of aged ewes to turn off.

When the supplies come from the range, the buyer may choose lambs, wethers one year old or older, or aged ewes. Which should be preferred will depend in a very considerable degree on the prices at which they may be bought. If lambs can be bought at the same price per pound as wethers, they will bring more profit, since they are likely to gain rather more in a given time, will produce gains inore cheaply, and will sell for more per pound when finished. For a similar reason wethers purchased at the same price as old ewes will bring more profit. But there have been instances, notwithstanding, in which larger profits have been made from ewes than wethers, and from wethers than from lambs, because of the higher relative prices that had to be pail for the lambs as compared with the ewes and wethers, and for the wethers as compared with the ewes. The increase in the weight of animals subsequent to time of purchase is favorable to the purchase of heavy animals, whereas the largest increase is obtained from thrifty animals not too heavily fleshed at the time of purchase.

The Season for Fattening.-Lambs may be fattened at almost any season, but ordinarily the fattening season extends from September or October until the end of the May following. When done previous to the setting in of winter, it is usually done on pasture, such az 
rape and fall turnips and the gleanings of harrest. fields. A wide door lies invitingly open for such fattening in large portions of the state, because of the extensive areas sown to grain and because of the easy nossibility of growing rape and turnips in nearly all of these. Such fattening may be done with or without a grain supplement. More commonly it is done without grain, unless for a short time before the close of the fattening period. Sheep and lambs thus fattened are commonly put upon the market in November and December.

Fattening in sheds more commonly begins in November and December, but it may begin earlier. When begun, say in November, it is thus easily possible to fatten two lots in succession in the same yards in one season, as will be apparent from what is said under the subhead next given. The chief difficulty about fattening the second lot arises from the scarcity of feeding stocks, although these are usually obtainable at the stockyards on into January.

Duration of the Fattening Period.--The duration of the fattening period will depend upon such conditions as the amount of flesh carried by the animals at the time that they are put on feed, the character of the foorl and the age of the animals. The lower the condition of flesh, the less carbonaceous the food and the less matured the animals, the longer will they take to fatten. Ordinarily, the fattening period is from 90 to 100 days, but sheep in fair condition and fed chiefly on corn mar in some instances be fattened in 60 to 75 days. The same is true of sheep fattened on good, well-grown rape 
pastures. But lambs that are low in flesh and that are fattened on a diet with a considerable proportion of protein in it, as bran and field roots, will require at least 120 days to fatten.

Foods Used in Fattening.-Sheep and lambs have been more commonly fattened heretofore in Minnesota on screenings and native hay, and such food has proved highly adapted to the purpose. Screenings have a great variety of seeds in them and more or less smail grain, and these are in many instances so blended as to make a good balanced ration. But the exceedingly variable character of screenings should not be lost sight of, when screenings are being purchased for feeding. If the screenings are light and chaffy, shelled corn or ground corn should be fed along with them. Screenings will also be less important as a food for sheep as better systems of farming are introduced.

Various kinds of grain may, however, be fed, according as they are available and cheap. Either corn, barley or oats may be chosen as the basis of the grair. fed. Along with these it is desirable to feed more or less bran. More bran should be fed with corn than with the other grain foods. Oats alone will fatten sheep in good form, but they are usually too dear to be fed thus with profit. Wheat also will fatten sheep satisfactorily, with or without adding other grain, as oats, for instance. A small addition of oil-cake in the peaform adds much to the value of the grain portion of a ration, but the relatively high cost hinders it from being extensively used. In the absence of oil-cake a little flax will prove helpful. But orl cake and flax are less 
necessary with screenings than with cereals. At the Minnesota experiment station the author obtained good results from feeding the following grain mixtures, as well as others that might be given, viz:--corn, oats and oil-cake in the proportions of 3,6 and 1 parts respectively, barley, oats and oil-cake in similar proportions and oats and oil-cake in the proportions of 9 and 1 parts respectively. In other instances bran was added to the various grains fed. On the whole the most satisfactory results were obtained from feeding a mixture of barley, oats and oil-cake with barley as the basal grain. The best gains made for a long period of feeding were obtained from lambs fed on a mixture of oats, bran, barley and oil-cake fed in the proportions of $3,3,3$ and 1 parts respectively, a small addition of field roots and native hay. The gains made per month for a period of 126 days were 10.5 pounds.

Corn and oats make an excellent grain food with some bran added. Even when oats are considerably dearer than corn, it will probably pay better to add some oats to the corn fed, though bran is being fed at the same time. Sheep do not relish bran as they do grain, especially when the bran is added in undue proportion.

The fodder's most commonly fed in Minnesota are corn and native hay, but with the carbonaceous grain foods that are so frequently fed, clover is much more suitable when it can be obtained. Good millet and oat hay are well adapted for such feeding, more especially when fed alternating with other fodder. A variety of fodders is better than a single fodder. When corn is the basis of the grain fed, clover hay may best accom- 
pany it. Corn ensilage when well made and fine in quality may be fed with advantage, but not so freely in very cold weather, and at no time should it be entirely substituted for dry fodders. Field roots are on the whole superior to ensilage and may be fed with the utmost freedom, but, for the relatively high cost as compared with ensilage, some kind of green food fed in small quantities tends to keep the digestion in tone.

The grain is usually fed unground and the fodder in its natural state, but it is now becoming more common to thresh or shred the corn fodder. When it is of fine growth it is perhaps not necessary to prepare it thus.

Feeding the Food.-Some who fatten sheep for the market prefer giving the grain in self-feeders, others feed just what the sheep will eat cleanly from time tu time. The former usually give the fodder in large racks not more frequently than once a day. Which of the two plans should be adopted will depend on the numiber of sheep fed and on the character of the food, also the nature of the help available. Large bands may be fed on screenings given in self-feeders with fairly satisfactory results. This method of feeding is almost universally practised at large feeding centers. But on farms where sheep are in smaller bands and where the help comes from within the home, better results will be obtained by feeding only what the sheep will eat clean of grain, twice a day. The fodder should also be fed twice a day and the racks cleaned out at least once a day. If the sheep can be graded on the basis of size and condition, and fed in separate lots, varying the food 
to suit the needs of each lot, the gains will be still more satisfactory.

Whatever the method of feeding adopted, the grain should be fed in moderation at first, and the sheep gradnally led up to full feeding. The more carbonaceons it is the more moderately should it be fed. For instance, while sheep may be fed oats tempered with a little bran with some freedom, at first, corn so tempered would have to be fed sparingly, and more bran wouli have to be added to the corn than to the oats. As much as half the mixture should be bran at first when corn is the only other ingredient, but it would probably be better, at least for a time, to make about one-sixth or even a larger proportion than that of oats, even though oats should be relatively dearer than corn. The freedom with which screenings may be fed at the first will depend on the character of the same. The amount fed daily should be increased very gradually until the sheep are on full feed. The injury from feeding too much grain at the first would result in indigestion, as manifested in the loss of appetite and in more or less of digestive troubles. When feeding corn as the basal food, three weeks are usually required to get the sheep on full feed. This leading-up process should be carefully managed even where self-feeders are not used.

Self-feeders are variously made, but more commonly on the principle of a box, oblong in shape, wider at the eaves than at the base, and with a small open space at the lower part of each side. The open space varies in width with the kind of grain fed, but is usually more than 2 inches, and through it the food comes into nar- 
row troughs on the same plane or level as the floor of the rack.

In experiments made by the author at the Minnesota experiment station, it was found that more trouble and loss resulted from feeding corn as the basal food in a self-feeder, than when the sheep were given just what they would consume. The same conld not be said, however, about the feeding of screenings. It is probably never safe to feed corn for any long period as the exclusive grain food, but it may form in a marked degree the preponderating grain food in feeding sheep and lambs, especially when fed along with clover hay and alfalfa.

A mount of Food Consumed.--The amounts of grain and hay consumed respectively will, of course, vary with the character of these, hence it is not possible to state exactly how much of each will be consumed. It may be mentioned, however, that in three experiments conducted by the author at the Minnesota experiment station, lambs which averaged 72.2 pounds in weight when the fattening period began, consumed on an average 2.92 pounds of food per day. Of this amount 2.07 pounds was grain and .84 pounds hay. The grain includer corn, oats, barley and oil-cake, fed variously, and the Lay was esentially native. Complete particulars are given in Bulletin No. 57, issued by the afore-mentioned experiment station in 1898. In two experiments conducted at the same station, wethers which averaging 115 pounds when the fattening period began, consumed 4.65 pounds of food per day, of which 2.89 pounds was grain, and 1.76 pounds hay. The food was essentially the same in kind as that fed to the lambs. Full particular 


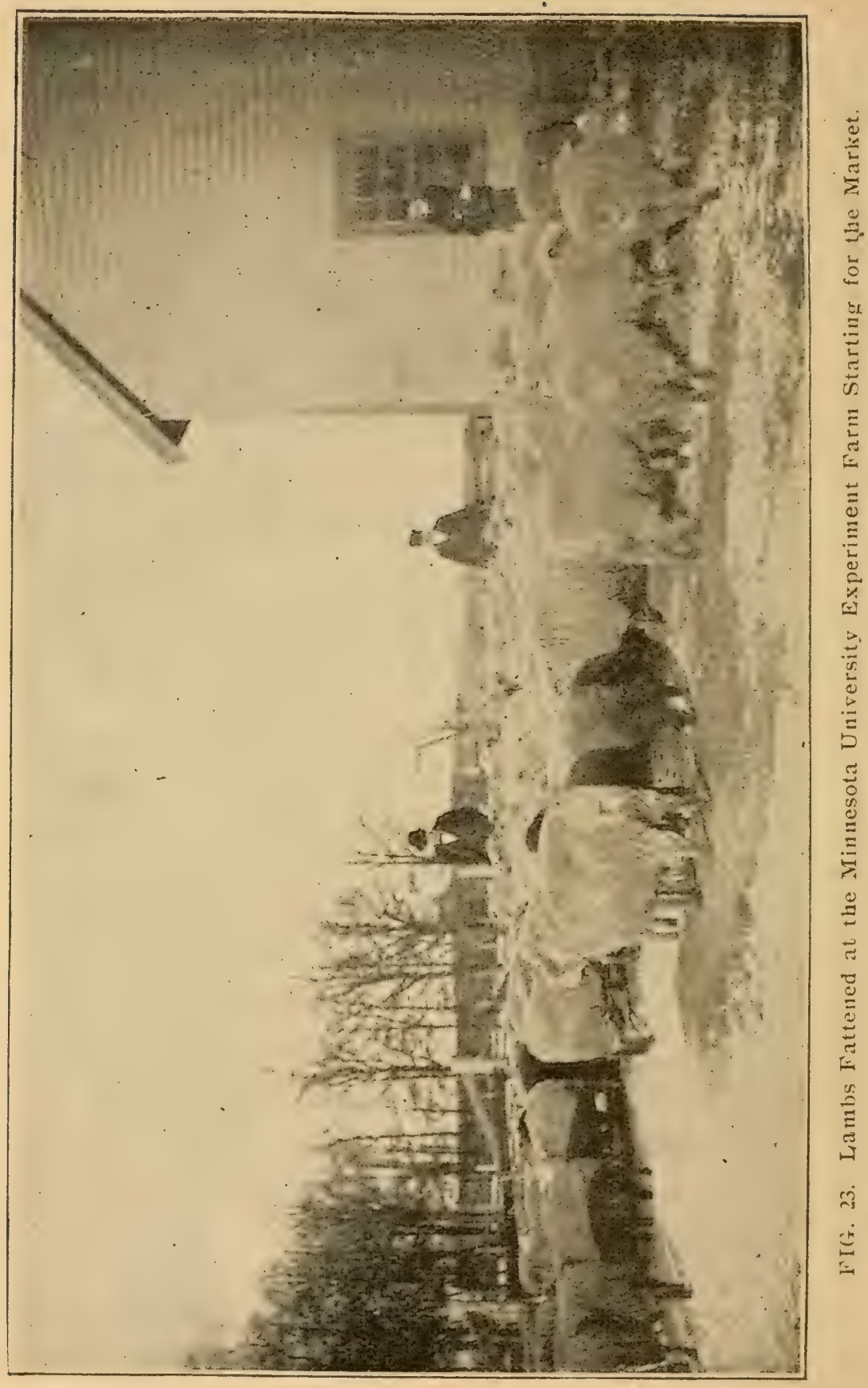


of these experiments are given in Bulletin No. 59, also issued in 1898. If good clover hay were fed, less grain would probably suffice, but there would then be a greater consumption of hay.

Increase in Weight.-The increase in weight made will probably vary with the class of sheep or lambs, the condition of the same when confined for fattening, the "ge of the animals fed, and the character of the food. In the afore-mentioned experiments the average gains made by the lambs per month of 30 days was 9.4 pounds. The lowest average increase per month from all the lambs in a single experiment was 7.1 pounds, and the highest 12 pounds. When lambs or matured sheep gain, say from one-quarter to one-third of a pound per day during a feeding period of 100 days, the gains are to be considered satisfactory.

Water and Salt.-Both water and salt should be accessible every day. When confined to a dry diet, and at the same time a forcing one, large quantities of water will be consumed. The sheep will drink of the same frequently when they have access to it. If kept on insufficient or irregular supplies of the same, well doing will be greatly hindered.

Sending to Market.-The aim should be to market promptly and as soon as the animals are fully ready for the block. Wlien kept longer, the proportionate gains will be less and the mortality is likely to be greater. This is more emphatically true when corn is the basal factor in the grain fed. The machinery of digestion under such conditions is more or less prone to break down. 
When the animals are fat and heavy they should be crawn rather than driven when the distance is considerable from the feed yards to the place of shipment. Bcfore shipping, the owner should be in touch with scme responsible salesman at the place of destination. Such a one can give valuable counsel as to the most f:vorable time for shipping. 


\section{CHAPTER XV.}

\section{Growing Winter Lambs.}

During recent years the growing of winter lambs has become a feature of sheep husbandry of considerable importance in some of the eastern states, though not much engaged in as yet in Minnesota. They are sometimes called hot-house lambs, probably from the forcing methods of feeding adopted in pushing them forward so as to have them quickly ready for the market. The demand for this class of meat is as yet limited in the markets of our western cities, but it will doubtless increase in the near future. There should be room for a considerable and constantly increasing number of farmers to engage in this work.

Who Should Grow Winter Lambs.-Those only should grow winter lambs who are favorably situated for the work. A favorable location implies reasonable proximity to a railway station and to markets, and facilities for sending and receiving messages by wire. The purchasers of winter lambs only want them usualIy in limited numbers and as they order them. It also means the possession of sheds reasonably warm, and of the ability to grow readily such succulent and other foods as are necessary to feed with a view to pushing the lambs rapidly forward. Especially should the lambing pen be comfortable and commodious.

Foundation Stocks.-As only the Dorset breed and 
to a less extent the Tunis among the pure breeds in America drop lambs in the antumn, one or the other of those breeds will have to be chosen if pure blood only is used. Such a course would be too costly, because of the relatively high price of purebreds. Nor is it necessary, as cheaper material may be used. It may be obtained as follows: Select grade females. These may be of various shades of breeding, but they will probably breed earlier if possessed of considerable Merino blood. Put them on good pastures and mate them with a good, vigorous purebred Dorset ram. The lambs thus obtained will probably come in January, February and March. If the lambs thus produced are sold early and the ewes are fed stimulating food as grain, with considerable wheat or barley in the mixture, the next crop of lambs may be looked for earlier. But, observe, all the female lambs that are possessed of promise should be retained for breeding. Those females when bred should drop their lambs from October onward. Those of them that breed late should be sent to the shambles. By continuing thus to use pure Dorset sires and to cull out the ewes which do not breed early, the habit of dropping lambs in the autumn will soon become fixed. This plan has been carried out by the author in an experimental way during recent year's and with much success. In some instances ewes of the first Dorset cross have produced lambs early in September. But usually it is not desirable to have lambs come thus early in the autumn, as they become too large for the requirement of the markets by the time that the demand arises for winter lambs. Sometimes, how- 
ever, there is a good demand for such lambs about the Christmas season.

From grade Merino ewes, even of the range types, lambs may be obtained the greater proportion of which will come in January and February when the ewes have been properly managed. The lambs usually bring good prices, but not so good as those dropped earlier, nor do all the ewes breed thus early. Some growers, however, follow this plan of obtaining winter lambs. As soon as the lambs are sold, oftentimes the ewes also are fattened ard sold.

When the Lambs Should Come.-The best months during which the lambs should come are November, December and January. When dropped earlier, as previously intimated, the lambs are too large by the time that the demand arises for this class of lambs; that is to say, from the Christmas season onward. The demand is probably greatest about or toward the approach of Easter, but it is good from the Christmas season onward. In about 60 to 75 days from the birth of the lambs, they should reach the weights most in favor in the markets; that is to say, from 50 to 60 pounds. And here it may be stated, that if extremely early lambs are wanted, the ewes will mate more readily before being put out on grass than for a short period subsequently.

The Lambing Pen.-In growing winter lambs it is important to know the date of the service of each ewe. Each may then be put into the lambing pen a short time before she produces her lambs. If the lambing pen is large enough to admit of keeping each ewe with her 
newly born lamb in a separate division of the same for several days the opportunity to give the lamb a good start is thus furnished. These divisions may consist of movable fencing or some such material properly adjusted. When drafted from the lambing pens, the latest arrivals should be put along with the youngest lot of lambs. Of the lambs and their dams there should be several grades, based upon the age of the lambs, that the latter may be fed according to their precise needs.

Some growers adopt the plan of keeping both sheep and lambs inside until the latter are sold. This method may be more economical of food, but is much more expensive in outlay for shelter. Nor is it actualIv necessary to the well-doing of the lambs. When a few days old they do not seem to mind the cold of Minnesota weather, and will do quite well if allowed the freedom of the shed or the yard along with their dams. They will probably take more food when they have such liberty, but it is pretty certain that they will also grow faster. It is in consonence with the nature of a lamb to give it a chance to play in the sunlight.

Feeding the Eves.-No difficulty should arise in furnishing food suitable for the ewes that have not yet produced lambs up to the time of housing them. Subsequently good, nutritious fodder and a light addition of grain, as bran and oats, should suffice until the lambs are born. After they are several days old the ewes should be fed with much liberality. In choosing food for them, two thoughts should be prominent, viz: to give them such foods as will produce an abundant milk flow and that will also maintain them in a good condition of 
flesh. Without the first, the lambs will not grow rapidly enough, and without the second the ewes will not breed sufficiently early the following season. Such fodder as medium or alsike clover and millet cut at the proper stage and well cured, are unexcelled. To the grain factors, bran and oats or barley, corn should be added, as the condition of the ewes may call for it. The allowance of roots, not more than two or three pounds per day, before lambing time, should now be increased to several pounds. Indeed the ewes may bo given practically all they will eat clean of the roots if such food can be spared. Ensilage will serve a good end in the absence of roots, but it is not equal to roots in providing milk.

Feeding the Lambs. - The lambs in each of the divisions should have a creep provided within the same, and should have a constant supply of grain and fodder, but more especially of grain. At the first, the grain food may consist of ground oats with the coarse part sifted out, later of ground or crushed oats unsifted, with oil meal added in the pea form, and still later the mixture may profitably be made up of unground oats, wheat and bran, cracked corn and oil-cake. Barley may also be added. While the lambs should be given all the grain that they will eat, the food should not be allowed to become stale. Only for a few days at the first is it necessary to have meal all the time in the troughs.

Disposing of the Lambs.-As orders come in for lambs, those about the right weights, and plump and fat should be chosen to fill them. Lean lambs, though large, should not be shipped until they are fat. It ruay 
be economy to castrate some of the older ones and to retain them for subsequent disposal, as circumstance.s may dictate. Much care should be exercised in drying off the ewes, as, when the lambs are sold the former will still be milking freely.

Heretofore the market for winter lambs has been in Chicago and other large cities further east. But a market is being established for them in St. Paul and Minneapolis. Within a reasonably short period there will doubtless be a market for winter lambs in all the large cities of the west as well as in those of the east.

Dressing the Lambs for Shipment.-To save in express charges the lambs are usually slaughtered and the stomach, intestines and aesophagus removed before they are shipped. The methods followed in dressing them differ somewhat in details, but substantially they are as follows: The lamb is suspended by a rope fastened around the hind leg so that the head comes within about a foot of the floor. An opening should then be made on one side of the neck with a sharp knife, preferably on the left side and in front of the neck vertebrae. Within the small cut thus made the knife should be given some sweep forward to make sure that the large artery found there is severed. 'The stomach, intestines and aesophagus are then removed without disturbing the heart, lungs or liver. Two spreaders from 12 to 15 inches long should then be inserted to improve the appearance of the carcass. The first is inserted in the outer and upper part of the hind flank and then crosses the back diagonally, entering the opposite side nearly or quite as far forward as the chest. The second crosses the first 
at right angles. The spreaders have shoulders about an inch up from the pointed ends. The caul fat should then be fastened by means of two skewers at the thigh and point of the spreaders so as to cover all the meat not covered by the skin. As soon as the animal heat is given off each lamb is wrapped in two separate wrappers. The first may be of muslin or even plain tough paper. About a yard will be required for each lamb, and it should be drawn tightly to prevent soiling wher: handled. The outer covering may be of burlap or sackino.

The method followed by Mr. W. F. Fletcher, of the Summit Park Farm, Minneapolis, is in some respects simpler. It differs from the method given above, first, in skinning the head and in removing the same at the first joint; second, in removing also the heart, lungs and liver with the paunch and intestines; third, in using only short spreaders, which remain inside the lamb only until it cools; fourth, in not spreading the caul fat; and fifth, in shipping in boxes made of half-inch dressed pine. Each foreleg is tied back and the lamb is put. ncok downward into the box, which stands on end, the hind legs projecting upward through an opening made in the end piece of the box.

Improving the Quality.-In growing winter lambs, the kind of dams wanted cannot readily be obtained in the absence of Dorset blood. $\Lambda$ s soon, however, as the ewes thus furnished can be obtained in sufficient numbers, other rams, as for instance, the Shropshire ol Southdown, may be used in service. Lambs of somewhat better mutton form and superior quality would 
thus be obtained. For this purpose Southdown sires would probably be the best, owing to the perfect muttor: form which they possess and to the early age at which they may be fattened. But when cross-breds are thus grown all the lambs should be disposed of, as, to breed thus for successive generations, would tend to the production of lambs at too late a season of the year. 


\section{CHAPTER XVI.}

\section{Shearing Sheep.}

In years gone by; that is to say, in the age of the spinning wheel and hand. loom, the practice of fir'st washing sheep and then shearing them somervat late in the season was almost universal. Now the tendency is more and more to shear early in the season and without washing. But, as washing may in some instances still be necessary, the process of washing will be included in the discussion.

Time for Shearing.-When sheep are shorn without being washed, the fleece should be removed quite early in the season, but just how early will depend on the weather, the condition of the sheep, and the means of providing shelter for them. The more fleshy the sheep the earlier should they be shorn, because of the greater heat in the body. When shorn early they can be kert more comfortable in warm weather and in consequence thrive much better. If troubled with ticks, they will leave the old sheep as soon as they are shorn. And when sheep that are being fattened are not to be sold until after the advent of warm weather, early shearing is simply indispensable. Usually they may and ought to be shorn sometime in April. When shorn thus early is will be necessary to shelter them at night for a short time, and also in days cold enough to produce discomfort. 
If sheep are to be washed before being shorn they cannot be shorn early, at least in any considerable numbers, as the water, unless artificially heated, is so cold as to endanger the health of the parties who do the work and also of the sheep. When sheep are washed in streams, lakes or ponds, the work cannot well be done before the end of May, and in consequence the sheep suffer much from heat in warm days.

Shearing Twice a Year.-Under Minnesota conditions it will seldom be necessary to shear sheep twice $i$ year, notwithstanding that such a practice may be commendable in warm climates. But there are instances when it will doubtless prove profitable to shear lambs dropped very early on the arrival of settled warm weather. Nor does it seem probable that it will pay to shear sheep in the autumn that are to go into the feeding yards. In experiments made by the author in Ontario, the difference in the gains made by sheep shorn and not shorn in the autumn were insignificant. The mean winter temperature of Minnesota is considerably lower than that of Southern Ontario, hence the necessity for retaining the full fleece in winter in Minnesota would be greater than in Ontario.

Washing Sheep.-When sheep are to be washed, a place should be chosen in which the water is waist deep or nearly so, where the bottom is rock or gravel, and where the shore or shores are firm, clean and grassy. More or less of current to carry away the dirt expelled from the fleece is also very desirable. A small enclosure of rails, poles, or woven wire is then erected on the bank, and open on the side next the water. In this the 
sheep are enclosed. One person hands the sheep to the washers, and if they are also tagged before being washed, as they ought to be, the services of a second person will be necessary in the enclosure.

The washer leads the sheep into water beyond its depth. He can then turn it readily at will so that attention may be given to all parts of the fleece. When washing the dirt from a fleece the two hands with the fingers spread somewhat are brought down on the fleece more or less distant from one another, and the wool between them is pressed. The pressure thus given expels the dirt which produces discoloration in the water. When no further discoloration can be thus produced, the fleece is washed sufficiently. The sheep is then conveyed to the shore, and as soon as it has emerged from the water is held for a short time lest it should fall to the earth from the weight of water in the fleece. The flocis should then be kept in clean pastures for a week or even for a longer period to allow the yolk washed out of the fleece to be replaced by yolk which, in the interval exudes from the glands of the skin.

The more elaborate systems of washing by means of constructing dams and thus producing a waterfall wil! not be considered here, as these are probably a thing of: the past. The same may also be said about home washing in tanks and with artificially heated water.

Shearing Sheep.-Shearing until quite recently has from time immemorial been done by hand. Now much of it is done by the aid of sheep-shearing machines run by some kind of power. A small flock may be thus shorn by using hand power, treadmill power or power 
furnished by a windmill. When a large flock is to be shorn and several machines are to be used simultaneously power generated by some powerful agent as steam or clectricity is necessary. The adrantages claimed for shearing by the use of machines are greater dispatch in performing the work, making ferver cuts in the wool and carcass of the sheep, doing neater and tidier work and sccuring a considerably larger amount of wool per fleece. These claims are probably correct, unless it be the last. The first time that a sheep is shorn with a machine more wool will certainly be obtained than from hand shearing because of the more close clipping. The increased amount will vary from a few ounces to more than half : pound per fleece. It is greater in proportion as the flecec is dense and the carcass possessed of folds and wrinkles. But to the author it is not clear how there can be any increase in the wool obtained from the same animal after the first shearing with the clippers. The disadvantages from using machines are that the clipper: are more or less liable to get out of order, the shearing is too close for best results under all range conditions and the expense of the investment is too much when the flocks are quite small. Sometime, and it may be soon, .the machines may be so perfected that they will be used by all shepherds.

The process of hand shearing is by no means uniform. The most expert shearers shear with both hands simultaneously, but ordinarily one hand only is used. More commonly sheep are shorn on a floor, but some shearer:s use a table. Each shearer has his own method of worling, but more frequently the work is done somewhat as 
follows: The sheep is placed on its buttock with its back to the shearer, who places his left hand or arin around the head. The wool is then shorn from the brisket up the side of the neck and down to the shoulder. The other side of the head and neck are then shorn likewise dorvn to the shoulder. The fleece is then opened down the belly and clipped first on the left side down to the hips and as far as the back bone and then on the other side similarly. The sheep is then laid flat on one side and is held thus by the shearer placing the left foot over the neck of the sheep while he removes the wool from one side of the buttock. The sheep is then laid over on the other side and the wool removed similarly. The shears used should have a nice, easy working spring or the hand will soon tire in working them. Care must be taken not to cut too far at one stroke lest the shears cut too high at the points and so necessitate a second cut, which very much injures the wool for being manufactured.

Preparing the Fleece for Market.-The way in which the wool is put upon the market materially affects the price. Each fleece should be done up neatly, and in that fashion that will meet the demands of the market. Before rolling each fleece all tags with filth adhering to them should be removed, also loose straw and dirt of any kind. It may then be done up as follows: It is spread on a clean floor or table, the inside being downward. The two sides are folded in so as to overlap considerably. The wool at the tail and neck is also turned inward. The fleece is then firmly and neatly rolled and tied with two strings, each a short distance from the end. 


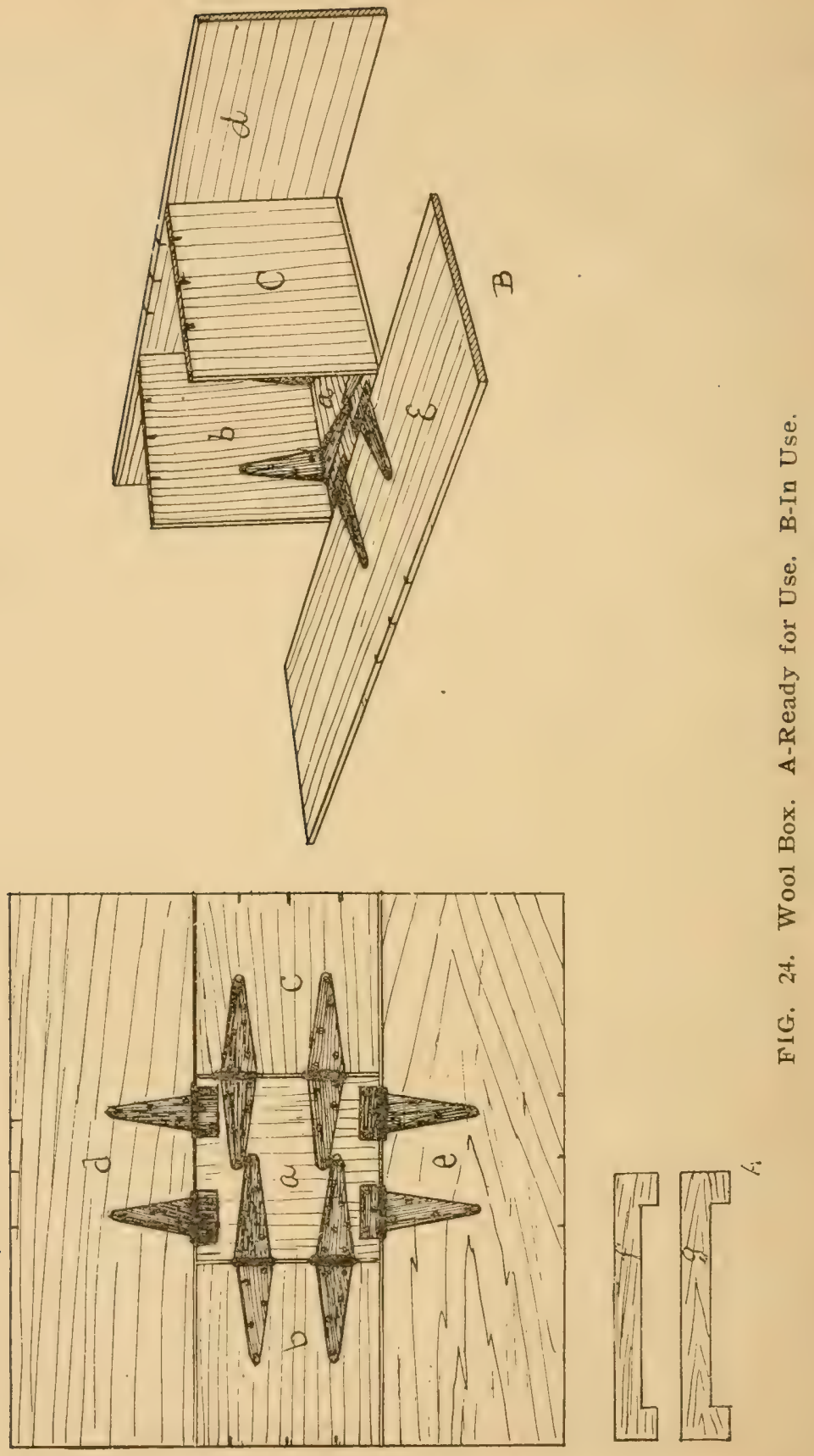


With some of the finer kinds of wool it may be necessary to use three strings each way.

The amount and character of the twine used are items of some importance. One string each way may answer for some kinds of wool, but two strings each way are better. Small hemp or linen twine should be used and of a size that will call for about one ounce of the twine to the fleece. What is now sold as No. 18 hemp twine is very suitable. It is said to furnish about 1,600 feet to the pound. With some the practice is common to tie with five strings each way, or even a larger number, and so coarse in character that the twine weighs from 3 to 4 ounces per fleece. The dealers very properly object to paying for cheap twine the same price as for wool. Moreover the hard fibres from coarse twine work more or less into the wool and injure the goods manufactured from it.

The Wool Box: When a large number of fleeces are to be tied annually the use of a wool box, if properly made, will aid materially in the dispatch with which wool may be tied, and also in giving added neatness to the fleece. The wool box shown in Figure 24 will serve well the needs of the average farmer who keeps a flock of sheep. It consists of five pieces or boards, three of which, viz.: $a, b$ and $c$, are each one foot square. The fourth and fifth pieces, viz.: $d$ and e, are each three feet long and one foot wide. The pieces $b$ and $c$, which are the two end pieces, are attached to a, the bottom piece, by strap hinges. As shown in the engraving these run across the grain of the wood in the bottom piece, to lessen the hazard of splitting the same. 
At the outer end of each end piece three notches are cut as shown in the engraving. They are made by sawing straight downward in the end of each piece to the depth of nearly an inch, and they should be only wide enough to hold the twine fast that is used in tying the wool. The pieces $d$ and e are the side pieces of the box when in place. They are attached to the bottom piece a, by T hinges. In the outer edge of each of these sides three notches are cut to receive the strings after the same manner as those cut in the ends. One should be in the centre of each board, and each one of the others at least three inches distant.

When using the wool box, place it on a block of wood or on a box considerably less in size than the wool box when lying open, and about three feet up from thr ground. It will be advantageous to screw the bottom down into the support to hold it firmly. Then sprear the fleece to be tied over the wool table with the outer side upward. Put the strings in place by inserting one end of each in the notches, stretching them over the boards and inserting them in the corresponding notches opposite. In preparing the string, wind the cord around a piece of board the same length as the wool table, and from end to end of the board. Then cut along both ends of the board with a sharp knife. The strings thus severed will be the right length. Next bring up the sides of the box $\mathrm{d}$ and e to the perpendicular, and put on one of the clamps $f$, not far from the end of the side pieces to keep them in place. Bring up the end pieces $b$ and e similarly and hold them in place with the clamp g. The strings are then tied. In some in- 
stances the wool box is placed nearer the ground, and the foot is used to press down the wool while it is being tied.

The wool is packed in large sacks for shipment. These are suspended filled with wool and sewed at the top. While being filled the wool is tramped down so that it lies compactly. The four corners of the sack are left so that they can be readily grasped by the hand. 


\section{CHAPTER XVII.}

\section{The More Common Diseases of Sheep.}

The diseases that affect sheep are probably less numerous and virulent than those which affect other classes of domestic animals. But when overtaken with disease the successful treatment of the same would seem to be relatively more difficult. This at least is the opinion of veterinarians who have studied the question. The explanation is found at least in part in the peculiar nature of the more common and fatal of the ailments that afflict sheep, since they are largely parasitical in character. The importance, therefore, of preventive measures in sheep husbandry cannot be overestimated.

In this chapter, the more common of the troubles and diseases that afflict sheep under Minnesota conditions will be discussed briefly. These include ticks, scab, tapeworm, stomach worm, grub in the head, goiter, ca. tarrh, bloat and various ailments that arise from constipation, more especially in the winter season. Some thing will also be said concerning ailments less common, though sometimes present.

Ticks.-The sheep tick (Mclophagus ovinus) is so well known that it is not necessary to describe it hers. It is nearly always present to some extent in every flock and at all seasons of the year. Sheep ticks produce much discomfort in a flock. They suck the blood and 
while doing so they irritate the animals. The irritation leads to rubbing, and the rubbing breaks the fleece, more or less, to its injury, and also leads to more or less of a loss in wool. The discomfort brought to the sheep also hinders their well doing to such an extent that they will not prosper if infested with ticks to any considerable extent.

Dipping is probably the best and the only satisfactory remedy for sheep ticks. The process is described in Chapter XVIII. For winter treatment parting the fleece in various places and dusting in sulphur or other insect powders has been recommended.

The liquid from steeped tobacco stems has also been applied by pouring it into spaces between the parted wool so as to saturate a considerable portion of the body underneath the wool. Such treatment, though more or less beneficial, is only partially effective. Sheep should be dipped twice a year for ticks, viz., in the spring and fall.

Ticks would seem to be always more or less present in a flock of sheep, but it should be possible to completely remove them as they live only a few days when removed from the sheep. In order to accomplish this it would probably be necessary to remove the flock from the surroundings recently frequented by them.

Scab.-Although there are three kinds of sheep scab in which the head, the feet and the body respectively are affected, only the last named would seem to have given trouble in Minnesota. Common scab (Psoroptes communis) causes greater loss to the sheep industry in the United States than any of the external parasites 
which prey upon them. Happily it is quite possible to destroy it, hence, sometime, it may be completely stamped out in this republic.

Common sheep scab is produced by minute insects, many of them too small to be seen without the aid of a microscope. Usually, however, if a tuft of wool is pulled out near the edge of the infested part, little moving objects may be noticed by the unaided eye near the base of the wool fibres or among the scales adhering to these. The mites irritate the skin by biting it, thus producing an inflammation which is accompanied by an intolerable itching. The inflammation is accompanied and followed by the formation of a layer of scabs, beneath which the animals live, but since they work outward they are more numerously found on the outer edges of the affected part, and since the rubbing of the sheep carries them to other parts of the body they are thus enabled to simultaneously carry on the work of torment in various centres on the same animal. The continuous unrest wears out the vital forces of the animal, and within a few months, if unrelieved, its death may follow. The mites work chiefly where the wool is longest, as on the back, -neck and flanks, and they work more actively in the autumn and winter when the wool is long than during the period immediately subsequent to shearing.

When sheep are continually rubbing, and when the wool becomes taggy and finally begins to drop off, the presence of scab is to be suspected. When once located, remedial measures cannot be applied too prumptly. The trouble is communicated by contact with the living 
mites. Such contact may be brought about by allowing sheep to graze on pastures which a short time previously had been grazed by infested animals, by allowing them to occupy corralls, yards or cars where the latter have recently been, or to follow them on the highway. More commonly it reaches farm flocks through the medium of sheep purchased in stockyard centers, and occasionally through the medium of stock rams conveyed as freight.

The remedy consists in dipping the sheep twice witl but a few days between the dippings, as described in Chapter XVIII, and in removing them from their old surroundings and pasture grounds as soon as dipped for a period of at least 20 days. The mites cannot live for more than 20 days apart from the sheep and ordinarily not more than 12 to 15 days. Dipping should be preceded by shearing when the weather conditions will admit of so doing. Such shearing will add to the effectiveness of the dip and to economy in its use. The first dipping should be followed by a second 8 to 10 days subsequently to destroy the mites that resisted the first dipping because the eggs that produced them had not been hatched. The second dipping should never be delayed beyond 14 days, lest the mites hatched subsequent to the first dipping should have in turn laid eggs. The eggs hatch in two or three days after they have been laid, and in 15 days the females are capable of depositing eggs. Though only a few animals in a flock should show pronounced symptoms of scab, the whole flock should be treated as it cannot be certainly known how far the infection has spread. And the fact should not 
be overlooked when introducing sheep from the stockyards, that one dipping is no certain guarantee that the animals are entirely free from scab mites.

Tape Worm.-Two species of tapeworm more or less infest the sheep of Minnesota in common with those of the United States. These are the fimbriate tape worm (Tarina fimbriata) and the broad tape worm (Tarina expansa.) The former, small in size, are found chiefly in the duodenum and gall ducts. The latter, 12 to 15 feet in length when matured, inhabit the intestines. The fimbriate species will not be further considered here as it would seem probable that nearly all the losses from tape worms which occur in Minnesota are cause $\bar{I}$ by the broad tape worm.

The life history of the broad tape worm, as also that of the other species named, is not fully known, and until it is the very best methods of dealing with it cannot be determined. It consists of a head and many segments. The segments shed off when mature and are voided from time to time, and in this way the pastures become sources of infection. It has been noticed that sheep which feed upon pastures low and damp are much more troubled by the disease than those that graze upori pastures that are more elevated. The disease is very much more fatal in lambs than in members of the flock that are older. The greatest fatality occurs in those under four or five months, and usually in the months of June and July, but it is sometimes fatal even in yearlings. It is thought that the embryos from the cast-off segments are taken up by the lambs when feeding on the pastures. They lodge in the intestines, and derelop 
rapidly in these, making a growth in some instances of a yard in a month. Several tape worms are frequently found in the one individual, but the number seldom exceeds half a dozen. They put in their baneful work by extracting nutriment for their own support from the intestinal contents, and by the irritation which their presence produces, inasmuch that food assimilation is seriously hindered. They also obstruct the intestinal canal by their great bulk.

The symptoms include an emaciated appearance, : pale and tight skin, dry and harsh wool and frequently in the later stages of the disease more or less of diarrhoea, accompanied by a slow and tottering gait. Death is caused by exhaustion. In the meantime the appetite may remain good, and in some instances it is abnormally so.

In dealing with the broad tape worm preventive measures are far more important than those that are remedial in character. These include the growth on the farm as far as practicable of all the sheep kept upon it, not allowing them to pasture on low grass pastures during the early months of grazing and confining them during these months to pastures that have been recently sown, as for instance, those from rye, mixed grains and rape, and what is even safer, feeding the flock on soiling foods in the yards until midsummer. Feeding an affected flock thus for one or two seasons would probably free it from this pest.

It cannot be said that the remedies prescribed even by the highest authorities have proved rery satisfactory. 'The aetheric oil of male fern is a favorite remedy. It 
is given in dram doses, along with 2 to 4 ounces of castor oil. And it is recommended to allow the animals to fast for several hours before administering the medicine.

Some respectable authorities claim that a decoction made from pumpkin seeds is an efficacious remedy. The seeds are first broken. They are then put into a pot and water is added. The water is brought to a boil and is subsequently kept simmering for 4 or 5 hours. Each lamb is then given the product thus obtained from one to three ounces of seed, according to its age and size, but not until it has first been fasted for 12 hours. If the decoction is too thick, dilute-it with water. Repeat the treatment every ten days until three or four treatments have been given:

When the labor and cost of remedial treatment is considered in conjunction with its incompleteness, and when the ill-effects of the stagnation in growth upon subsequent development are taken into the account, the vast superiority of preventive over remedial measures in relation to tape worm will be at once apparent. The gasoline treatment, however, may prove more satisfactory. (See page 184.)

The Stomach Worm.-The stomach worm (Strugglus Contortus) is a small-thread-like worm that finds conditions which seem congenial to its well being in the fourth stomach of sheep. During recent years this worm, sometimes called round stomach worm, has led to more serious loss in lambs than probably all other diseases combined. When mature it is about an inch long. If the stomach of an infected animal is exam- 
ined immediately after death, the worms may be seen with the naked eye, either floating about in its contents or adhering to the mucous membrane. They are then of a reddish color as they feed in part upon the blood of the animal. When present in large numbers the contents of the stomach resemble a constantly moving mass.

The symptoms of the trouble resemble so closely those caused by tape worms, that in the absence of a post mortem examination one cannot be easily assured of the cause of the trouble. The infested animals have a starved appearance. The skin becomes pale and the wool dry and harsh. Scouring is more or less frequent, and in some instances constant. But the best evidence is the presence of small worms which may sometimes be detected in the droppings. They are white in color when thus seen. The life history of the stomach worm is not yet fully known. It is certain that it is frequently found in older sheep, but does not usually seem to harm them to anything like the same extent that it does lambs. The older sheep and probably also infected. lambs drop the egg in the pastures. How long it can live in these is not known, but it is thought that it can so exist for months. It is probably taken directly into the stomach by the lambs when grazing. More commonly it injures them while yet sucking their mother's or soon after they have been weaned. It has also been noticed that lambs feeding on old pastures are more likely to suffer harm from stomach worms than lambs feeding upon fresh pastures. In this fact we have the clue to the best method of combating the trouble; that is to say, by preventative measures. 
The preventative measures are of a two-fold character. They consist, first, in grazing the ewes on pastr.res sown that same season, such as spring rye, mixerl grains, as oats and barley, rape, corn and sorghum; and second, in confining the lambs or both lambs and ewes to the sheds and yards until the weaning period, and feeding them on soiling food and adjuncts. It is not yet certain that either method will prevent losses from stomach worms, but the indications point in that direction. The lambs at the Minnesota station were serionsly harmed by stomach worms in 1898. It is supposed the eggs were picked up in a small grass paddock on which lambs brought in from the range bad been previously confined. The lambs of 1899 were confined in the yards until the weaning season, but the ewes were allowed to graze. They did exceedingly well. No evidences of stomach worms were present that year, no: have they appeared the present year, although the lambs are being grazed with their dams on freshly sown pastures in the same paddocks.

The best remedy heretofore tried is kuown as the benzine or gasoline treatment. The common gasoline used in household economics would seem to answer the puipose quite as well as the more expensive benzine. The dose commonly recommended is from one teaspoonful to one tablespoonful according to the age and size of the animal. For a dilutant use either flax tea of a thin consistency, or what is probably better, sweet skimmill. Four ounces of the dilutant and two teaspoonfuls or two drachms of gasoline, well shaken together, are sufficient for a lamb that weighs 50 pounds. A measuring glass; 
that is to say, a graduate such as may be obtained from any druggist, should be used to insure greater accuracy as to the dose given. The mixture is put into a sma!i glass bottle so strong that when well shaken it is not easily broken. It is given to the lamb, held on its buttock between the knees of the individual holding $i$, and with its back toward him. The head should not be held further back than the top line of the body, and great care should be taken to avoid stangulation while giving the medicine. Before treatment the lambs should be fasted for at least 12 hours, and also for a few hours subsequently.

It has been recommended to treat the lambs thus for two or three days in succession and once again a week later. But if lambs have to be treated thus often after they have been weakened by the presence of stomach worms, to the author at least it is evident, that the lambs will not be of much value that same season. Nor will farmers care to resort to measures so heroic. They would almost rather lose the lambs. It is to be hoped, therefore, that the plan so successfully tried recently and on a number of occasions by Dr. M. H. Revnolds, of the Minnesota experiment station, and Dr. Brimhali, of the state board of health, will prove equally successful in all cases. They have had excellent results from treating the whole flock, old and young, but once, and then giving them a change of pasture. They used doses of gasoline varying from 2 drams for a small lamb to $S$ drams for a large-sized mature sheep. The gasoline was put into a ressel containing the dilutant. The mixing was done by drawing the liquid into the syringe and 
ejecting it again, and a svringe was used in administering it. The medicine was gently forced from the syringe into the sack at the side of the mouth. If treatment can be thus simplified and at the same time prove efficacious, this mischievous disease will have been shoru of half of its terrors. It may further be mentioned that Drs. Reynolds and Brimhall have also obtained results from using the gasoline treatment in the manner described above for tape worm that were decidedly encouraging.

Grub in the Head.-This trouble has prevailed to a considerable extent in some parts of Minnesota. In a majority of instances it does not affect any considerable number of animals in one flock, but to this there are some exceptions. The grubs, minute at first, but over half an inch long when full grown, are deposited within the nostrils of sheep at some time during the occurrence of hot weather, by a certain species of the gad-fly (Oestrus ovis.) They crawl up into the sinuses adjacent to the brain and there develop slowly. The invaded parts become more or less inflamed, and this inflammation sometimes extends to the brain and leads to the death of the sheep. Fatal results more commonly occur toward the approach of spring. This species of the gad-fly, about two-fifths of an inch in length, is so swift in its morements when seeking a place to deposit its young, that it can seldom be seen. But when sheep crowd together in time of hot weather in some shady place and hold their heads quite close to the ground, the presence of the gad-fly may be suspected. When the fly lodges within the nostril the animal runs about and 
strikes the ground with its fore paws in its efforts to dislodge the intruder.

Grub in the head does not usually prove fatal, but in a considerable number of instances it does, more especially when several grubs are lodged in one animal. Its presence produces more or less discharge from one or both nostrils, at first clear and thin but later thick and mucous. There is usually more or less of coughing and sneezing. Later the affected animals walk with lowered head, lifting the feet high as they walk, but the movements of the head are various. The eyes become red, and watery, there is more or less grating of the teeth and ruming of frothy saliva from the mouth. The appetite wanes and the animal becomes stupid. Smyptoms so pronounced often end fatally within a week or two, but in some instances recovery follows, owing to the expulsion of the grubs:

Remedial measures for grub in the head have proved of so little value that they will not be considered here. Preventive measures may, however, do much to ward off this trouble. These are two-fold in character. First, the nostrils of the sheep are smeared occasionally with some offensive smelling substance, as fish oil, or equal parts of tar and fish oil. It should be applied with a brush and repeated every few days during the season of danger. Or, second, the sheep can be housed in darkened sheds during the heat of the day, as then only does the fly work. The whole period during which the fly may invade flocks in Minnesota is not certainly known, but it is thought that it covers at least the months of July and August. 
Goitre.-Goitre is more or less prevalent in Minnesota, and in some seasons causes considerable loss in lambs. When present the thyroid glands of the neck are more or less enlarged, and in some instances so as to form laroge swellings commonly spoken of as "lumps in the throat." It would seem to be fatal only in lambs, and usually at birth or within a short time thereafter. Sometimes the lambs are dead at birth. At other times they are so low in vitality that they die within a few hours. In yet other instances the swelling gradually grows less and finally disappears, but not infrequently it remains, though relatively reduced in size.

The cause or causes which lead to the trouble are not certainly known. It has been claimed that it is influenced by the character of the water drank or by the pastures grazed, but neither claim has been satisfactorily established. Others contend that any influence that will lower the vitality of the dams, especially when pregnant, favor's goitre. Among these influences are close confinement, foul air, poor food and lack of exercise. The most potent of these would seem to be lack of exercise, as it has been noticed that ewes of a sluggish disposition are more apt to produce goitred lambs than those of the opposite temperament. It is also thought that goitre is to some extent hereditary.

When goitre occurs, treatment would seem to be of little avail. Sometimes, however, iodine has been applied to the swelling with apparent benefit. Until more is known regarding the causes of the trouble preventive measures can only be adopted in a tentative way. The sheep should be kept under good sanitary conditions. 
It would seem to be especially important that they are encouraged to take exercise, particularly in winters of deep snowfall, and, as far as possible, breeding from affected animals should be avoided.

Catarrh.-Catarrh is caused by exposure to storms wet and cold, or to dranghts when the sheep are at rest in the sheds. Warm housing, followed by or alternating with sudden exposure, is also a frequent cause of catarrh. Proninent among the symptoms are discharges at the nostrils and a watery inflamed and slightly sunken condition of the eyes. The discharge from the nostrils is at first thin and watery, and later thick and of $a$ yellowish color and in some degree offensive.

Nasal catarrh is not accompanied by a cough. Treatment by giving medicines, unless for the purpose of toning up the system, is of little avail. The animals which suffer from the ailment must first be protected from the causes which produced it. They should then be given liberal food supplies to tone up and to build up the system. When catarrh is chronic and obstinate, the affected animals should be culled out and sent to the block, unless when there are special reasons for keeping them longer, as in the case of very valuable breeding animals. Bloat.-Bloat is simply undue distension of the first stomach. It is caused by the generation of gas consequent upon taking hurriedly into the stomach large? quantities of certain kinds of green food by animals that are hungry. Prominent among the foods that are most dangerous when thus taken into the stomach are, alfalfa, clover and rape. But certain kinds of weeds may also produce bloat when eaten g'reedily by hungr: 
sheep. The danger is always greater when the pastures are wet by dew or rain, and when they are in the most succulent condition.

Preventive measures are both simple and effective. They consist first, in not allowing sheep to graze on pastures that are likely to produce bloat when the stomach is empty, and more especially when the pastures are wet, and second, in cutting and feeding such food after it has wilted more or less.

When bloat occurs, treatment, to be of any avail, must be prompt and decisive. The gas generated will sometimes cause death from suffocation in a very few minutes. When such danger is imminent, the paunch should be at once punctured. The best instrument for removing the gas is the trocar, which is used to puncture the paunch, and provide an avenue for the escape of the gas. Every sheep owner should have one of these instruments. They may be obtained at certain hardware houses and drug stores. In their absence, puncture with a clean, long-bladed penknife, and insert a large goose quill for the escape of the gas. If the gas should cease to escape, the contents of the paunch should be pushed down by a knitting needle or something else that will answer by pushing it down inside of the quill. Puncture in the barrel depression, midway between th: last rib and the hip, and about three inches below the backbone. Point the instrument slightly inward.

A round piece of wood, as for instance, a piece of a limb, may bring relief, if held like a bit far back into the mouth. It may be thus held by tying a string to each end at the sides of the mouth and then tying both string: at the back of the head of the sheep. 
If the breathing of the affected animal is not too labored, give 1 ounce doses of hyposulhphite of soda dissolved in one pint of water every half hour until the bloating subsides. This treatment may answer in certain instances without using the trocar or knife, but it should also follow the use of the trocar to check fermentation and to neutralize the poisonous effects of the gas generated. In treating this trouble, great despatch and promptness must be shown.

Digestive Troubles.-Digestive troubles arising from food too dry and woody in the winter season, occur not infrequently. The most common of these is inpaction of the food in the third stomach. It is the forerunner and companion of constipation, and in some instances it leads to inflammation of the bowels. This constipated condition of the bowels is responsible for much of the debility, poverty and general ill-doing that too frequently characterize flocks in winter. When the vitality of the sheep is thus weakened it becomes much more susceptible to various ailments than it would otherwise be, as for instance, catarrhal and kidney ailments. When impaction occurs it may be relieved by giving epsom salts. The dose for a mature animal of, say 150 pounds, is from 4 to 6 ounces, dissolved in a pint of hot water. If not relieved within 10 hours, the dose should be repeated. But any tendency to constipation should be warded off by feeding daily some such laxative food as field roots, wheat, bran, oilcake or flax, along with the dry food. So important is it to feed more or less food of this nature to sheep in the winter, that the attempt to carry them through that season, without more or less oi it, is of doubtful propriety. 
Ailments Less Prevalent.- - Some ailments that are less prevalent, though sometimes present will now be discuss$\epsilon$. They include foot rot, gid, lung worms, nodular disease and spear grass tumors.

Foot Rot, in that form sometimes spoken of as foul in the foot, is not really prevalent in Minnesota or indeed in the Northwest, but it sometimes occurs. When it does appear it is usually caused by conining the animals to quarters either within or without that are unclean. In the contagious form it is very seldom if ever found, except when infected animals have been brought in from abroad. Though not apparently hereditary, some breeds, especially the larger ones, are more subject to it than those of a less size. It occurs more frequently among sheep that have been brought from dry pastures to those opposite in character, owing to changes of structural development, in the hoof, brought about by changed conditions.

In the earlier stages of the disease it is not easy to distinguish between the two forms of foot rot under discussion. In contagious fot rot, swelling and inflammation above the horn and particularly between the claws are among the first symptoms, whereas the other form is essentially a disease of the horn. In contagious foot rot, as also the non-contagious form, the horn of the hoof becomes soft. Later it disintegrates and falls array piecemeal. Ulcers are formed on the exposed parts and the discharge from these has a most offensive odor. In severe cases much of the hoof is shed. The accompanying lameness is, of course, proportionate to the disease. When the forefeet are badly affected the sheep feed upon their knees. 
As soon as any indications of the disease appear, action should be prompt. 'The excessive horn should be cut away and any filth as dirt or offensive matter removed. The affected parts should then have creolin applied every other day until healing is properly started. When a large number are to be treated they should be driven through a shallow vat or trough containing a misture of creolin, soft soap and water, in the proportions of 1,1 and 10 parts respectively, and covering the bottom of the vat to the depth of not less than one inch. The treatment is essentially the same for both forms of foot rot discussed above.

Gid (Coenurus cerebralis) is a parasitic trouble which happily has not been markedly prevalent in Minnesota. The egg which produces the trouble may come from dogs, wolves, coyotes or foxes. The sheep may take these up in the pastures or when drinking. When hatched in the stomach they are in a few instances carried to the brain through the circulatory system and there they develop. Sheep thus affected hold the head in a peculiar position, as up or down, but oftener to one side. 'They walk betimes in a circle, act stupidly, stagger and have convulsions. In nearly all instances the affected animals die not many days subsequently to the first appearance of pronounced symptoms. About all that can be done by the flock-master is to keep dogs away from the flock as far as this may be practicable, and to burn or bury the heads of animals that may have died from the effects of the trouble.

Lung Worms.--Lung worms in the United States are of two species. These are the hair lung worm (Stron- 
gylus ovis pulmonalis) and the thread lung worm (Strongylus filuria.) 'The hair lung worms are very small, and they penetrate the air passages of the lung; to their endings. The thread lung worms are much larger and they inhabit the bronchial tubes. The eggs, or the worms themselves, at some stage of development, are taken up by sheep and also by lambs in the pastures or in water, and in some way find their way into the lungs. The symptoms are somewhat similar in the two forms of this trouble. They include more or less difficulty in breathing. A dry and pale skin, harsh wool, and in the later stages especially, a deep cough. N'asal discharge also is then copious, when the thread lung: worm is present. It is much less common than the hair lung worm. Both are frequently found in the same animal. Happily neither species has given much trouble in Minnesota. For the hair lung worm, treatment has availed but little.

For the thread lung worm fumigation with certain substances and tracheal injections have been found helpful, but it cannot be said that they have proved satisfactory. Where either trouble has appeared, much care should be given to renewing the pastures frequently and to providing the flocks with pure water.

Nodular Disease.-This trouble, which would see!n to be American in its origin, is caused by a worm, which, in the adult form inhabits the large intestines. Its complete life history is not yet known. The adult worms are so small and adhere so closely to the intestines of infected animals, that they are not readily seen by the naked eye. Its presence leads to the formation 
of small, lumpy substances known as nodules, and it works the greatest barm to sheep in the winter and spring. The nodules are scattered along the digestive tract from the stomach to the anus. Each nodule contains a green-colored cheesy mass, and in it is imbedderl a worm. Later these work out of the nodule into the - intestine, after which mature eggs are laid and reach the pastures in the excrement.

This trouble does not as yet seem to have worked great harm in the Northwest, although it is present to some extent. It is only when a large number of nodules are formed that the consequences can be called serious. In some of the eastern states flocks have betimes suffered severely from it. The symptoms are somewhat obscure. Sometimes diarrhoea is present and at other times constipation. The appetite is frequently increased, since nutrition is withheld in proportion as the worms are numerous and active in the intestines. When the disease proves fatal, dropsical swellings frequently appear in the region of the throat and lower jaw in its later stages.

Owing to the comparatively recent discovery of the disease and to the difficulty of reaching :- with medicines, treatment has proved of but little avail. Frequent chariges in pasture would seem to be the most effective means of preventing its spread.

Spear Grass Tumors are swellings that may rise on various parts of the animal because of the penetration of the skin and flesh by the small spines or needles produced by what is popularly known as spear grass or needle grass. The correct name is porcupine grass (stipa spar- 
tea) and it is probably distributed over nearly all the native pastures of the Northwest. The small pointed needles formed on the grass in the advanced stages of its growth lodge in the wool and eventually penetrate the skin. This result is hastened by the motion of the fleece and also by the twisting and untwisting of the spiral awns attached to the needles under the influence of changing conditions as to moisture. Their presence causes swellings and in these swellings pus is formed in some instances, hence running sores are frequently the final outcome.

Treatment will not be necessary where preventative measures are given due attention. If both sheep and lambs are shorn before the maturing of the needles in the pastures, they will give but little trouble. The time of such maturity will vary with the season, but in Minnesota the needles do not fall earlier than probably toward the end of June. Happily they fall within a week or two and then it is that the sheep should if possible be kept off pastures thus infested. The presence of this grass can easily be detected since it grows up above the other grasses of the prairie and comes out in head late in May or early in June. It is usuallyscattered but thinly over the prairie and each plant has but few stems. The needles borne on the end of the seed-heads are somewhat less than an inch long and are very stiff and sharp. There is attached to them a spiral awn from say 3 to 6 inches in length. Close pasturing in the early spring will soon destroy this grass, and as the land is cultivated it disappears. 


\section{CHAPTER XVIII.}

\section{Dipping Sheep.}

Sheep are dipped chiefly with a view to rid them of insect pests as ticks and the scab mite. When, however, the proper dips are used it is now pretty generally conceded that they influence favorably the action of the glands concerned in wool production, because of the cleansing influence which they have upon the skin. Judicious dipping, therefore, should increase the growth of the wool and also improve its quality.

How Often to Dip.-Nearly all authorities on sheep are agreed that they should be dipped twice a year, viz., in the spring and also in the fall. But so many dippings are not considered as necessary with the fincwooled breeds, since ticks apparently do not multipl! so rapidly in these. In the spring the dipping should be done a few days subsequently to the shearing of the flock, and a warm day should be chosen for it, as the sheep have at that time no covering to protect them. In the autumn they should be dipped a short time before being brought into winter quarters and while the weather is yet fine. Sheep young and strong, however, may be dipped in case of necessity when the weather is cold, even when the thermometer is hovering about zero. But when thus dipped the sheds in which they remain while drying ought to be comfortable. It is probably possible to remove ticks altogether by dipping, but this is a feat 
that seems to have been accomplished in very few instances. Its realization would probably necessitate ${ }^{+}$wo dippings at a time instead of one, with an intervas of from one to two weeks between them. It would also necessitate treating sheep similarly brought onto the farm from without. If a flock were thus completely rid of ticks further dipping would not seem to be an absolute necessity.

To remove scab from a flock two dippings in succession are necessary, the first to destroy the mites that cause the trouble and the second to destroy the mites that come from the nits which hatch out subsequently to the first dipping. The second dipping should take place from $\&$ to 10 days subsequently to the first.

Freedom from insect pests and well doing in the flock are intimately associated. A flock infested with ticks cannot prosper as it otherwise would and when badly infested it will be difficult to maintain it in a good condition of flesh. Provision, therefore, should be made for dipping sheep on every farm on which they are kept.

Various Dips Used.-The various dips used may be divided into two classes, viz., proprietary and homemade dips. The formula for making proprietary dips is in nearly all instances secret. Many of the dips of both classes have for their basis such ingredients as tobacco, tobacco and sulphur, arsenic and carbolic acid. One of the oldest of the home-made dips has for its basis lime and sulphur.

Whether the preference should be given to the proprietary or home-made dips will depend largely on the number of animals to be dipped. Where only a small flock 
is to be thus treated there would probably be economy in using some of the prepared dips, but where the flock is large the same would probably be true of the home-made dips.

The advantage from using the proprietary dips consists in their being at all times ready for use, so that no time is consumed in that way. The disadvantages from using them include their greater relative cost, and in some instances the uncertainty as to their efficacy.

A majority of the proprietary dips have proved effective when the directions for using them have been exactly observed. And here it may be observed that it is important when using those dips to adhere closely to the directions given. The same may indeed be said of all dips and more especially of those which contain ingredients more or less poisonous. To have them do their work properly and at the same time without hazard to the sheep or to the men dipping them they should be of a certain strength. To single out any of the preparatery dips as being superior to the others would be invidious and would probably be attended with the hazard of doing injustice to some at least of the makers of those dips. But it may be mentioned that Chloro-naptholeum and Zenoleum have met with much favor in the Northwest as also some of the tobacco dips.

Prominent among the home-made dips are those known as lime and sulphur, tobacco, tobacco and sulphur, arsenical and carbolic.

The formula given for making the lime and sulphru. dip by Dr. E. Salmon, chief of the Bureau of Animal Industry, is substantially as follows: Take 8 to 11 
pounds of unslaked lime and add enough water to slake the lime and to form what is termed "lime paste." sift into this three times as many pounds of flowers of sulphur as there were pounds of lime at the outset. Place the mixture in a kettle or boiler and boil from two to three hours, adding water when necessary. Pour the mixture into a tub, vat or barrel as, for instance, a kerosene barrel. Insert a spigot from 3 to 4 inches up from the bottom of the barrel that the liquid may be drawn off without sediment. When put into the dipping vat add enough warm water to make 100 gallons of the mixture.

The objection has been made to this dip that it injures the wool, making it dry and harsh in consequence of the caustic action of the lime. The wool buyers often discriminate against such wool, as much as 2 to 3 cents per pound in the price paid. It has the merit, however, of cheapness and efficacy and when used shortly after sheep have been shorn the objection does not apply. But it may be that this dip is slightly prejudicial to the healthy action of the pores of the skin. This has been both claimed and denied. It is greatly important when using this dip to keep the sediment out of the mixture.

Tobacco dip may be made as follows: Take 21 pounds of prepared tobacco leaves and soak them in water in a covered vessel for 24 hours. Then bring the water almost to the boiling point. Remove the vessel from the fire and allow the liquid to draw for at least one hour. Next strain the liquid pressing the leaves at the same time to extract as much as possible of 
the nicotine and add enough water to make 100 gallons of the dip.

The tobacco dip is comparatively cheap, and it is probable that it may be further cheapened by using the tobacco stems rejected by those who manufacture this product. But the amount used would pretty certainly have to be increased in order to produce the desired effect. This dip has the further merit of improving the quality of the wool, as it makes it more soft and pliable. It should, however, be used soon after it has been made as the organic matter which it contains will decompose readily.

The formula for preparing the tobacco and sulphui dip as authorized by the officials of New South Wales having such work in charge is substantially as follows: Use 1 pound of good leaf or manufactured tobacco and 1 pound flowers of sulphur in making every 6 gallons of the dip when ready for use. Steep the tobacco in water in a covered vessel for 24 hours. The evening before using the dip bring the liquid thus obtained almost to the point of boiling. Remove from the fire and allow to stand until morning. Mix the sulphur in water so that the mixture wili sy of the consistency of gruel. Strain off the infusion: and press the tobacen leaves while doing so. Mix the liquid thus obtainerl with the sulphur gruel and add water until the dip thrs obtained amounts to 6 gallons.

The tobacco and sulphur dip is thought to be one of the best made. It has rendered excellent service to the flocks of New South Wales and other Australian colonies. It ought, of course, to be used warm. 


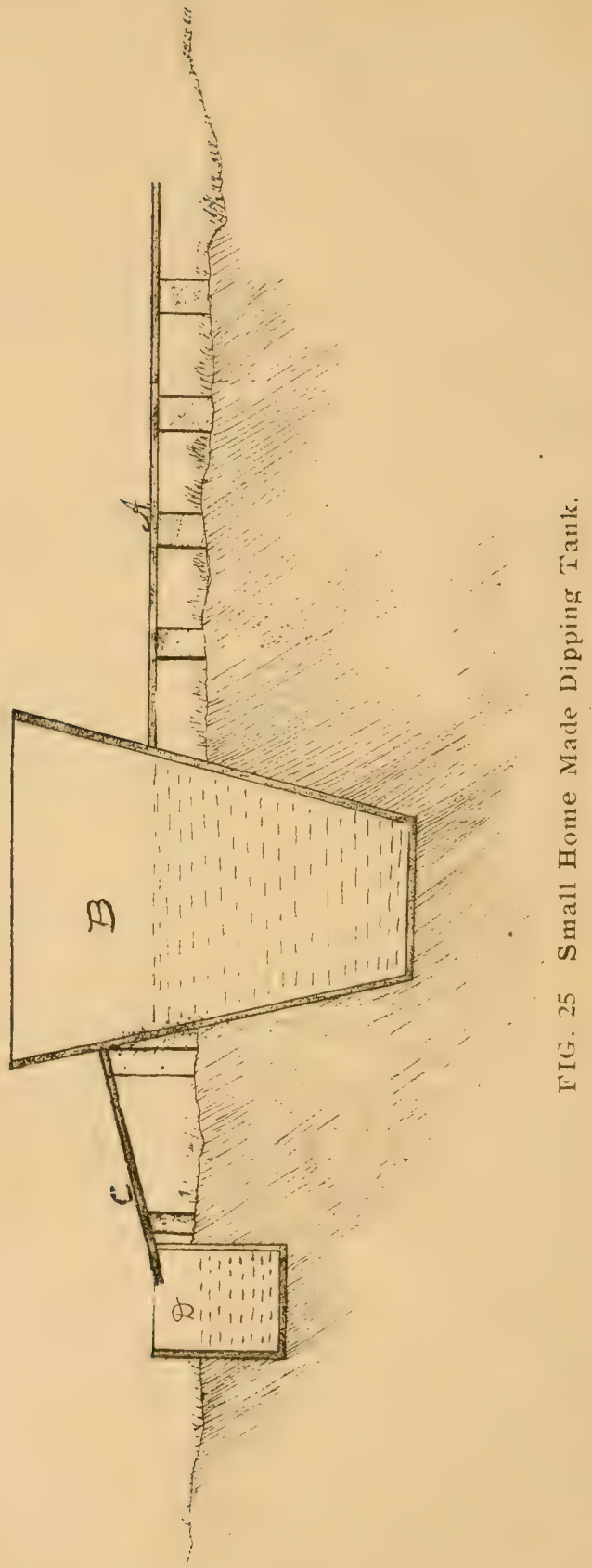

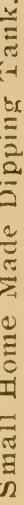


The arsenical and carbolic dips kill ticks and scab mites readily, but owing to their poisonous nature they have to be used with great caution. Since the dips previously described are not thus dangerous or only slightly so the formula for the arsenical and carbolic dips will not be given here.

Dipping Vats and Dipping.-The nature of the dipping vat or tank to be used should be largely determined by the size of the flock. For a small flock such as is kept on the average farm a steel tank will answer the purpose sufficiently well. Several makes of these have been put upon the markets during recent years by reputable firms. Home-made dipping tanks will probably cost less at first, but they are not likely to last so long ts a steel tank properly cared for.

Figure 25 represents a home-made tank cheap in construction, economical in the use of dip and convenient for those who may do the work. It is given by Stewart in "The Domestic Sheep." A represents a platform of boards nailed onto $2 \times 4$ inch scantlings. This platform may be of the same length as the tank or a little shorter and it may extend out, say 36 inches from the tank. The tank B is 48 inches long, 30 inches deep, 24 inches wide at the top and 10 inches at the bottom. It is sunk into the ground to about half its depth. The frame may consist of $2 \times 4$ inch scantling and the lining of $1 \frac{1}{4}$ inch flooring tongued and grooved and pitched at the joints. C ropresents a sloping platform which drains into another tank D. This tank should be considerably shorter than the dipping tank to facilitate the colecting of the ooze which is returned from time to 


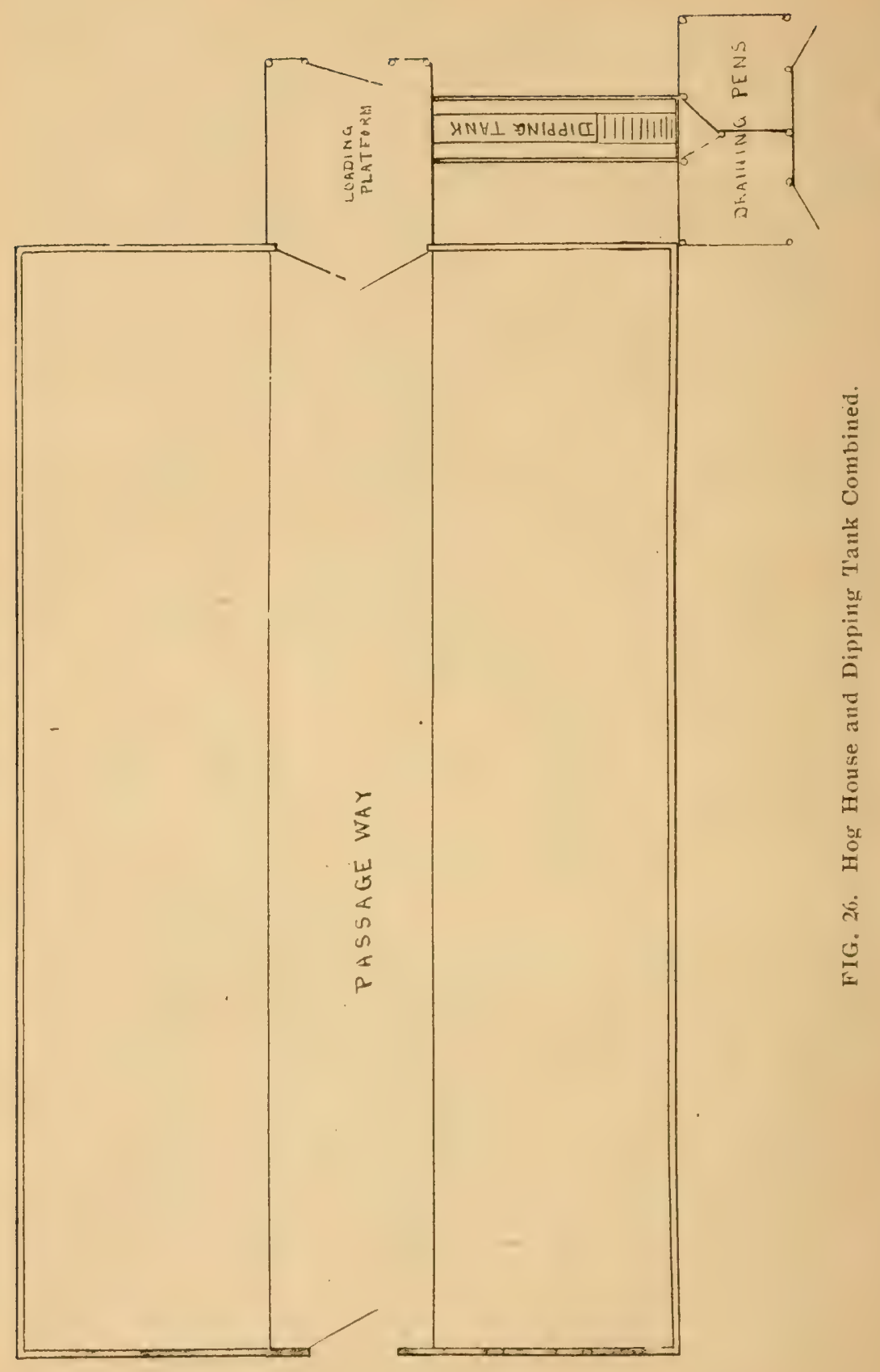


time as the dip drains from the sheep. When using this tank a sheep is caught and laid on platform A. It is then grasped by the fore and hind legs respectively by two persons, one at each end of the platform, and lifted into the tank back downward, where it is held for the requisite time. It is then lifted out onto the draining platform and held there long enough to allow the dip to drain from it. The process may be hastened by the holders of the sheep moving one hand first over one side of the animal and then over the other.

When a larger flock is to be dipped the plan follower by George Harding and son, of Waukesha, Wis., is a model of convenience. The accompanying sketch in Figure 26 will aid the description now submitted. The dipping tank is at the end of the hog house, which is built on sloping ground so that at the end where the tank is, a platform could be made to aid in loading young cattle, sheep and swine into a wagon for shipment. The platform extends out 6 feet from the building and is about $2 \frac{1}{2}$ feet from the ground. The passage way inside the piggery is 40 feet long and 6 feet wide and holds about 40 sheep at one time, according to size and breed. The rear side of the loading platform is enclosed by the door of the passage way which opens outward and which is as wide as the passage. But swaller doors may be used as shown in the engraving, and the rear side of the platform enclosed by a permanent fence. The end of the loading platform may have \& gate to swing inward or it may be temporarily enclosed.

The tank itself is 9 feet long inside at the top and 6 
feet at the bottom. The end next the platform is perpendicular, and the opposite end slants upvard at an angle of about 40 degrees and has slats on it to enable the sheep to climb up into the draining yards. The depth is 3 feet 8 inches and the top of the tank is nearly on a level with the platform. The width at the top is 2 feet and at the bottom 1 foot, inside measurements being used.

The tank is made by setting up 5 pairs of $2 \times 4$ inch scantlings connected at the bottom with $2 \times 4$ inch pieces set on edge. It is sheeted on the inside with two thicknesses of match flooring and the flooring is well coatea with paint. The draining pen or platform is $12 \times 6$ feet.

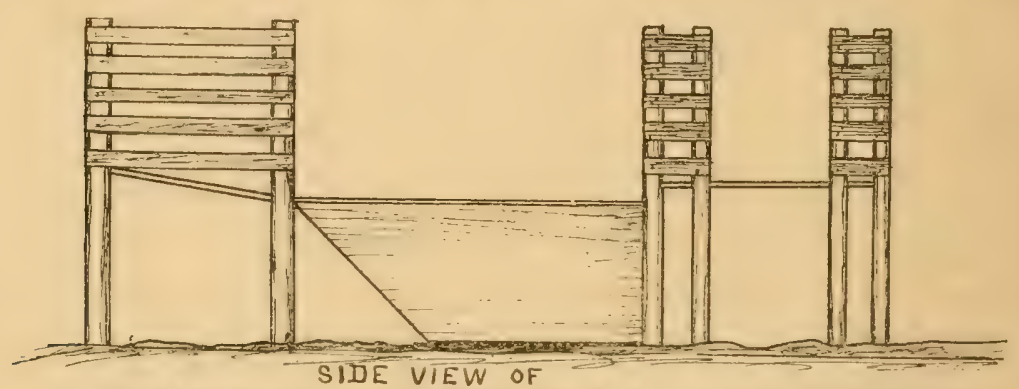

DRAINING PENS, DIPPING TANK \& LOADING PLATFORM

FIG. 27 .

It is divided by a partition in the center and each division will hold 8 sheep at one time. The floor of the two divisions thus formed slants a little torvard this partition and under it is a depression leading into the tank, so that the drip or ooze from the fleeces runs back into the same. The floor of the platform is covered with tin formerly used for roofing. A gate is hinged at the end of the partition next to the tank which swings botlı ways. The sheep are thus kept draining in one divis- 
iu. of the yard while the other is being filled. The yard is protected by a three-board fence running around it and each division has a gate for the exit of the sheep when the dip has drained from them.

One man puts the sheep into the tank. Two men tend them while in the tank, one on the outside and the other in the space between the tank and the piggery. A boy tends the gate to let the drained-off sheep out of the yards. In this way all are kept comfortably busy. One hundred sheep may thus be dipped in one hour when all things have been made ready.

The dip is mixed with hot water in pails before it is put into the tank. And the water in the tank is also made warm to add to the effectiveness of the dip.

The water is heated in a kettle used for cooking food in the piggery. The piggery has eve troughs and these fill the tank after it has been cleaned out subsequent to each dipping. The water thus collected in part sup. plies the piggery.

A tank may be similarly constructed apart from is building, but in that case a yard would have to be made in lieu of the passage way in the piggery from which the sheep would be taken into the tank. 
Page

Age at which to breed ewes.......................

Ailments less prevalent ........................190

Alfalfa for hay ......................... 71

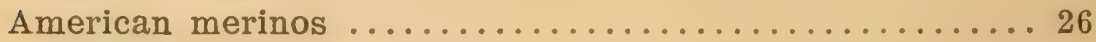

Arsenical and carbolic dips .....................201

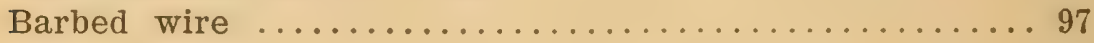

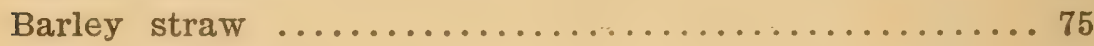

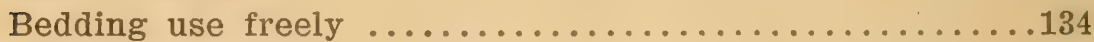

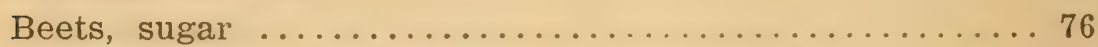

Benefits, from sheep husbandry.............. 9

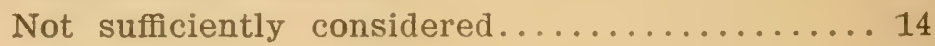

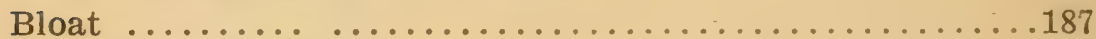

Danger from .......................... 68

Breeds adapted to Minnesota conditions ........... 23

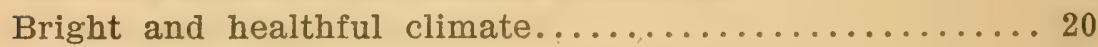

Bromus Inermis . ......................... 72

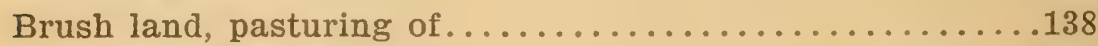

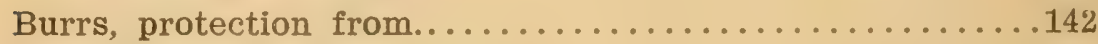

Cabbage, for pasture ...................... 61

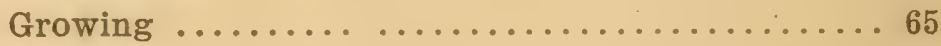

Grazing ........................... 68

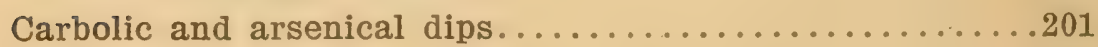

Carrots .............................. 76

Castrating and docking ........................ 110

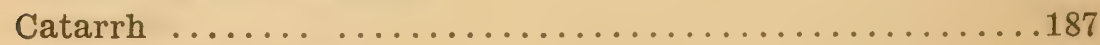

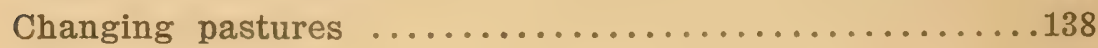

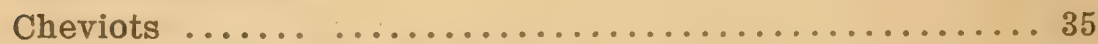

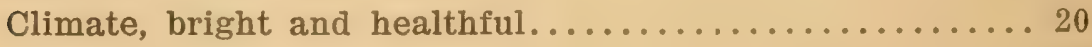

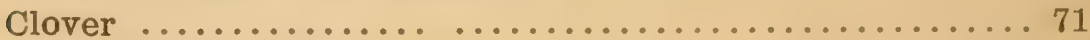

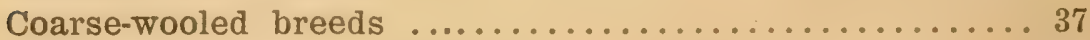

Corn, for fodder.......................... 74

For stover ......................... 74

Growing .......................... 61 
Grazing

Corralling at night

Cotswolds

Cross breeding

Crossing, zigzag

Delaine merinos

Digestive troubles

Dip, how often to.

1)ips used

ilpping vats

Dribases of sheep

shesiroying weeds

bycking and castrating lambs..................110

Dorsets

Drafts, freedom from

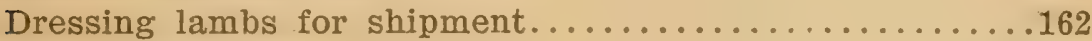

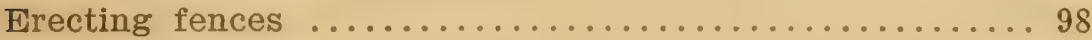

Ewes, management of $\ldots \ldots \ldots \ldots \ldots \ldots \ldots \ldots \ldots \ldots \ldots \ldots$

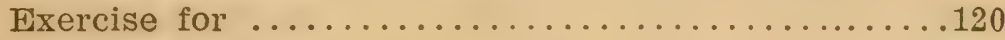

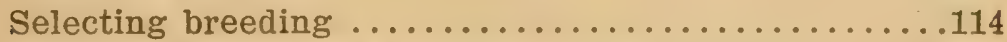

Management of, till mating season...........114

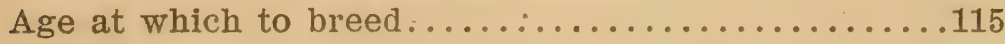

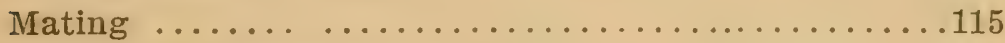

Going into winter quarters................... 117

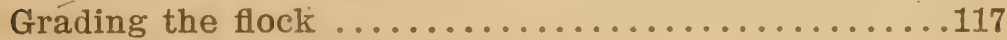

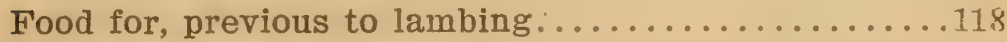

In the lambing season.....................

Food for, subsequent to lambing............. 120

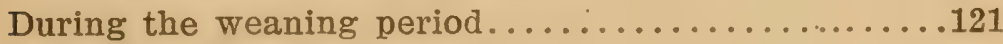

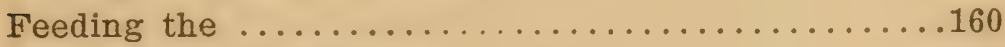

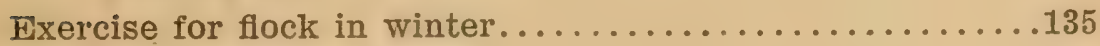

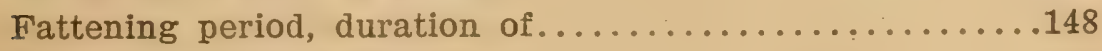

Fattening sheep and lambs.........................

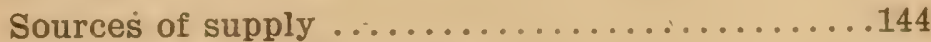

The class of sheep to fatten............... 145

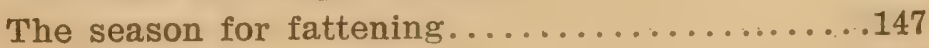

Foods used in ....................... 149

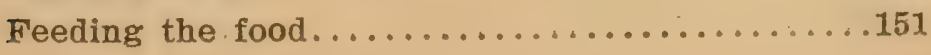




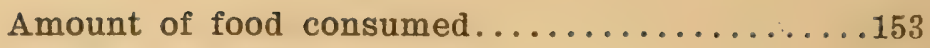

Increase in weight $\ldots \ldots \ldots \ldots \ldots \ldots \ldots \ldots \ldots \ldots \ldots$

Feeders, two classes of......................... 145

Feeding young lambs ............................ 109

Feeding ewes with winter lambs................. 160

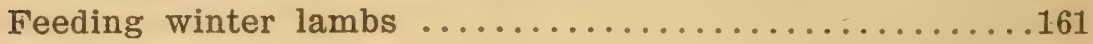

Fencing, amount of $\ldots \ldots \ldots \ldots \ldots \ldots \ldots \ldots \ldots \ldots \ldots$

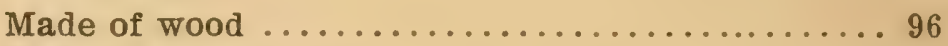

Made of smooth wire................ 96

Made of barbed wire.................. 97

Made of woven wire................. 97

Made of woven pickets................... 98

Posts for ......................... 98

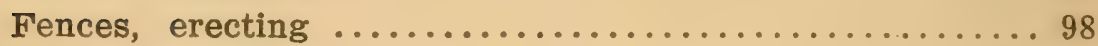

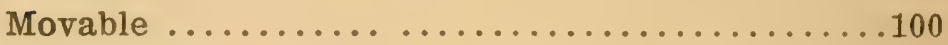

Fertility, maintenance of $\ldots \ldots \ldots \ldots \ldots \ldots \ldots \ldots \ldots \ldots \ldots$

Field roots, varieties of.................. 76

Fine-wonled breeds ............................ 25

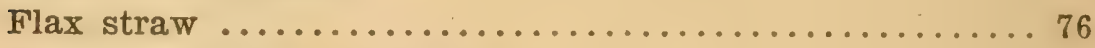

Fleece, preparing for market................... 169

Fleece and form, leading essentials of.......... 50

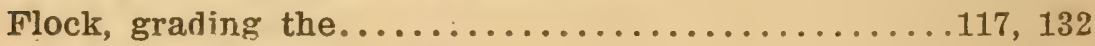

Fodder and grain in winter...........................

Fodders for sheep, requisites in.............. 70

Food, used in fattening .........................

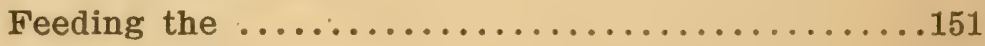

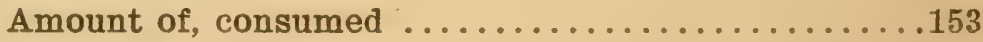

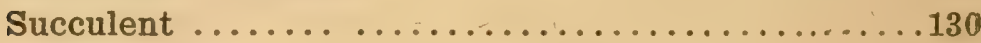

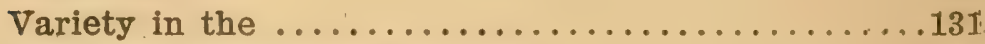

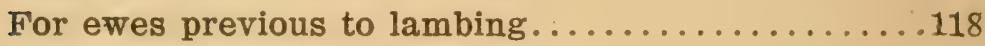

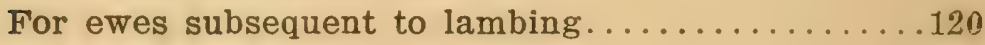

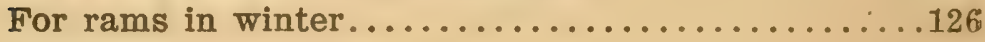

Varied production of $\ldots \ldots \ldots \ldots \ldots \ldots \ldots \ldots \ldots$

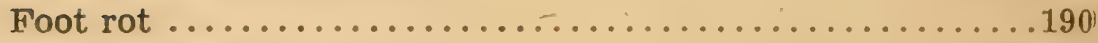

Gid (Coenurus cerebralis) ......................191

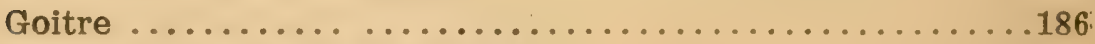

Grades, establishing a flock of............... 43

Grading the flock ..................... 117 and 


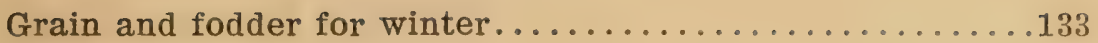

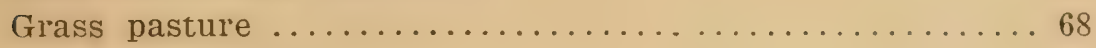

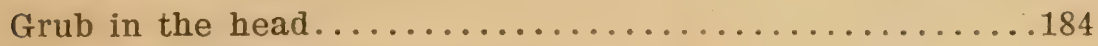

Grazing supplemental pastures............... 66

Growing supplemental pastures............... 61

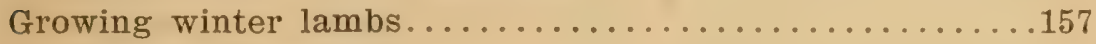

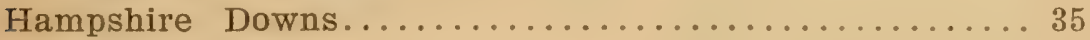

Hay, varieties of.......................... 71

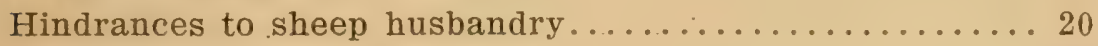

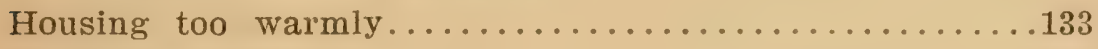

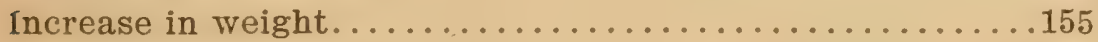

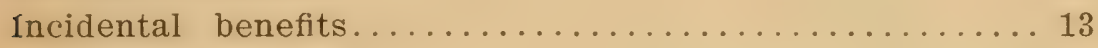

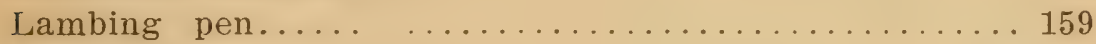

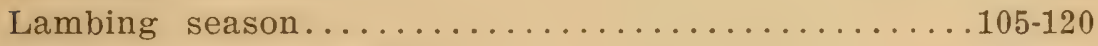

Lambs, care of newly born.................... 106

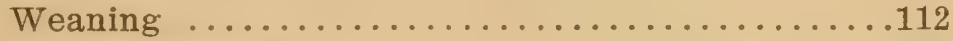

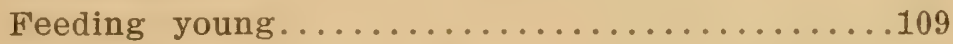

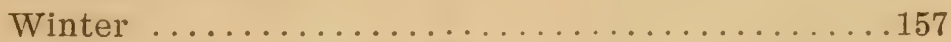

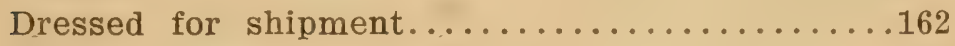

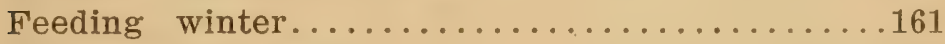

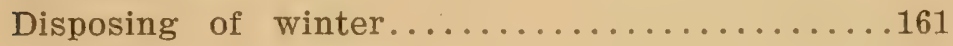

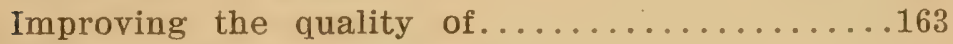

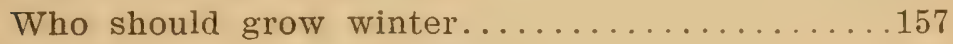

Foundation stocks of winter............... 157

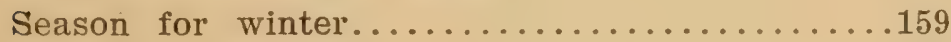

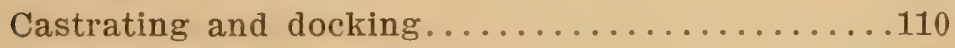

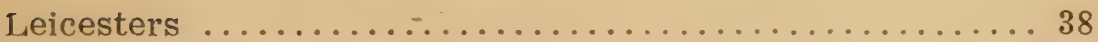

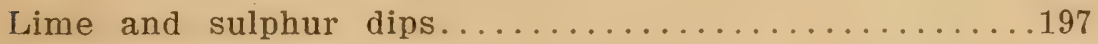

Lincolns . . . . . . . . . . . . . . . . . . . . 38

Lumber, sheds built of ................. 80

Lung worms ............................... 191

Maintaining fertility . . . . . . . . . . . . . . 12

Males, select, from one breed.............. 45

Management of ewes till mating season..............114

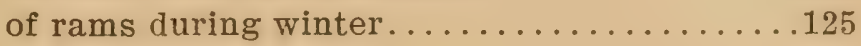

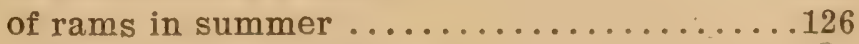

of rams at mating season............127

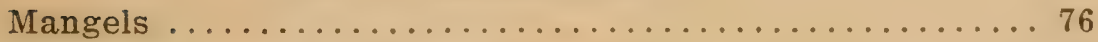

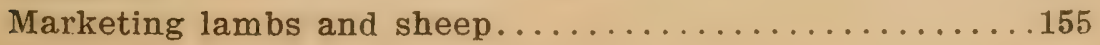




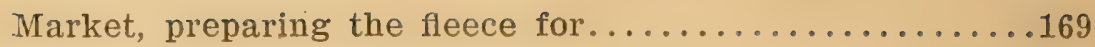

Materials for shelter........................ 19

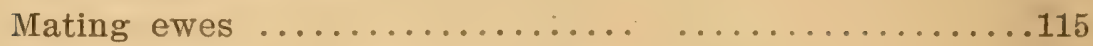

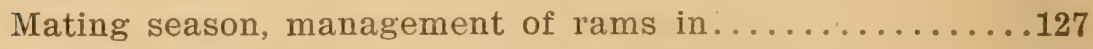

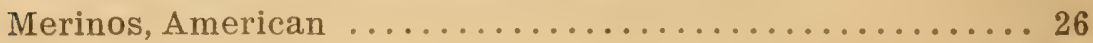

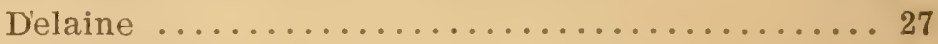

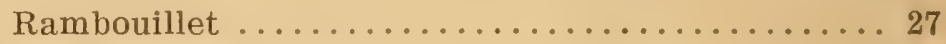

Middle-wooled breeds..................... 29

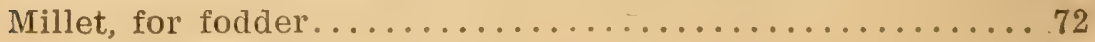

for pasture ............................ 59

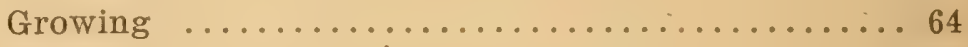

Grazing .......................... 67

Mixed grains, for fodder ................... 73

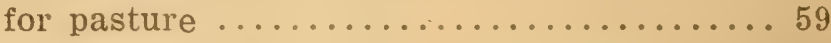

Growing ..................... 64

Grazing ...................66 67

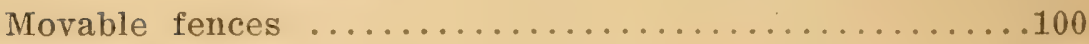

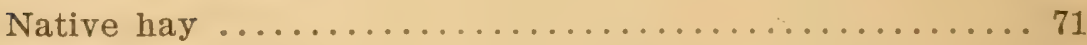

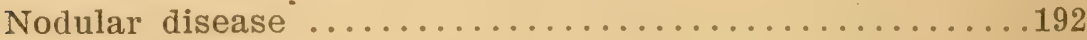

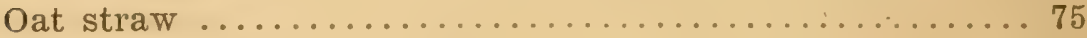

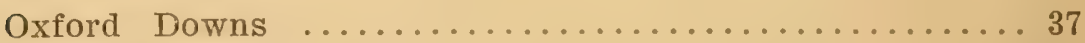

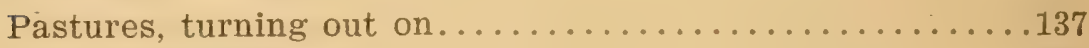

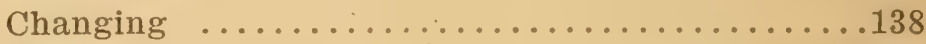

Supplemental ............... 53,55,61, 66

Utilizing summer ................ 10

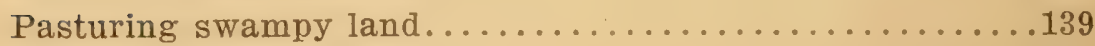

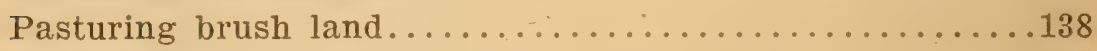

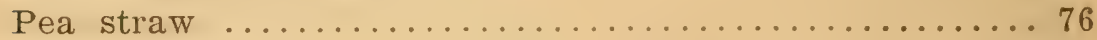

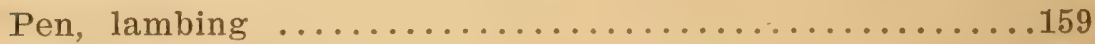

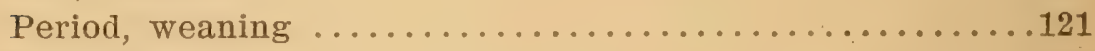

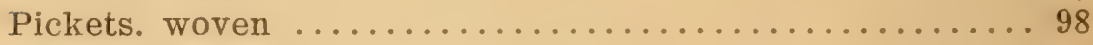

Plentiful shade ......................... 17

Poles, sheds of ........................... 79

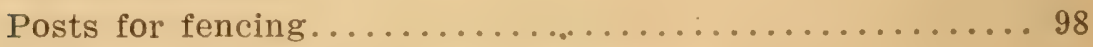

Present hindrances to sheep husbandry........... 20

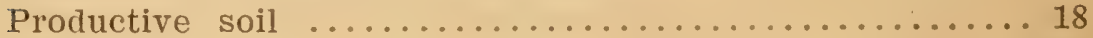

Proprietary dips ........................ 196

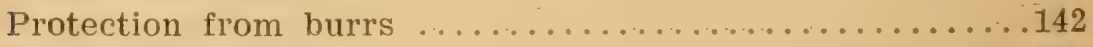

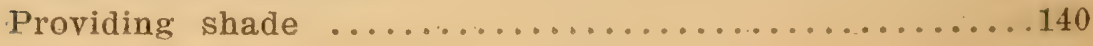


Pure breds, great opening for .............. 41

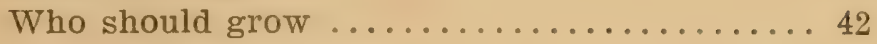

Establishing a flock of............. 42

Quarters, winter ........................... 130

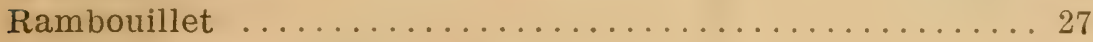

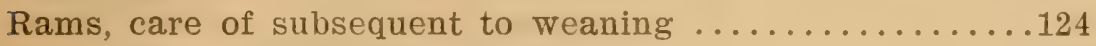

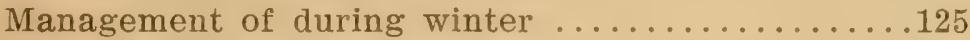

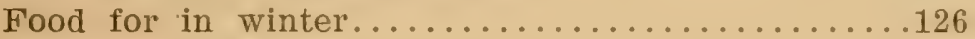

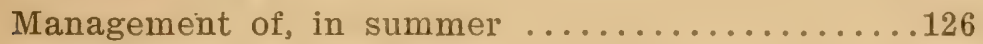

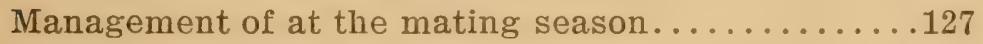

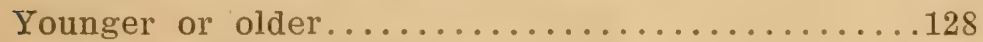

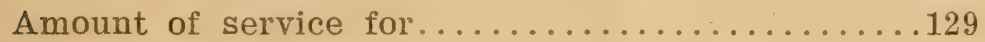

Returns twice a year .................... 9

Requisites in fodders for sheep............... 70

Rape, for pasture........................ 59

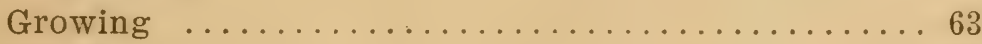

Grazing ...................... 66

Roots, varieties of field.................... 76

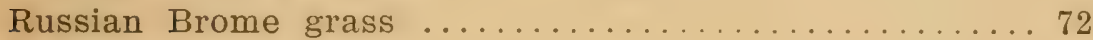

Rutabagas............................... 76

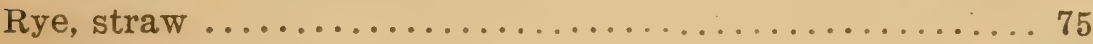

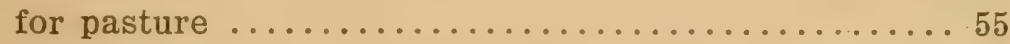

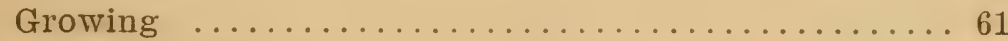

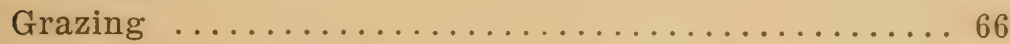

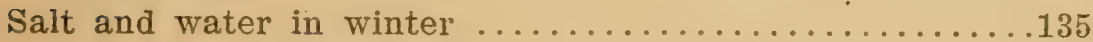

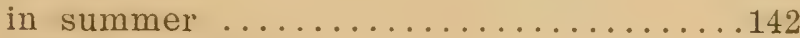

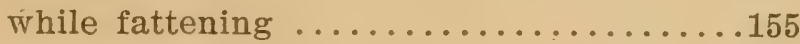

Scab

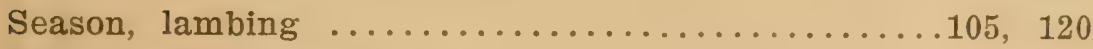

Selection of males ...................... 45

of breeding ewes ........................

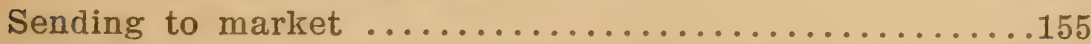

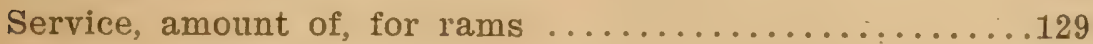

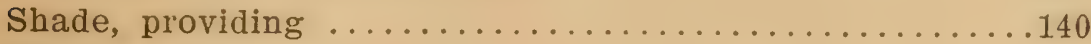

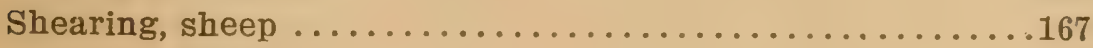

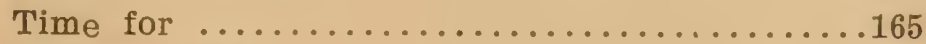

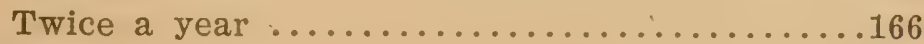

Sheds, sheep ............................. 80

Site for $\ldots \ldots \ldots \ldots \ldots \ldots \ldots \ldots \ldots \ldots \ldots \ldots$ 
Sheep, fencing for $\ldots \ldots \ldots \ldots \ldots \ldots \ldots \ldots \ldots . \ldots 9$

Sheds ...................... 80

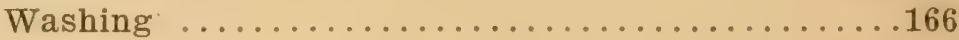

Shelter for $\ldots \ldots \ldots \ldots \ldots \ldots \ldots \ldots \ldots \ldots \ldots$

Tagging the .................... 1361

Trimming .......................... 136

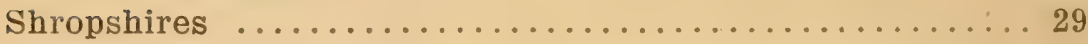

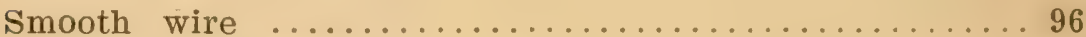

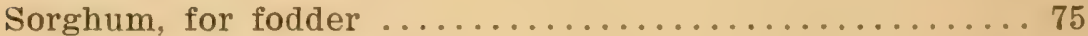

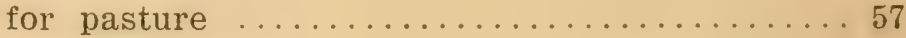

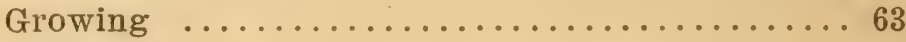

Grazing ...................... 66

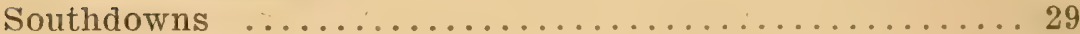

Soy beans, for pasture ....................61

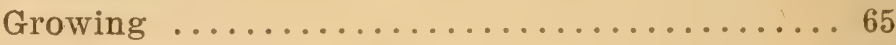

Grazing ................... 67

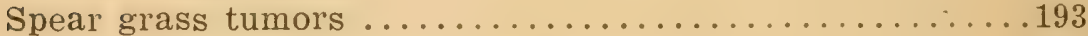

Stomach worms (Strongylus Contortus) ............180

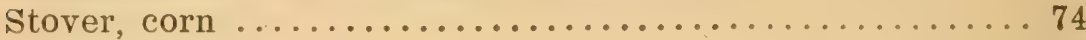

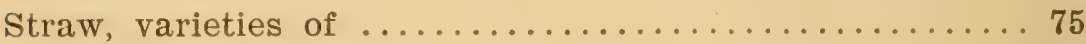

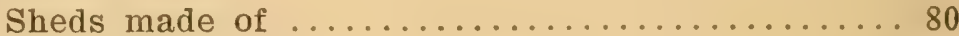

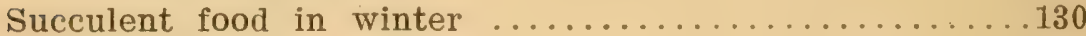

Suffolk Downs ......................... 35

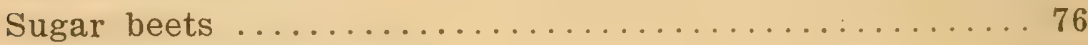

Sulphur and lime dips ......................... 197

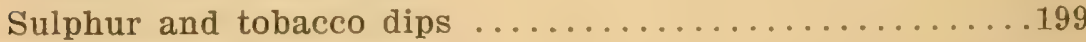

Supplemental pastures-

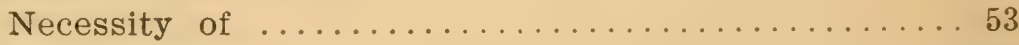

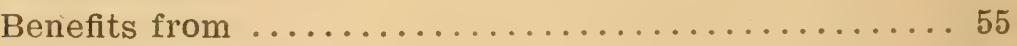

Plants best suited for ................. 55

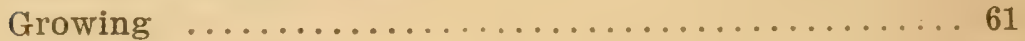

Grazing ............................. $66^{\circ}$

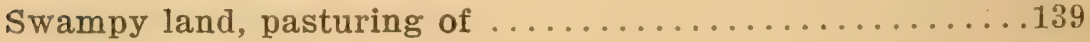

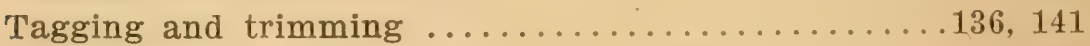

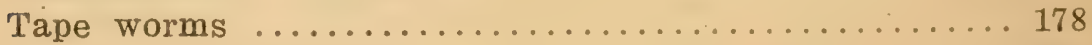

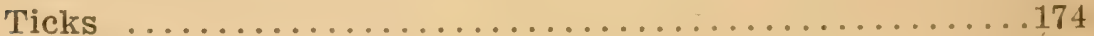

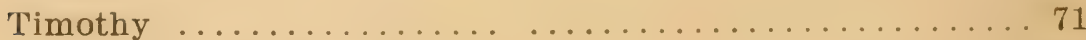

Tobacco and sulphur dips.................... 199

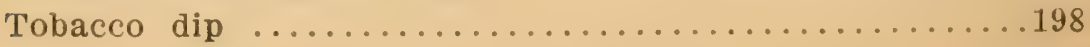




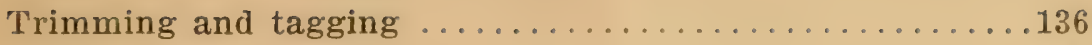

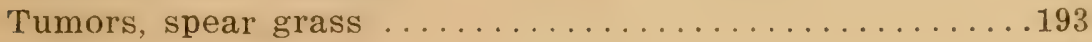

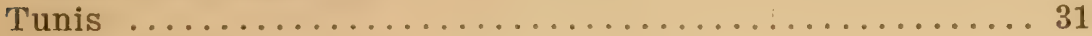

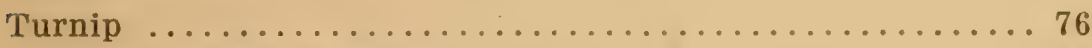

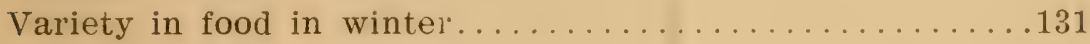

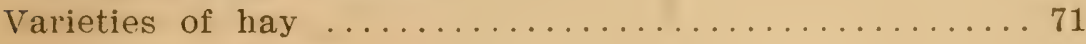

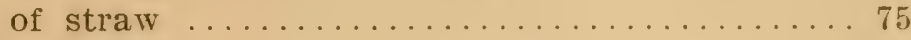

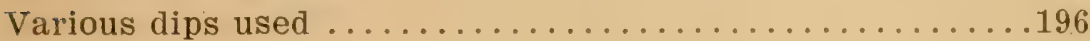

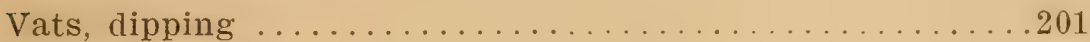

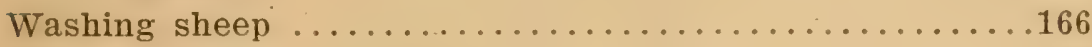

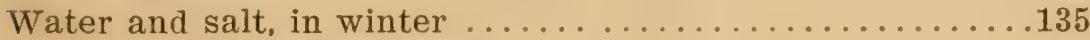

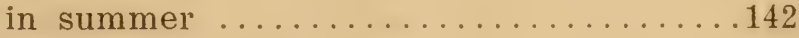

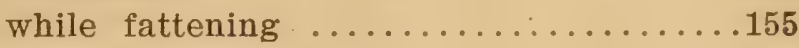

Weaning, care of rams subsequent to................ 124

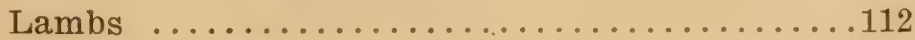

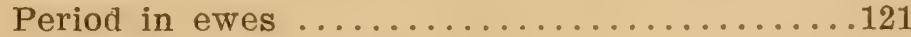

Weeds, destroying of, by sheep ............... 11

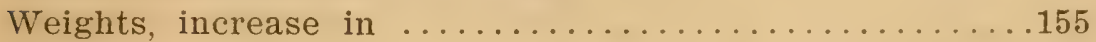

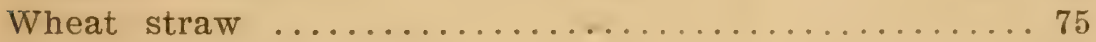

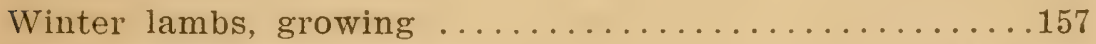

Quarters, going into ............117, 130

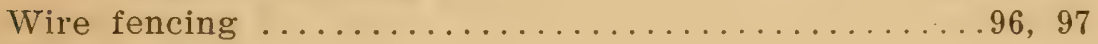

Wood, fence made of $\ldots \ldots \ldots \ldots \ldots \ldots \ldots \ldots . \ldots . \ldots . \ldots$

Wool, preparing, for market.....................

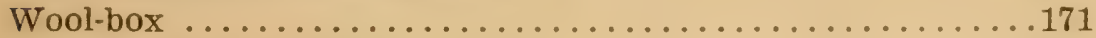

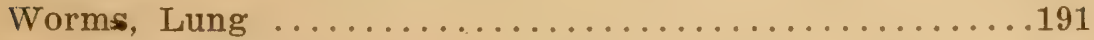

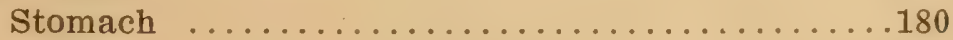

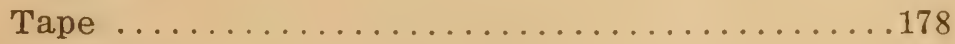

Woven picket fence ....................... 98

Woven wire fence . ....................... 97

Zigzag crossing ......................... 49 




LIBRARY OF CONGRESS

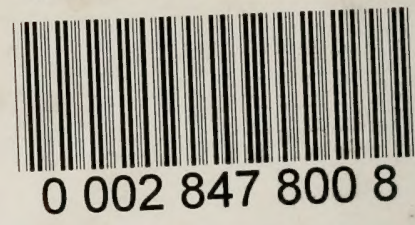

